\title{
Myanmar Country Forest Note
}

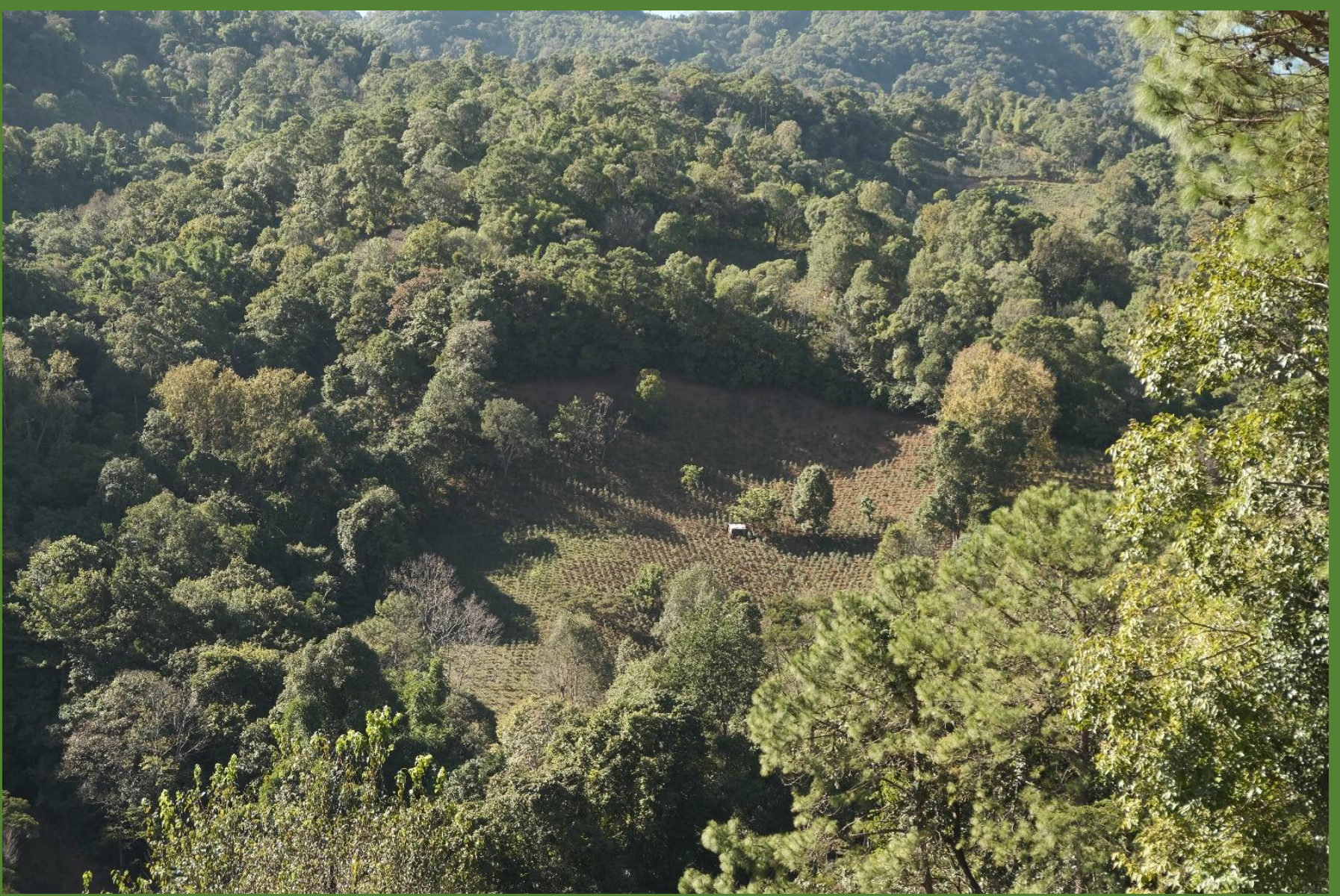

World Bank

June 2020 


\title{
Myanmar
}

\section{Myanmar Country Forest Note}

June 2020

\author{
Environment, Natural Resources and The Blue Economy Global Practice
}

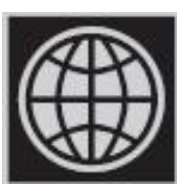

(C) 2020 The World Bank

1818 H Street NW, Washington DC 20433

Telephone: 202-473-1000; Internet: www.worldbank.org

Some rights reserved

This work is a product of the staff of The World Bank. The findings, interpretations, and conclusions expressed in this work do not necessarily reflect the views of the Executive Directors of The World Bank or the governments they represent. The World Bank does not guarantee the accuracy of the data included in this work. The boundaries, colors, denominations, and other information shown on any map in this work do not imply any judgment on the part of The World Bank concerning the legal status of any territory or the endorsement or acceptance of such boundaries.

\section{Rights and Permissions}

The material in this work is subject to copyright. Because The World Bank encourages dissemination of its knowledge, this work may be reproduced, in whole or in part, for noncommercial purposes as long as full attribution to this work is given.

Attribution-Please cite the work as follows: "World Bank. 2020. Myanmar Country Forest Note. (C) World Bank."

All queries on rights and licenses, including subsidiary rights, should be addressed to World Bank Publications, The World Bank Group, 1818 H Street NW, Washington, DC 20433, USA; fax: 202-522-2625; e-mail: pubrights@worldbank.org. 


\section{Myanmar Country Forest Note}

Table of Contents

EXECUTIVE SUMMARY

INTRODUCTION

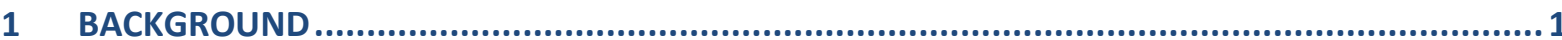

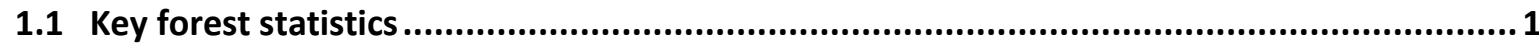

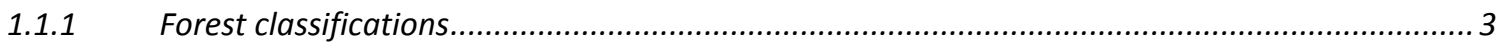

1.2 National goals for the forest sector.............................................................................. 4

1.3 National policies and plans related to forests ..................................................................5

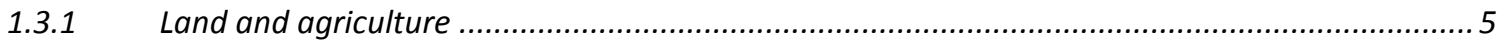

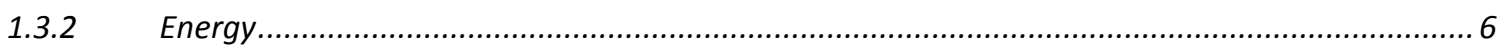

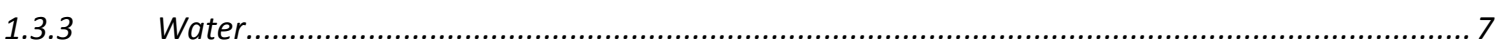

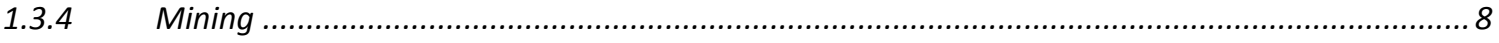

1.4 Forest sector information related to Nationally Determined Contributions.........................8 8

1.5 Network of forest Protected Areas .................................................................................9

2 CONTRIBUTION TO LIVELIHOODS AND SUSTAINABLE DEVELOPMENT ................................ 11

2.1 Livelihoods, inclusion and poverty relevance of forests ................................................ 11

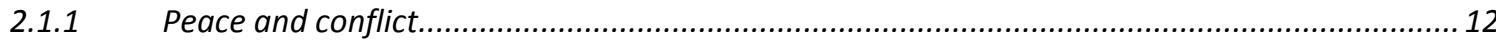

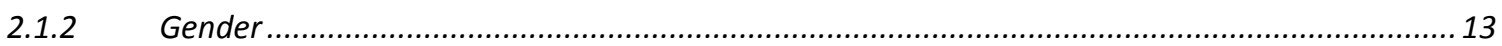

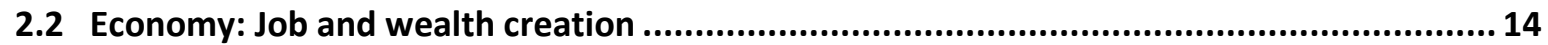

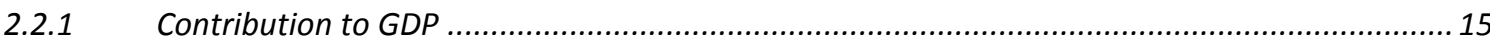

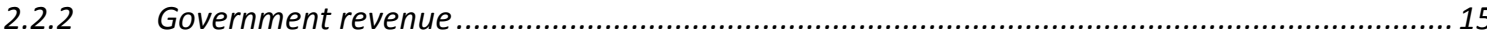

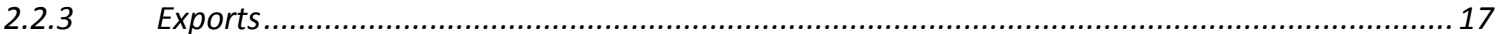

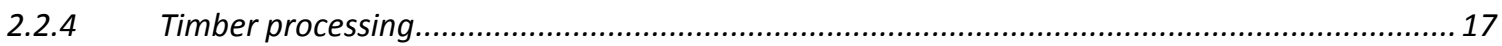

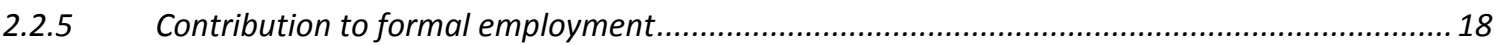

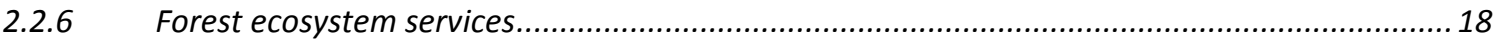

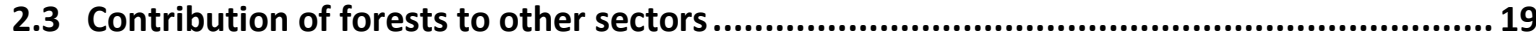

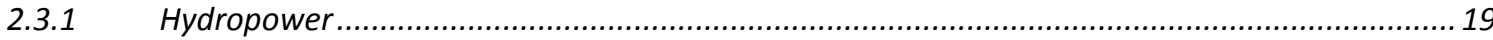

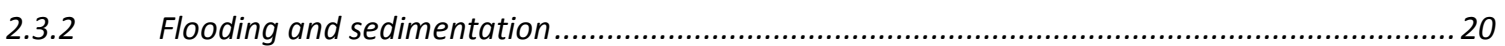

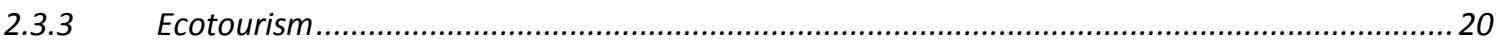

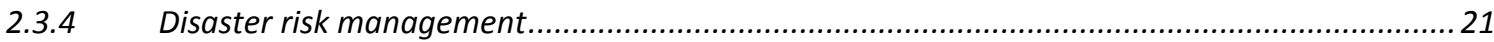

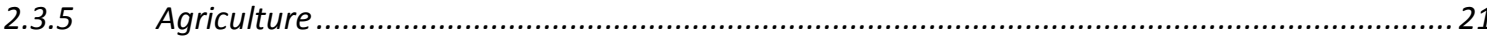

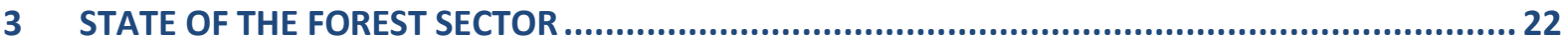

3.1 Challenges and Drivers of Deforestation and Degradation............................................. 22

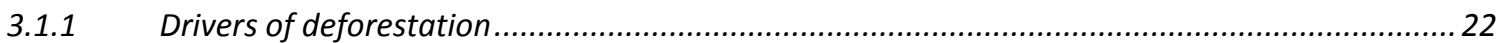


3.2 Competing uses of land and their impact on forests ........................................................ 24

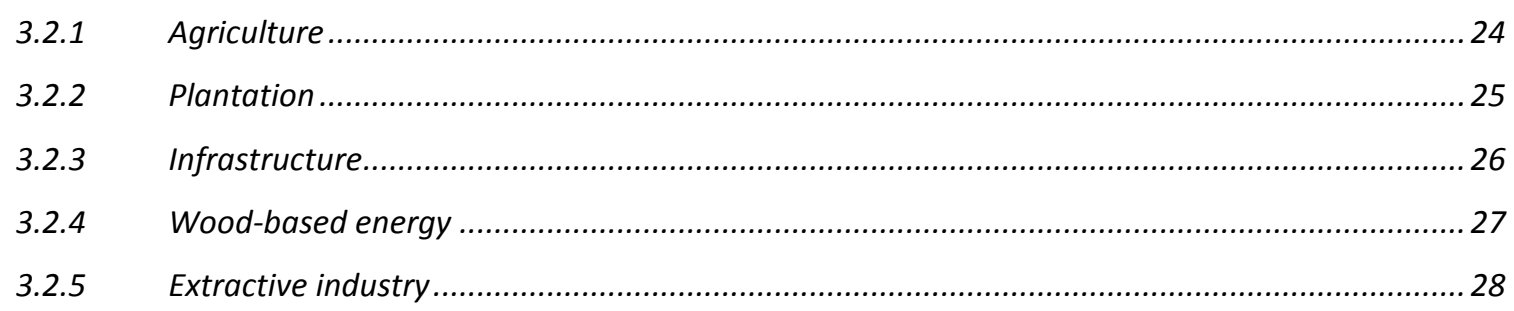

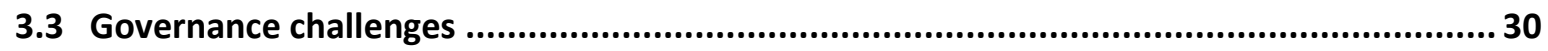

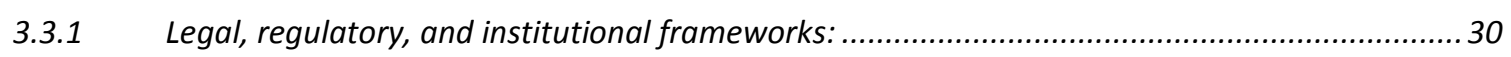

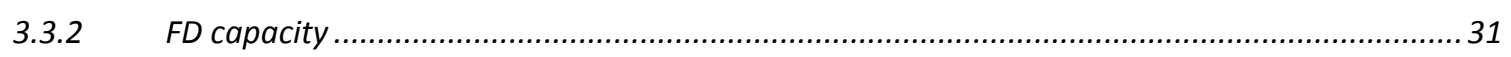

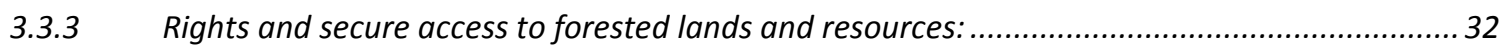

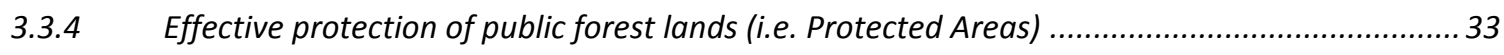

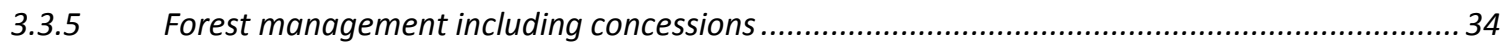

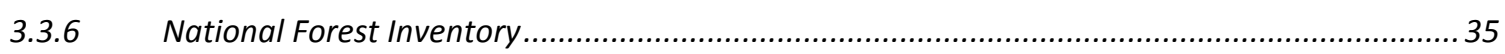

3.3.7 In June 2020, Finland signed an agreement with the FD to finance the NFI, to be implemented

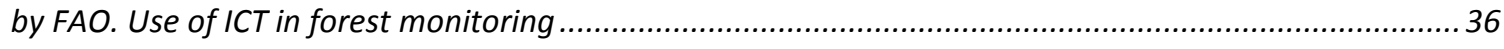

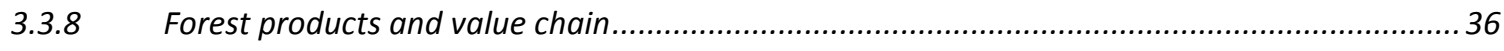

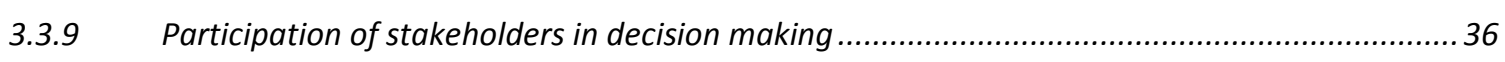

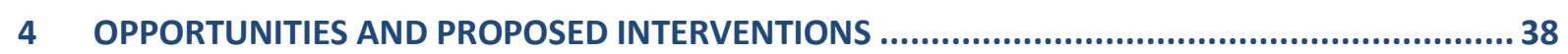

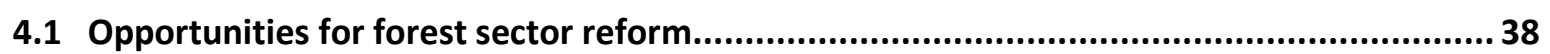

4.2 Recommendations and proposed interventions.................................................. 40

4.2.1 Institutional strengthening and reform for improved forest management and governance ..... 40

4.2.2 Toward a more inclusive and participatory forest management approach .............................42

4.2.3 Transform to a plantation-based forest economy with more private sector engagement ........ 43

4.2.4 Support expansion of forest protection and seek financial viability of Protected Areas ............ 45

4.2.5 Cross-cutting forest management issues..........................................................................46

4.3 Entry points for cross-sectoral opportunities and interventions................................. 47

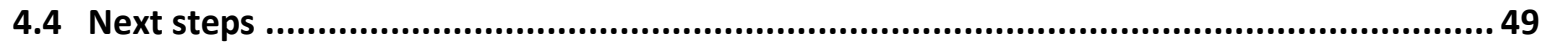

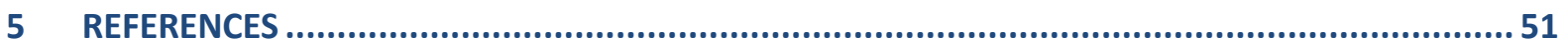

ANNEX 1: ASSESSMENT OF FOREST TENURE .............................................................61

ANNEX 2: ASSESSMENT OF ENABLING CONDTIONS FOR private plantations .............................65 65

ANNEX 3: ASSESSMENT OF WOODFUEL ...................................................................68

ANNEX 4: Recommendations for Interventions in the Forestry Sector ................................... 71

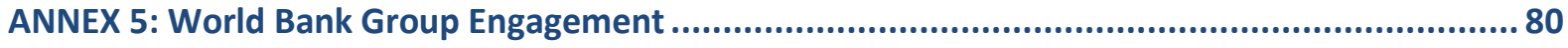




\section{ACKNOWLEDGEMENTS}

This report was prepared by a team led by Nina Doetinchem and Werner Kornexl. The core World Bank team was composed of Aye Marlar Win, Elisabeth Steinmayr, Htet Lynn, Hugh Speechly, Lesya Verheijen, Martin Fodor, Matthew Owen, Prof Ohn Lwin, Rory Hunter, Srinivas Shivakumar Mahalingam, Thiri Aung, and Yann François.

The extended team included Bonnie Ann Sirois (financial management), Degi Young (gender), Mio Takada and Indira Janaki Ekanayake (agriculture), Morten Larson, Thi Thi Han and Thinzar Htun (mining), Shelley Mcmillan (water resources management), and Zubair Khurshid Bhatti (governance).

The report was produced under the overall guidance of Mariam J. Sherman (Country Director, Myanmar), Gevorg Sargsyan (Head of Office, Myanmar), Christophe Crepin and Stephen Ling (Practice Managers, SEAE2).

The team received expert advice from peer reviewers Andrea Kutter, Andrew Mitchell, Muhammad Najeeb Khan, Nalin Kishor, and Neeta Hooda.

The team would also like to acknowledge the generous support provided for preparation of the report by the Program on Forests (PROFOR), Carbon Finance Assist Trust Fund, and the Korea Green Growth Trust Fund. 


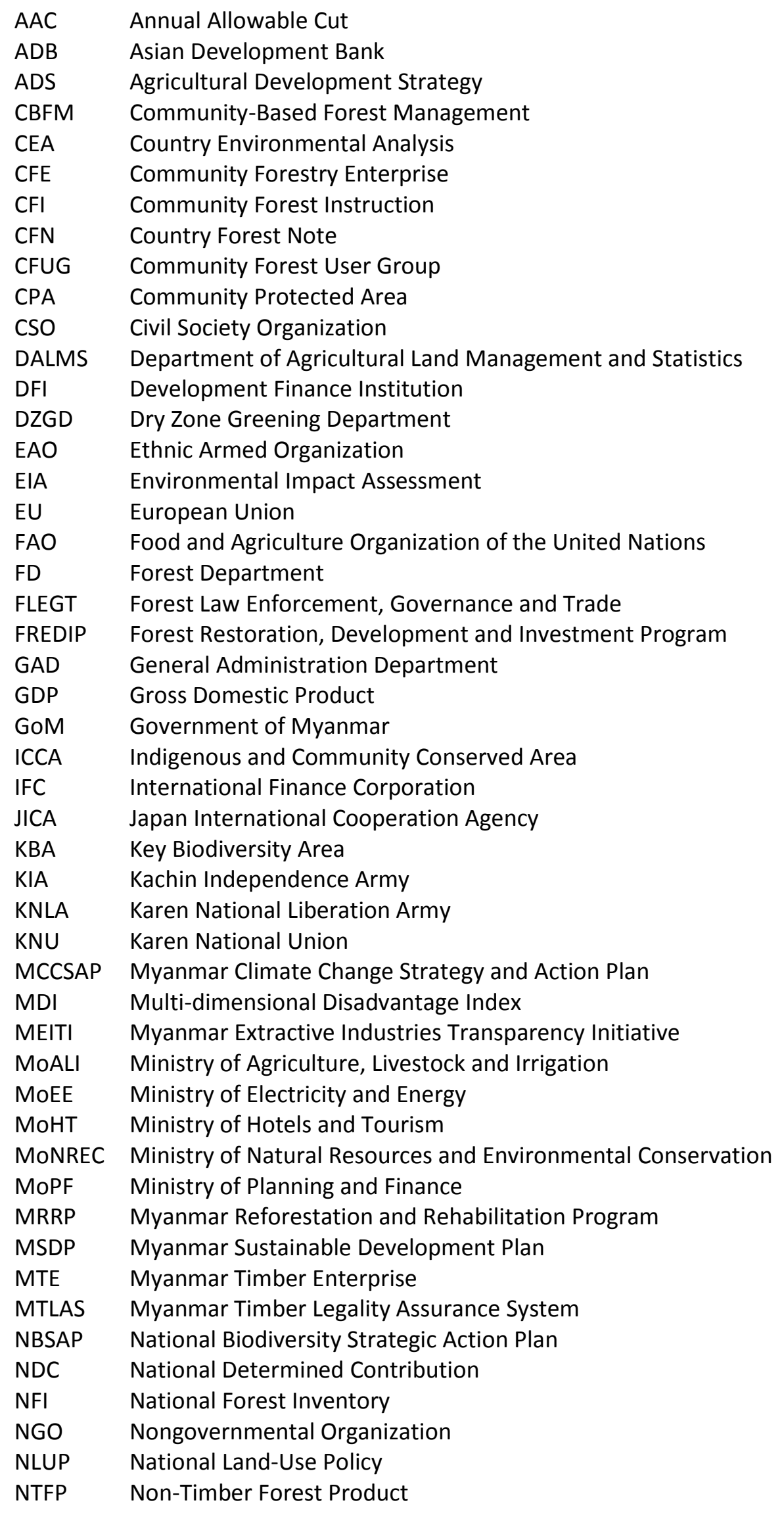


NWCD Nature and Wildlife Conservation Division (of the Forest Department)

PA Protected Area

PES Payment for Ecosystem Services

PFE Permanent Forest Estate

PPF Protected Public Forest

PROFOR Program on Forests

REDD+ Reducing Emissions from Deforestation and forest Degradation

RF Reserved Forest

SEA Strategic Environmental Assessment

SMEs Small and Medium Enterprises

VFV Vacant, Fallow, and Virgin

VPA Voluntary Partnership Agreement

WBG World Bank Group 


\section{EXECUTIVE SUMMARY}

\section{Overview}

Myanmar's rich tropical forests have historically sustained a sizeable timber industry serving domestic and international markets. Rates of timber extraction rose significantly after 1990, peaking between 2010 and 2015, when controls over forests were weak. Much of the remaining forest estate in government reserves, including areas transferred for community forestry, is now degraded or encroached, and illicit timber harvesting continues, despite a ban on unprocessed log exports and other recent control measures.

Ongoing sector reforms and strong government commitments under the Myanmar Restoration and Rehabilitation Program provide a sound basis for moving away from an extractive and inefficient timber industry to a more inclusive and integrated model of forest landscape restoration with greater community ownership and private sector engagement, to ensure that Myanmar's forests continue to provide sustainable economic, social, and environmental benefits. This requires more diverse management approaches and the collaboration with partners who can expand forest management capacity and coverage, including commercial plantations, community forestry, and engagement with ethnic groups who aspire recognition of rights to forest under customary tenure. It also requires new sources of finance.

This Country Forest Note (CFN) summarizes the status of Myanmar's forests and the investments and policies relevant to the forest sector. It aims to inform a strategic, programmatic approach for the management of forests, built on an understanding of the cross-sectoral challenges that the sector faces. It builds on the Forest Sector Report ${ }^{1}$ of the Country Environmental Analysis by filing gaps in data and knowledge, including from new studies on private sector plantations, woodfuel, and forest tenure. The CFN takes a uniquely cross-sectoral perspective that considers how other sectors impact forests, and vice versa, and where opportunities lie for better cross-sectoral coordination.

\section{Opportunities in the forest sector}

Myanmar's forest sector has been central to the country's economy and society, particularly over the last century. Myanmar's forests contain some of the world's most valued timber species and Myanmar has one of the longest-standing forest management systems in the tropics. Despite a reduction in timber revenues over the last decade, the extraction, processing, and trade in timber and non-timber forest products (NTFPs) is still a vital part of the rural economy and livelihoods. In 2015/16, forestry officially accounted for 0.2 percent of GDP, and forest exports earned US\$207 million (or 1.9 percent of total export earnings). ${ }^{2}$ But unlicensed and illegal timber exports may be worth four times the documented value ${ }^{3}$ and official statistics tend to greatly underestimate the economic importance of forests, due to non-recordation of informal trade and incomplete information on the value of ecosystem services. A lack of data therefore hampers accurate quantification of the true contribution of the forest sector to Myanmar's economy, and to its environmental resilience and social fabric.

Forest products underpin rural livelihoods and provide a safety net for income and jobs lost due to COVID-19. Rural people depend on timber, NTFPs and agroforestry for food, medicine, and woodfuel, which is by far the country's most important energy source and the primary fuel for 60-80 percent of households. The forest sector provided around 32,000 formal jobs in 2015/16 and generated MMK143 billion (US\$102 million) in wage earnings, in addition to undocumented informal employment.

\footnotetext{
1 World Bank (2019). Myanmar Country Environmental Analysis - Forestry Resources Report (https://www.worldbank.org/en/country/myanmar/publication/myanmar-country-environmental-analysis).

2 Data from Myanmar's Central Statistical Organization.

${ }^{3}$ Raitzer and Nam 2015; UNODC, 2013.
} 
Forest-based industries and sustainable plantations are among the few activities with the potential to provide gainful and green employment at scale in rural areas, while promoting restoration of degraded land and conservation of biodiversity. Myanmar loses significant economic value from wasteful processing of high-value timber. Drawing on examples such as Vietnam, which created a thriving timber sector in only ten years, Myanmar could derive much greater value from the forest sector if the enabling environment was more conducive.

Community forestry and smallholder plantations are financially and socially viable and can contribute meaningfully to rural income generation if the right incentives are in place. Communitybased forestry provides tenure security that stimulates investment and creates trust, income, and business opportunities.

Forests and mangroves also provide significant ecosystem services as water catchments, habitats for flora and fauna, carbon sinks, sources of soil nutrients, and increasingly important disaster risk protection. Mangroves are being lost at a rate of 2.2 percent per annum and require specific strategies for sustainable management to be put in place or strengthened.

Forest governance and peace processes are intertwined. Two-thirds of Myanmar's remaining forests are managed by ethnic minorities, often located in conflict areas. Good forest governance and inclusive natural resource management in these areas has the potential to contribute to the national peacebuilding process and reduce conflicts.

While 43 percent of the land area of Myanmar is still under forest, only 38 percent of this can be considered intact. 26 percent of forest cover was lost between 1990 and 2015, with over-extraction of timber a leading cause of forest degradation. Although the recorded rate of timber extraction has significantly reduced in recent years due to a decline in availability of high-value species and stronger regulation, deforestation and forest degradation outside the permanent forest estate (PFE) ${ }^{4}$ remains a significant concern, driven by encroachment, agricultural expansion, conversion to infrastructure, and woodfuel extraction. The PFE covers about 25 percent of Myanmar's land area (FD data), but only 60.4 percent of the PFE actually has forest cover (closed plus open forest).This means that of the total forest area of Myanmar (29 million ha), only 41 percent (or 11.8 million ha) lies within the PFE under the management of the FD (Enters 2017).

With no national forest inventory and incomplete data on local forest dynamics, the drivers of deforestation and forest degradation both within and outside the PFE are insufficiently understood. The viability of Myanmar's future forest economy depends on whether the country succeeds in preserving its remaining forests, and the speed with which reforms of community forestry (CF) and private plantations can be implemented.

\section{Achievements and challenges}

Commercial timber has been extracted in huge volumes over the last century, peaking between 2010 and 2015, when Myanmar had the third largest absolute forest loss in the world. Due to growing scarcity of over-harvested species, logging restrictions, an export ban, and other sector reforms, the value of timber exports dropped from US\$2.2 billion in 2011 to US\$443 million in $2016 .{ }^{5}$

The government has initiated policy actions to address forest loss and degradation, including a log export ban in 2014; a 12-month logging ban in 2016, and a 10-year logging ban in the Bago Yoma Region, which has experienced particularly high deforestation. This has been combined with legislative and regulatory reform, including the Environmental Conservation Law in 2012; new Forest Law in 2018; Biodiversity and Conservation of Protected Areas Law in 2018; and revised Community Forestry

\footnotetext{
${ }^{4}$ PFE is Forest Land as classified in the Forest Law, and accounts for 41 percent of all Myanmar's forests. It comprises Reserved Forest (priority areas for timber production) and Protected Public Forest (lower timber priority, mainly for local use). ${ }^{5}$ FAOStat 2018.
} 
Instructions in 2019. The government is working towards a Voluntary Partnership Agreement with the European Union under its Forest Law Enforcement Governance and Trade (FLEGT) Action Plan.

The Government has initiated a process of reform to move from an extractive and inefficient wood industry to a more inclusive and integrated model of forest landscape restoration, with more community ownership and greater private sector engagement. The main government initiatives in the forest sector are the Myanmar Restoration and Reforestation Program (MRRP) (2017/18-2026/27), the National Forest Master Plan (NFMP) (2001/02-2030/31), the Comprehensive Master Plan for the Greening of the Central Dry Zone (2001/02-2030/31), the National Biodiversity Strategy and Action Plan (2015-2020), and the new 10-year Re-establishing Natural Habitat Program (2019/20-2028/29).

The MRRP aims to restore 1 million hectares of degraded and deforested land by 2026 through a combination of plantations, CF, agroforestry, natural forest regeneration, and enrichment planting, potentially generating multiple benefits for people, the economy, and biodiversity.

Community forestry is a central element of the MRRP and a potentially powerful driver of change. Local communities have had weak statutory rights to claim forest access and user rights, with the exception of allocations made under the Community Forestry Instructions which grant communities (renewable) rights to manage forests for 30 years. Progress with CF has therefore been slower than planned, and CF covered only 614,579 acres $(248,711$ ha) by March 2019, far short of the NFMP 2030/31 target of 2.27 million acres (919,000 ha). Despite recent strengthening of the legal basis for $\mathrm{CF}$, more comprehensive technical and financial support is needed for CF to achieve its full potential.

In light of Myanmar's high rates of forest degradation and deforestation, additional effort is required to restore forest cover through reforestation and afforestation, both within and outside the PFE, including in community forests. Law enforcement has had only a limited effect on controlling illegal timber exports, and timber theft from plantations and other forested areas. The main potential for reforestation lies with attracting private investment in commercial timber plantations of longerrotation species (such as teak) and shorter-rotation species that can produce cash benefits after 4-8 years (such acacia). However, the current enabling environment is not sufficiently conducive for private forest companies to engage more widely and create the rural jobs needed for economic recovery after COVID-19. Licensing processes are slow and lack transparency, and companies find the areas offered for private plantations too small, and the social risks too high. In addition, Myanmar does not offer adequate financing for national entrepreneurs to engage in plantation forestry. CF Enterprises are a new concept that can facilitate collective livelihood improvement, though the capacity of communities to take advantage of this opportunity is still low. Given limited government resources and outreach, such partnerships with the private sector and local communities are essential for consolidating and expanding forest cover, alongside efforts to tap into new sources of finance.

Around 65 percent of forests lie outside the PFE, mostly on land designated as Vacant, Fallow and Virgin (VFV) under the administration of the Ministry of Agriculture, Livestock and Irrigation (MOALI). In some areas, ethnic armed organizations (EAOs) have developed their own administrative mechanisms for forest and land management, such as the Karen Land Policy 2015, Karen Forest Policy 2015, Karenni Land Policy 2016, and Kachin Land Forest Policy (draft). The Karen National Union operates its own CF scheme and has certified more than 60 community forests.

Forests on VFV lands are often under customary tenure and considered ancestral domains by communities. An expansion of CF into VFV lands with overlaid customary claims can be seen as extending the Union government's jurisdiction over ethnic areas and may result in conflict. There have also been examples where ethnic communities in mixed-control areas are interested in CF establishment and in related dialogue with Forest Department (FD) staff. This complex and fluid political context shows the importance of the FD following a demand-driven approach that emphasizes Free, Prior and Informed Consent in land allocation decisions. The recent National LandUse Policy recognizes customary land rights, but requires supporting legislation to unify policies and laws across the sector to eliminate contradictions on forest management on VFV lands. 
Although the current direction is positive and there is strong political ownership by Government and society, progress in forest sector reform and implementation is still slow. After several years of isolation, the sector still has to deal with historic legacy issues and lacks the financial and human resources to accelerate reforms and the implementation of programs. The sector further struggles to attract private capital and technology, and to offer an inclusive enabling environment for forest communities and the private sector to generate jobs and incomes.

\section{Opportunities for the future}

Myanmar's forestry sector is at a crossroads, with an opportunity to transition from an extractionbased industry to a modern, integrated and sustainable sector. The ongoing shift towards a new forest economy based on partnerships with the private sector and local communities can be accelerated, encouraging investors to make long-term investments and facilitating much-needed community support. During the contraction in employment expected after COVID-19, there is an opportunity for mass community engagement in restoring forests and establishing plantations.

While recent policy reforms have set the stage for the process of change, implementation will depend on institutional capacity to deliver these reforms. With overlapping responsibilities, overstretched institutions, a highly centralized governance framework, and disjointed monitoring and reporting systems, significant investments and reforms will be needed.

Sector transformation will require a shift from publicly dominated forest management to a more inclusive and integrated forest landscape management and restoration model that includes community ownership and more private sector involvement. A functional review of forestry sector institutions, with a focus on the FD as the apex agency responsible for forest management, would be timely to guide alignment of institutional functions and capacities, help improve agency accountability, minimize functional overlaps, and prioritize critical skills development.

To overcome near-term capacity constraints, partnership models for service delivery can accelerate the shift to a more collaborative forest management model, complementing FD staff capacity at local levels with a cadre of service providers and community facilitators to fill shortfalls in facilitation and extension services, including improved dialogue and service provision to ethnic communities.

Government will need to strengthen efforts for forest sector governance and tackle illegal logging through increased anticorruption efforts, and collaborative efforts through the Extractive Industries Transparency Initiative, FLEGT, and others. Continued illegality is undermining not only sectoral targets for increased forest cover through both conservation and restoration efforts, but also investor confidence for plantation development. New measures will be needed to increase transparency, accountability, and citizen engagement to address irregularities and challenges in governance, which have resulted in leakage of forest resources to organized crime and shadow markets.

\section{Cross-sectoral planning}

The drivers of deforestation and forest degradation are intimately linked and require cross-sector planning, multi-stakeholder dialogue and a joint vision on the role of forests in Myanmar's development. While not diminishing the critical role of the forestry sector itself in reform, there is an urgent need for cross-sector dialogue and a nationally integrated approach to preserving the country's remaining intact forests and restoring those that are degraded. The table below highlights entry points and opportunities for promoting intersectoral collaboration on forest-smart development.

Entry points for improved cross-sectoral planning for forest-smart development

\begin{tabular}{|l|ll|}
\hline Sector & \multicolumn{2}{|l|}{ Cross-sectoral entry points } \\
\hline Agriculture & $\bullet \quad \begin{array}{l}\text { Strengthen coordinated policy and implementation between the Ministry of Natural } \\
\end{array}$ & $\begin{array}{l}\text { Resources \& Environmental Conservation (MoNREC) and MoALI; } \\
\text { • }\end{array}$ \\
& Build budgeted partnerships for coordinated extension services for agroforestry; \\
& Remove ambiguity in overlapping authority of MoNREC and MoALI on VFV land;
\end{tabular}




\begin{tabular}{|c|c|}
\hline Sector & Cross-sectoral entry points \\
\hline & $\begin{array}{l}\text { - Ensure promotion of agroforestry, crop combinations, and multi-cropping systems; } \\
\text { - Incorporate interventions to increase canopy cover and reforestation in agricultural } \\
\text { investment packages, especially in rice producing areas; } \\
\text { - } \quad \text { Provide micro-finance to increase farmer productivity and reduce expansion into forests; } \\
\text { - } \quad \text { Ensure that leases of forested VFV land avoid tree cover loss; } \\
\text { - } \quad \text { Simplify procedures for establishing CF on VFV land; } \\
\text { - } \quad \text { Identify opportunities for PES schemes, e.g., downstream irrigation schemes or reservoirs; } \\
\text { - Link to agro-ecotourism to incentivize farmers regarding value of forests and provide } \\
\text { additional income to reduce deforestation, including carbon finance. }\end{array}$ \\
\hline Energy & $\begin{array}{l}\text { - Accelerate rural electrification and off-grid electricity solutions to reduce pressure on } \\
\text { forests to meet energy needs currently met by woodfuel; } \\
\text { - } \quad \text { Promote fast-growing woodlot species, including bamboo for charcoal or industrial heat; } \\
\text { - Incentivize sustainable sourcing of biomass energy by promoting use of residues from } \\
\text { wood processing, making supply chain linkages, and reducing regulatory requirements; } \\
\text { - Strengthen application of environmental and social safeguards to ensure that impact on } \\
\text { - Implement EIA guidelines for hydropower from } 2018 \text { Strategic Environmental Assessment. }\end{array}$ \\
\hline Water & $\begin{array}{l}\text { - Identify priority areas for reforestation to counter flooding, landslides, erosion and } \\
\text { - } \quad \text { Fedimentation, especially of irrigation and hydropower investments. } \\
\text { integrate reforestation/watershed management activities into the Decision Support } \\
\text { System in the Hydro-Informatics Center; } \\
\text { - } \quad \text { Explore opportunities for PES schemes, especially for irrigation and hydro power schemes; } \\
\text { - Deepen understanding and recommendations of how good governance can be strengthened } \\
\text { across sectoral agencies, including water sector agencies. }\end{array}$ \\
\hline Land & $\begin{array}{l}\text { - Advance the national land law for management of forests on VFV lands; amend current laws } \\
\text { to expand the role of community members in land use decision making; } \\
\text { - Sustain dialogue on statutory recognition of ethnic customary land and tenure systems; } \\
\text { - } \quad \text { Prioritize cadastral surveys in areas of encroachment in high value conservation forests. }\end{array}$ \\
\hline Mining & $\begin{array}{l}\text { - Strengthen EIA review, approval, and implementation to reduce mining impacts on forests; } \\
\text { - } \quad \text { Foster discussion on opportunities for PES or an environment fund in the mining sector; } \\
\text { - Identify and promote opportunities for Biodiversity Offset Plans by mining projects.; } \\
\text { - Identify opportunities for mining companies to fund reforestation activities under CSR. }\end{array}$ \\
\hline Tourism & $\begin{array}{l}\text { - } \quad \text { Coordinate policy and implementation with Ministry of Hotels \& Tourism for eco-tourism; } \\
\text { - } \quad \text { Operationalize revenue flow from eco-tourism to provide finance streams for forest and } \\
\text { biodiversity protection, and diversify community employment and benefit-sharing; } \\
\text { - } \quad \text { Consider ecological tax on tourists and earmark for conservation and PA management; } \\
\text { - Develop operating standards and requirements for sustainability of tourism development. }\end{array}$ \\
\hline
\end{tabular}

\section{Recommendations}

Recommended actions specific to the forest sector are proposed across key strategic areas (see summary table) to ensure that forestry becomes a well-functioning, sustainable sector of the economy. The framework serves as a base for prioritizing interventions and orienting the dialogue with the Government, development partners, private sector and civil society in support of the implementation of existing Government programs and strategic plans. It also serves as an input for emerging operations that support Government programs.

Priority actions recommended to strengthen Myanmar's forestry sector

\section{\begin{tabular}{l|l} 
Challenge & Summary of recommendations
\end{tabular}}

\section{Planning, Management, and Monitoring of Production Forests}

Overharvesting and weak controls lead to

degradation of forest reserves

- Establish a National Forest Inventory system;

- Produce major forest type maps;

- Validate reserve boundaries and maps; 
- $\quad$ Strengthen monitoring and law enforcement capacity for adherence to forest management as per forest management plans and harvest allowances.

Weak understanding of regulations from consumer countries limits market-readiness
- Align Myanmar Timber Legality Assurance System with requirements of consumer countries;

- Implement national certification standards;

- Implement good governance recommendations under FLEGT.

\section{Myanmar Timber Enterprise}

Overharvesting and high value log export with little value addition, high wastage, and limited transparency sector institutions, including Myanmar Timber Enterprise;
- Carry out a functional review and reform of forest

- Undertake a capacity and skills assessment, with reorientation of staffing, greater decentralization, and more outsourcing.

\section{Plantation (state-owned and private)}

Government plantations have high failure rates due to inadequate maintenance and budgets

Domestic entrepreneurs constrained by unpredictable timber supply and a focus on minimally processed exports.

Planted forests can be attractive investments, but Myanmar lacks an integrated plantation industry to access sophisticated markets.

Foreign investors perceive numerous investment challenges.

- Consider partnership models with communities or private sector;

- Ensure adequate maintenance and supervision support for public plantations.

- Develop and implement the Myanmar Industrial with industry;

- $\quad$ Explore diverse plantation models to attract investment on leased FR or VFV land;

- Consider a range of finance sources, including institutional and industrial investors, development finance institutions, and multilateral development and Commercial Plantation Strategy, in cooperation bank loans;

- Develop and implement a commercial plantation strategy;

- Create a multi-stakeholder body that includes the private sector.

\section{Processing}

Timber processing SMEs face challenges with credit, enabling environment, access to timber, market information, productive infrastructure, and research and technology support

- $\quad$ Create cross-ministerial team to improve SME enabling environment;

- Simplify procedures to establish and run wood enterprises;

- Promote technology and training for national labor force;

- Promote national and foreign investment in integrated industries;

- Assess market acceptability of lesser utilized species;

- Collect and disseminate market information.

\section{Community-based forest management}

Limited handover capacity and slow approval of CF applications. High dormancy of CF User Groups (CFUGs) and significant local capacity gaps in CF implementation
- Develop delivery mechanism for CF implementation, including:

- Clarify responsibilities and strengthen deliver functions of local FD staff and agricultural extension services;

- Develop cadre of service providers and community facilitators; 


\begin{tabular}{|c|c|}
\hline Challenge & Summary of recommendations \\
\hline & $\begin{array}{l}\text { Create open access CF database and } \\
\text { information systems; } \\
\circ \quad \text { Strengthen CF outreach program. }\end{array}$ \\
\hline $\begin{array}{l}\text { Ethnic areas with customary tenure and forest } \\
\text { management systems need practical solutions }\end{array}$ & $\begin{array}{l}\text { Develop legal and technical processes for effective } \\
\text { tenure for customary groups. } \\
\text { Explore opportunities for recognizing ethnic } \\
\text { initiatives for community-governed forest } \\
\text { conservation and management models (that align } \\
\text { with broader national objectives). }\end{array}$ \\
\hline $\begin{array}{l}\text { CFUGs have limited access to finance, especially } \\
\text { for value-added processing }\end{array}$ & $\begin{array}{l}\text { Develop financing options for CFUGs, including } \\
\text { from MFIs; } \\
\text { - Provide technical support to non-parastatal } \\
\text { producer cooperatives; } \\
\text { Develop a CFE/SME incubator and accelerator } \\
\text { support program. }\end{array}$ \\
\hline $\begin{array}{l}\text { CFUGs and the private sector have limited } \\
\text { experience of partnerships }\end{array}$ & $\begin{array}{l}\text { - Implement capacity development program for } \\
\text { entrepreneurs; } \\
\text { - } \quad \text { Carry out market analysis of NTFP and other wood } \\
\text { products; } \\
\text { - } \quad \text { Create a CF platform to promote CF products and } \\
\text { identify business opportunities and partnerships; } \\
\text { - } \quad \text { Promote plantation development in CF. }\end{array}$ \\
\hline $\begin{array}{l}\text { CF expansion often entails handing over state } \\
\text { forests with insufficient stocking or insufficient } \\
\text { tangible benefits. } \\
\text { There is potential for using CF in mangrove } \\
\text { areas, which have experienced significant } \\
\text { decline. }\end{array}$ & $\begin{array}{l}\text { - } \quad \text { Expand CF in reserved forests; } \\
\text { - } \quad \text { Recognize customary lands and explore options for } \\
\text { community participation; } \\
\text { - } \quad \text { Accelerate CF establishment in mangrove areas; } \\
\text { - Strengthen dialogue with ethnic communities to } \\
\text { recognize customary tenure and promote CF. }\end{array}$ \\
\hline Protection & \\
\hline $\begin{array}{l}\text { Challenges for Protected Areas include } \\
\text { incomplete zoning, patchy management plans, } \\
\text { inadequate data management systems, and } \\
\text { weak local capacity }\end{array}$ & 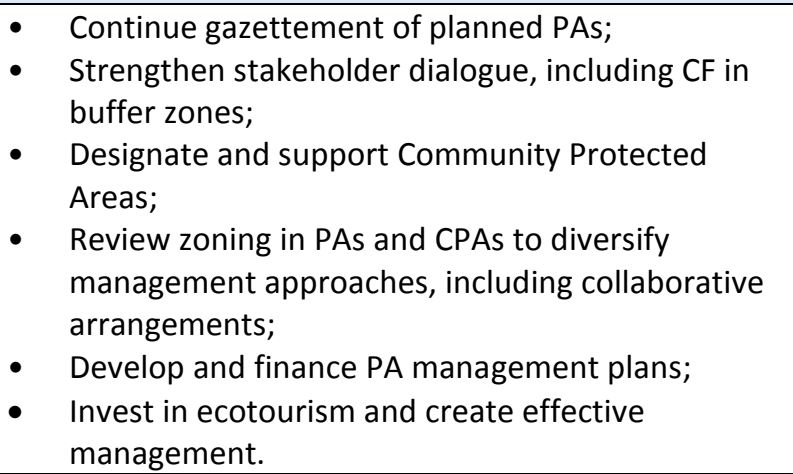 \\
\hline $\begin{array}{l}\text { National Protected Area system is insufficiently } \\
\text { funded }\end{array}$ & 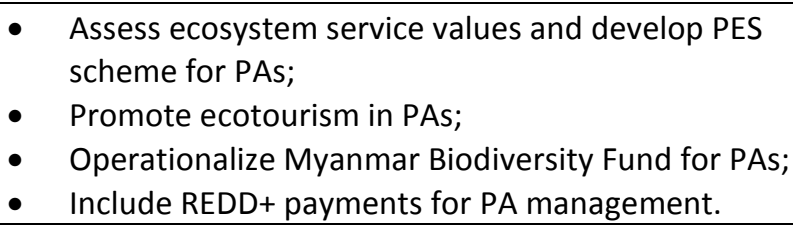 \\
\hline $\begin{array}{l}\text { More than half of Myanmar's mangroves have } \\
\text { been lost over the past } 20 \text { years }\end{array}$ & $\begin{array}{l}\text { - Strengthen cross-sectoral collaboration and } \\
\text { governance for coastal landscapes to address main } \\
\text { drivers of mangrove loss (primarily agricultural } \\
\text { expansion); } \\
\text { - Identify and promote mangrove-compatible green } \\
\text { business and livelihoods models; } \\
\text { - Strengthen investment case for mangrove } \\
\text { conservation and restoration in the context of } \\
\text { disaster risk management and climate change }\end{array}$ \\
\hline
\end{tabular}




\begin{tabular}{|c|c|}
\hline \multirow[t]{2}{*}{ Challenge } & Summary of recommendations \\
\hline & $\begin{array}{l}\text { mitigation; explore new financing opportunities, } \\
\text { including blue carbon. }\end{array}$ \\
\hline $\begin{array}{l}\text { Watershed forests are vital to sustain } \\
\text { hydropower }\end{array}$ & $\begin{array}{l}\text { - Analyze potential for PES and other schemes to } \\
\text { finance rehabilitation of watershed forests. }\end{array}$ \\
\hline \multicolumn{2}{|l|}{ Stakeholder dialogue and citizen engagement } \\
\hline $\begin{array}{l}\text { Multi-stakeholder processes that are inclusive, } \\
\text { participatory, and cognizant of local conflict } \\
\text { dynamics are needed to prevent tensions arising } \\
\text { from forest conservation and restoration } \\
\text { initiatives. }\end{array}$ & 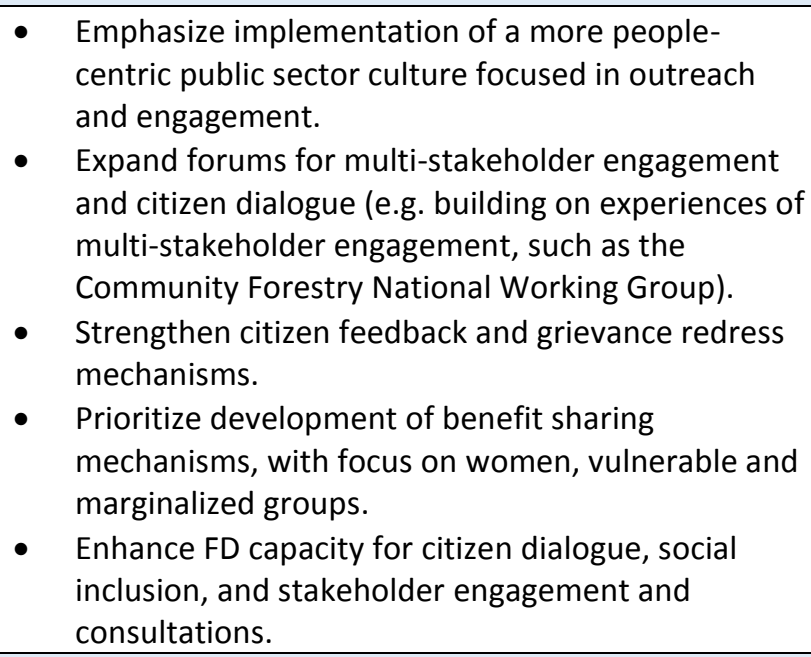 \\
\hline \multicolumn{2}{|l|}{ FD skill development } \\
\hline $\begin{array}{l}\text { In contrast with centralized governance, } \\
\text { emerging modalities rely on decentralized } \\
\text { partnerships and new capacities }\end{array}$ & $\begin{array}{l}\text { - } \quad \text { Enhance decentralized FD technical capacity; } \\
\text { - Engage, communicate, and consult private sector } \\
\text { and civil society; } \\
\text { - } \quad \text { Establish mechanisms for citizen feedback. }\end{array}$ \\
\hline $\begin{array}{l}\text { Weak governance leads to leakage of forest } \\
\text { resources and benefits to organized crime and } \\
\text { shadow markets }\end{array}$ & $\begin{array}{l}\text { - Support President's anticorruption initiative and } \\
\text { offer channels for collaboration between NGOs and } \\
\text { FD; } \\
\text { - Improve transparency and accountability, including } \\
\text { satellite monitoring, citizen engagement, financial } \\
\text { surveillance, law enforcement. }\end{array}$ \\
\hline \multicolumn{2}{|l|}{ Nature-based solutions } \\
\hline $\begin{array}{l}\text { Ecosystem restoration can reduce vulnerability } \\
\text { to disasters and increase resilience to climate } \\
\text { change }\end{array}$ & $\begin{array}{l}\text { Scale-up nature-based solutions for disaster } \\
\text { resilience, including mangrove restoration, } \\
\text { productive agroforestry, green infrastructure, } \\
\text { forest restoration on slopes and watersheds. }\end{array}$ \\
\hline \multicolumn{2}{|l|}{ Forest tenure } \\
\hline $\begin{array}{l}\text { Protection and recognition of forest tenure } \\
\text { rights is critical if forest-dependent communities } \\
\text { are to play a greater role in forest and } \\
\text { biodiversity preservation }\end{array}$ & $\begin{array}{l}\text { - Adopt and enforce a comprehensive policy and } \\
\text { legal framework to reform forest tenure, including } \\
\text { for local and ethnic communities; } \\
\text { - Engage all stakeholders and political leadership in } \\
\text { the implementation of forest tenure reforms; } \\
\text { - Improve local capacities to gather information on } \\
\text { forest land holding patterns and socio-cultural } \\
\text { factors affecting them; } \\
\text { Urge development partners to support dialogue on } \\
\text { forest land and resource management; and } \\
\text { strengthening of research capacities. }\end{array}$ \\
\hline \multicolumn{2}{|l|}{ Woodfuels } \\
\hline $\begin{array}{l}\text { Woodfuels meet the energy needs of most } \\
\text { households and important economic sectors. } \\
\text { With diminishing forest resources, it is essential } \\
\text { that forest resources are sustainably managed, } \\
\text { woodfuel processing and utilization becomes as } \\
\text { clean and efficient as possible, and fuel }\end{array}$ & $\begin{array}{l}\text { Promote appropriate alternative fuels (LPG for } \\
\text { household cooking; rice husk pellets and briquettes } \\
\text { for industrial heat and steam; charcoal briquettes } \\
\text { for commercial catering); } \\
\text { - Promote sustainable woodfuel production through } \\
\text { residues from commercial plantations; mixed- }\end{array}$ \\
\hline
\end{tabular}


Challenge

switching strategies are well-informed and strategic.
Summary of recommendations

purpose household planting in woodfuel deficit areas; and sustainably managed $\mathrm{CF}$, with preferential market support

- Support sustainable charcoal industry through lighter touch regulation for compliant producers; and training and exchanges on improved charcoal production.

- Develop a national cookstove strategy to harmonize subsidies and support local manufacture. 


\section{INTRODUCTION}

The operational centerpiece of the World Bank Group (WBG)'s Forest Action Plan is a shift toward a new business model that moves away from the project-by-project and instrument-driven approach that has shaped the forest portfolio over the past few years to a more programmatic approach that strategically positions the WBG to support countries delivering on forest-smart interventions. To better understand the cross-sectoral dimensions of forestry and the relevance of forests for poverty and economic development, the Forest Action Plan promotes Country Forest Notes (CFNs).

CFNs typically attempt to answer three main questions:

- Why? Why are forests important for livelihoods and poverty reduction? What are the economic contributions from the forest sector? What services do forests provide to other sectors?

- What? What are the current challenges and policy issues in the forest sector? What are the drivers of deforestation? What are the required policy changes and investment needs to address these challenges? What Government programs are in place to address these?

- How? How can the World Bank's engagement in the forest sector become smarter and more strategic? What is the nature of current engagement and what can be done to address the challenges in a more programmatic manner across sectors? What knowledge and financing is needed to achieve this?

\section{Expected Impact of Country Forest Notes:}

- Elevate and advance political dialogue on forests with governments, donors, private sector and other in-country partners;

- Programmatically organize and sequence WBG engagement on forests and activities that impact forests by assessing needs and identifying potential interventions and investments;

- Promote greater inter-sectoral collaboration on forests and promote forest-smart solutions; ${ }^{6}$

- Strengthen forest-related inputs into strategic diagnostic processes such as Strategic Country Diagnostics and Country Partnership Frameworks;

- Help leverage greater resources for forestry support (IBRD, IDA, private sector, etc.).

The Myanmar CFN builds on the forest resources sector assessment that was conducted under the Country Environmental Analysis (2019). That assessment (a) deepened understanding of challenges in the forest sector by summarizing available information on institutional capacity, governance and policy issues, and emerging forest programs; (b) analyzed the main drivers of deforestation and forest degradation; (c) analyzed Government efforts to promote forest reform (and community forestry in particular); and (d) proposed a policy framework with recommended actions to advance the country's engagement on forests.

The assessment under the CEA focused on "why" forests are important for Myanmar and on "what" can be done within the forest sector. As the CEA was meant to help the Bank to re-engage in the environment sector, it was important to create trust and confidence among stakeholders. The CFN will build on this process and fill critical analytical gaps that are relevant for the implementation of key Government policy reforms. The CFN will also address "how" the World Bank can contribute to the solutions in a programmatic and cross-sectoral manner in the specific context of Myanmar.

The CFN will frame the World Bank's future engagement in the forest sector in Myanmar. The Bank is supporting the Ministry of Natural Resources and Environmental Conservation (MoNREC), through

\footnotetext{
${ }^{6}$ 'Forest-smart' is an integrated approach that considers how other economic sectors such as agriculture, transport or energy and mining impact forests, and how forests impact those sectors, thereby identifying and addressing the root causes of deforestation and supporting better development planning at the landscape level.
} 
its Forest Department (FD), with the preparation of the Forest Restoration, Development and Investment Program (FREDIP, P168254). FREDIP will enable the Government to access IDA resources to support implementation of the ambitious Myanmar Reforestation and Rehabilitation Program (MRRP, 2017/2018 - 2026/2027) and will contribute towards specific targets under Myanmar's National Forest Master Plan (NFMP, 2002-2031).

Investment financing will help the Government to meet its forest sector policy and strategy targets, in particular to increase the area of Reserved Forest (RF) and Protected Public Forest (PPF) to 30 percent of national land area, to expand Protected Areas (PAs) to 10 percent of land area, and to establish around 920,000 ha of community forestry (CF) - as defined in NFMP and reflected in Myanmar's forest-related targets under the Nationally Determined Contributions (NDC) for the Paris Agreement under the United Nations Framework Convention for Climate Change. In the shorter term, the ambitious target of MRRP is to restore close to 1 million ha of degraded and deforested land within RF and PPF by 2026, including establishing over 311,746 ha under CF.

The success of FREDIP will depend upon significant institutional strengthening and realignment of the FD towards skills development for service delivery, in line with ongoing policy reforms. Success will further lie in a profound understanding of cross-sectoral issues - including tenure, woodfuel consumption, fiscal incentives, mining, infrastructure, agriculture, industrial development, and disaster risk management - and will require sectoral silos to be broken down to facilitate coordinated interventions with other responsible line agencies.

The CFN is structured in line with corporate guidelines. It builds on the CEA process and other available information and data. During the CEA process and an early identification mission for FREDIP, a number of analytical gaps were identified that are relevant to the success of engagement on forests. These were then addressed through in-depth analytical work as part of the CFN preparation process:

A. Status of forest tenure and customary and communal rights, especially on VFV lands;

B. Trends and recommendations for ensuring enabling conditions for private plantations;

C. Opportunities in the woodfuels sector to contribute to Myanmar's NDC targets; and

D. Major cross-sectoral policy issues affecting forests.

Independent studies were commissioned for themes $A, B$, and $C^{7}$, while theme $D$ (cross-sectoral policy issues) was given particular attention during the development of this CFN.

The CFN presents a holistic approach to forest management that embraces a range of forest functions. These include community livelihoods and inclusion, environmental services that support and protect the productivity of other sectors (such as agriculture and tourism), and traditional timber industries.

\footnotetext{
7 World Bank. 2020. An Assessment of Forest Tenure in Myanmar: Securing Forest Tenure for Sustainable Livelihoods. Washington, DC: World Bank Group World Bank. 2020. Incentivising Sustainable Private Sector Investment in Timber Plantations in Myanmar. Washington, DC: World Bank Group World Bank. 2020. Myanmar Woodfuels Sector Assessment. Washington, DC: World Bank Group.
} 


\section{BACKGROUND}

\subsection{Key forest statistics}

In 2015, approximately 43 percent (29.4 million ha) of Myanmar's land area was forested (FAO 2015). ${ }^{8}$ Of this, around 42 percent was closed forest and 58 percent open forest. 11 percent of the total (3.19 million ha) was considered 'primary forest' (with no visible indication of human activity). The rest was 'other naturally regenerated', with clear indication of human disturbance.

Myanmar's forests are estimated to contain 1,342,118 $\mathbf{m}^{\mathbf{3}}$ in growing stock (FAO 2015). 78 percent of this stock is concentrated in the four largest States and Regions (Shan, Kachin, Sagaing, and Tanintharyi) (Figure 1). Based on the stocking data, Myanmar's forests are estimated to contain 3.3 billion metric tons ( $\mathrm{t}$ ) of forest biomass (oven-dry weight), including above-ground biomass, belowground biomass, and leaf litter (FAO 2015), including 1.29 billion t of forest carbon.

Figure 1: Forest and land cover in Myanmar, 2017

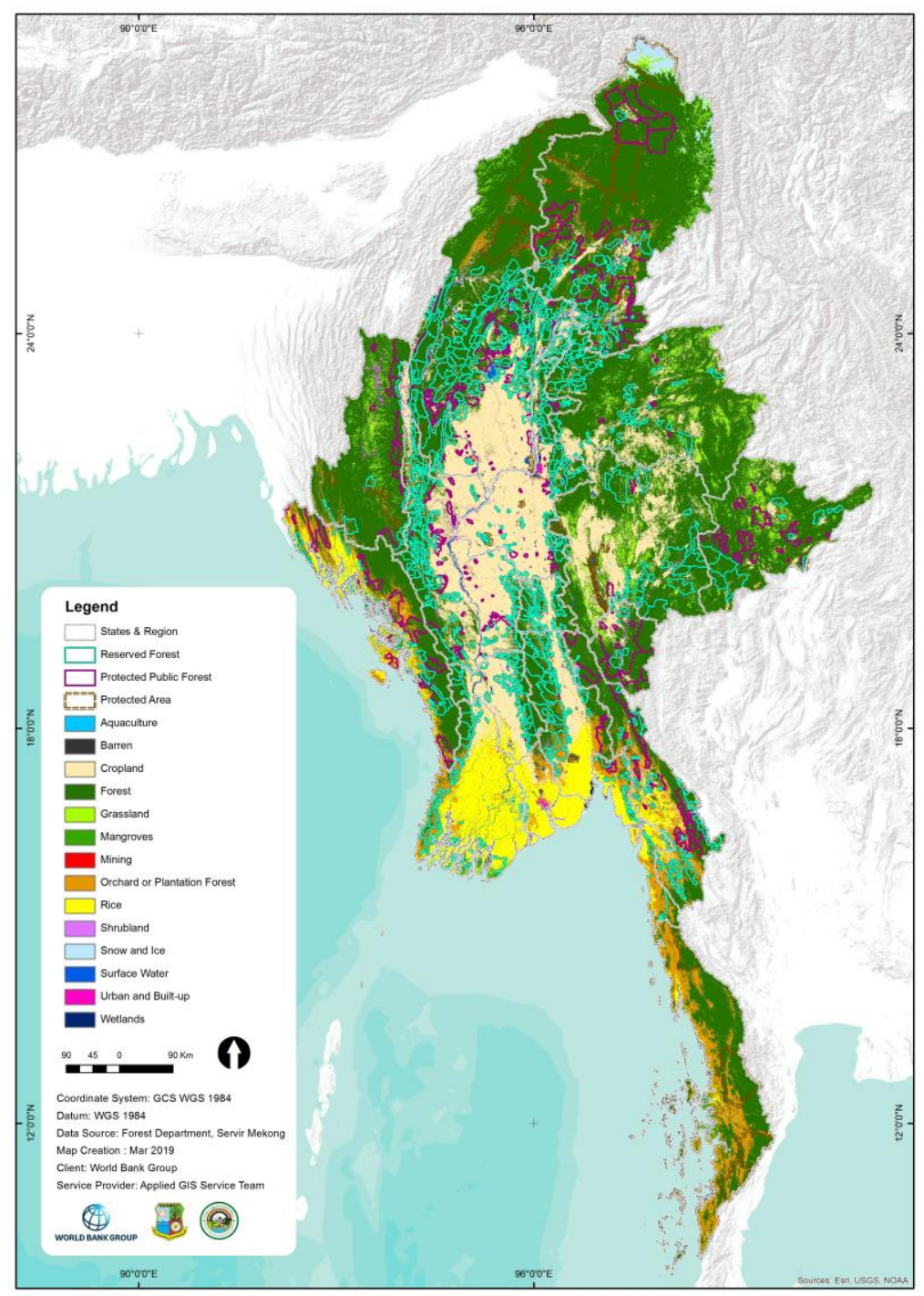

Source: SERVIR-Mekong 2017.

\footnotetext{
${ }^{8}$ The Government of Myanmar follows the FAO's conventional definition of 'forest': "Land spanning more than 0.5 ha with trees higher than $5 \mathrm{~m}$ and a canopy cover of more than 10 percent or trees able to reach these thresholds in situ. It does not include land that is predominantly under agricultural or urban land use." (FAO 2014). Forests are subcategorized into 'closed' (>40 percent canopy cover) and 'open' (10-40 percent canopy cover), the latter normally degraded.
} 
In 2014, only 38 percent of the country's forests could be considered 'intact' (over 80 percent canopy cover) (Bhagwat et al. 2017). The large extent of the 'other wooded land' category is partly explained by the prevalence of long fallow forest cultivation (shifting cultivation) in ethnic areas (Bhagwat et al. 2017).

Since 1975, Myanmar has lost a significant portion of its forest cover. Between 1975 and 2015, forest cover declined from 41,196 million ha to 29,388 million ha, a loss of 11,808 million ha, equivalent to a reduction from more than 60 percent of land area to 44 percent (Figure 2). 'Closed forests' fell from almost 45 percent of land area in 1975 to 18.3 percent in 2015, reflecting a severe loss in forest density.

Figure 2: Forest cover by forest class ('000 ha), 1975-2015

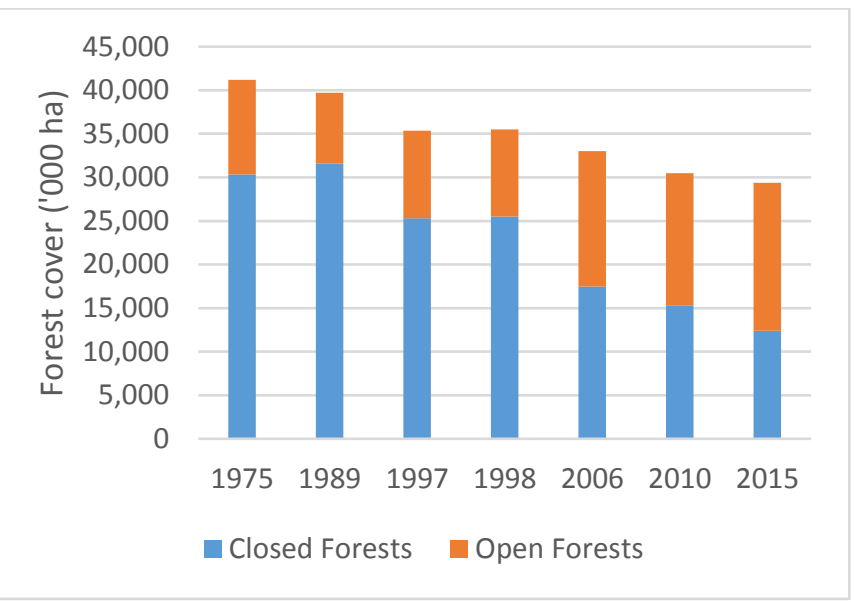

Source: FAO 2015, 2016.

Between 2010 and 2015, Myanmar had the third largest absolute forest loss in the world. During this period, the average annual rate of forest loss doubled to 1.8 percent (averaging 407,000 ha per year), from 0.9 percent between 2000 and 2010 . Forest decline accelerated in the early nineties, with average annual rates of forest loss at 1.2 percent for 1990-2000, 0.9 percent for 2000-2010, and 1.8 percent for 2010-2015, resulting in a total loss of around 10 million ha. ${ }^{9}$

From 2002 to 2014, the rate of decline in 'intact forests' (over 80 percent canopy) was 0.94 percent per year, amounting to over 2 million ha of intact forest loss (Bhagwat et al. 2017). Forest loss was widespread, but with concentrations in northern Shan, Kachin, Tanintharyi, southern Chin, southern Bago, and southern Rakhine (see Figure 3). Over-extraction accounted for 23 percent of the loss of intact forests, with a further 50 percent due to land use change to mining, agriculture, or infrastructure (Bhagwat et al. 2017).

\footnotetext{
${ }^{9}$ Inter-Agency Standing Committee and European Commission 2019.Accessed February 25, 2019.
} 
Figure 3: Lost intact forest (ha) for Myanmar townships (2002 to 2014)

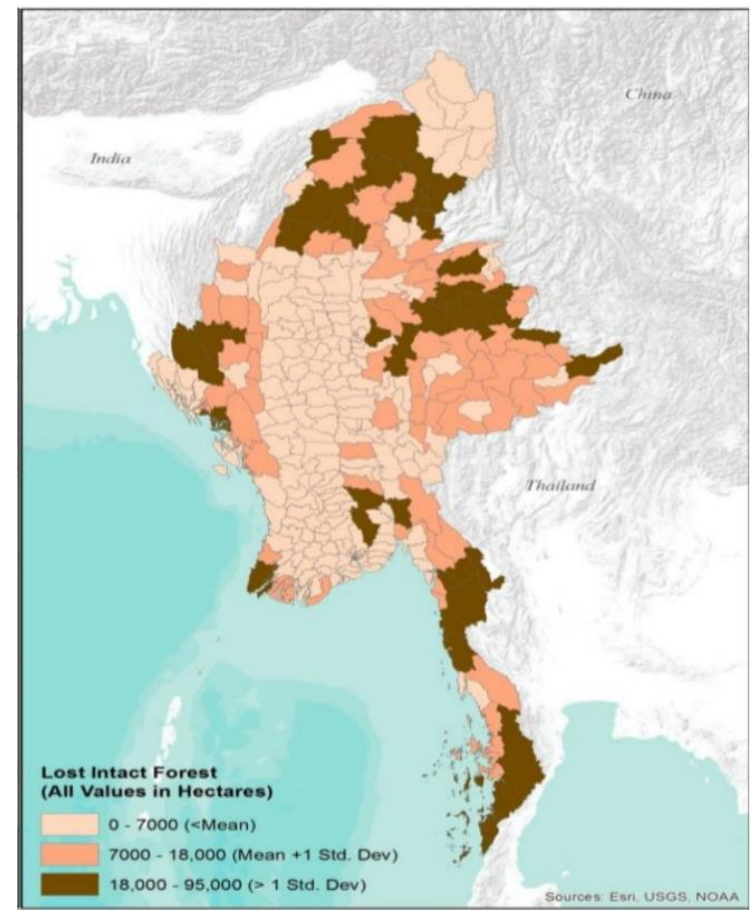

Source: Bhagwat et al. 2017.
Figure 4: Mangrove area change (2000-2014)

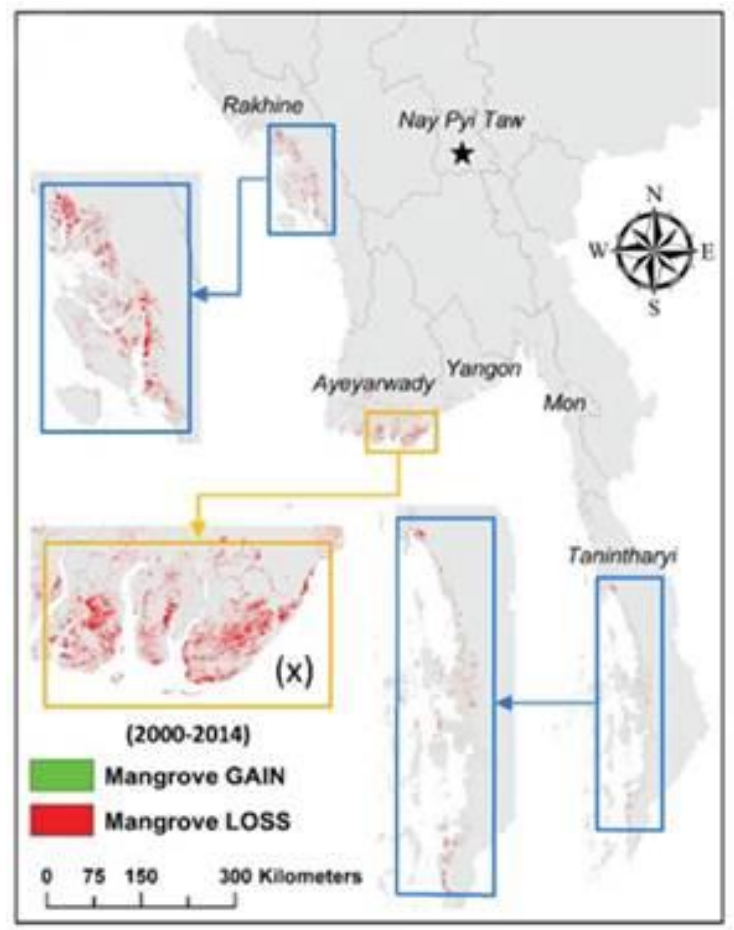

Source: Estoque et al. 2018.

From 2000 to 2014, Myanmar also lost 191,122 ha of mangrove forest (Estoque et al. 2018). Mangrove cover has been declining at an alarming rate of 2.2 percent per annum since 2000 (averaging 14,619 ha per year). The loss was predominantly in Rakhine State and the Ayeyarwady Region (Error! Reference source not found.), resulting in decreased evapotranspiration and loss of carbon stock. The main cause is the expansion of rice cultivation, which is estimated to account for nearly 88 percent of mangrove loss between 2000 and 2012 (Richards \& Friess 2016). Only 1.6 percent of mangrove loss could be attributed to aquaculture.

\subsubsection{Forest classifications}

Under the National Forest Policy (1995), extensive areas of forested land have been gazetted to form the Permanent Forest Estate (PFE). The PFE comprises (a) Reserved Forest (RF) (priority areas for timber production); and (b) Protected Public Forest (PPF) (lower timber priority, mainly for local use), together covering about 25 percent of Myanmar's land area (FD data). Only 60.4 percent of the PFE actually has forest cover (closed plus open forest).This means that of the total forest area of Myanmar (29 million ha), only 41 percent (or 11.8 million ha) lies within the PFE under the management of the FD (Enters 2017). Protected Areas (PAs) have also been established for biodiversity conservation.

Table 1 summarizes the current area of the PFE and PAs, and progress toward the achievement of designated area targets in the NFMP. 
Table 1: Status of the PFE

\begin{tabular}{|l|l|c|c|c|}
\hline \multicolumn{2}{|c|}{ Category } & $\begin{array}{c}\text { Total area } \\
\text { (ha) }\end{array}$ & $\begin{array}{c}\text { \% of } \\
\text { national } \\
\text { land area }\end{array}$ & $\begin{array}{c}\text { NFMP target } \\
\text { (\% of land } \\
\text { area) }\end{array}$ \\
\cline { 1 - 4 } $\begin{array}{l}\text { Permanent Forest } \\
\text { Estate }\end{array}$ & Reserved Forest & $12,041,601^{\mathrm{a}}$ & $17.80 \%$ & $30 \%$ \\
\cline { 2 - 5 } & Protected Public Forest & $5,041,364^{\mathrm{a}}$ & $7.45 \%$ & $10 \%$ \\
\hline
\end{tabular}

Note: PAs partly overlap with RF and PPF, so summed area figures should not be quoted.

Sources: a. MRRP semi-annual progress report, April-October 2018; b. FD Planning and Statistics Division 2010, as cited in UN-REDD Program 2013, Myanmar REDD+ Readiness Road Map.

FD holds the mandate to manage land in the PFE, while non-PFE land is administered by other agencies, including the Ministry of Agriculture, Livestock and Irrigation (MoALI), and the General Administration Department (GAD) under the Ministry of Union Government Office. Most of the forest outside the PFE lies on land designated as Vacant, Fallow, and Virgin (VFV), which falls under the management of Department of Agriculture, Land Management and Statistics (DALMS) within MoALI. Unclassified forests outside the PFE have ambiguous tenure and are vulnerable to informal extraction and land use change. Those under customary community management lack adequate statutory recognition and are vulnerable to conversion, including appropriation for agriculture through the VFV Land Management Law (2012) and VFV Law Amendment (2018). There is an acute need for statutory recognition of customary tenure, especially in ethnic areas (see assessment of forest tenure in Annex 1).

\subsection{National goals for the forest sector}

The Myanmar Reforestation and Rehabilitation Program (MRRP) (2017-2026) aims to restore around 1 million ha of degraded and deforested land within the PFE by 2026. This is to be achieved through a combination of plantation establishment (both state-owned and private), CF, agroforestry, natural forest regeneration, and enrichment planting. The MRRP is implemented by the Forest Department (FD) and Dry Zone Greening Department (DZGD) of MoNREC.

The following laws, rules and regulations have also been developed to support implementation of the MRRP and sustainable forest management:

- The Forest Law (2018) was amended to allow ownership of teak to be assigned to any person or organization, to permit more flexible zoning within RF and PPF, to confirm formal legal authority to MoNREC for CF rollout, and to allow commercialization of timber-based CF.

- The Conservation of Biodiversity and Protected Areas Law (2018) allows for the designation of community-managed PAs, and for communities to benefit from PA income through Payment for Ecosystem Services (PES) mechanisms.

- The Community Forestry Instruction (CFI) (2019) was a significant revision of an initial 1995 version and sets out procedures for sale of timber and non-timber forest products (NTFPs) from community forests.

The following important controls have also been enacted to address forest loss and degradation:

- 2014: a raw log export ban was announced, requiring all log exports to be processed;

- 2016/17: a temporary logging ban was introduced as part of the National League for Democracy's 100-day plan; and

- 2016/17: a 10-year logging ban in the Bago Yoma area was introduced.

The new forest reforms emphasize restoration and include CF. The MRRP and the revised CFI provide the framework for a long-needed program that has the potential to address legacy issues in the sector, such as social exclusion. The MRRP sets clear targets for forest restoration and the scaling-up of CF, 
which, if implemented as planned, will be a significant step forward. Global experience shows that CF and smallholder plantations are financially and socially viable, and can contribute meaningfully to generation of rural income, business opportunities, and partnership building between the public sector, private sector, and communities, if secure tenure and incentives are in place (World Bank 2019d).

Other national programs in the forestry sector include:

- National Forest Master Plan (NFMP) (2002-2031). The NFMP was developed to cover all forest-related activities, including wildlife and nature conservation, for the whole country. It includes a target to increase RF and PPF to 30 percent of total land area and PAs up to 10 percent, by 2030.

- Integrated Plan for the Greening of the Central Dry Zone (2002-2031). Based on an assessment of current land use status in the Central Dry Zone, this Plan elaborates a range of measures for soil management, development of water resources, reforestation, natural forest management, training, research and extension, development of woodfuel substitutes, infrastructure development, and institutional strengthening.

- Myanmar Sustainable Development Plan (MSDP) (2018-2030). Forestry development can make an important contribution to achieving the goals of MSDP Pillar 3, People and Planet, in particular Goal no. 5, 'Natural Resources and Environment for National Posterity'.

- The National Strategy and Action Plan for Mangrove Conservation and Coastal Management and the Inle Lake Watershed Conservation Action Plan both have relevance to forested areas.

The Government of Myanmar (GoM) has made commitments for the legal and traceable supply of timber to the European Union (EU) and international markets. The EU Forest Law Enforcement, Governance and Trade (EU-FLEGT) Action Plan sets out seven measures that together prevent the importation of illegal timber into the EU, improve the supply of legal timber, and increase demand for timber from responsibly managed forests. Myanmar is in a preparatory phase to establish strong foundations for a successful negotiation, should Myanmar and the EU decide to negotiate a Voluntary Partnership Agreement (VPA).

The Myanmar Forest Certification Committee was set up to develop standards to ensure the sustainable management of Myanmar's forest resources. It serves as the national governing body of the Myanmar Timber Legality Assurance System (MTLAS) and the Myanmar Forest Certification Scheme.

\subsection{National policies and plans related to forests}

A number of national and sectoral policies, and planning priorities and targets are relevant or are impacting forests in Myanmar. These are discussed briefly in the following sections.

\subsubsection{Land and agriculture}

Forest governance is closely linked to the land administration system and agricultural policy in Myanmar. Key policies and laws include:

- the Farmland Law (2012), which provides the legal basis for the issue of tradeable private titles.

- the Vacant, Fallow and Virgin (VFV) Management Law (2018), which defines 'VFV' land (previously called 'Land at Government Disposal') as including unclassified forest areas. It is a residual administrative category of land not under private or state ownership, but does not yet provide for recognition of prior customary rights, which is the de facto tenure system in ethnic areas. It also provides for long-term reallocation of large areas of these lands (up to 50,000 acres) to private companies. 
- the National Land-Use Policy (NLUP) (2016) was developed through a consultative process as an attempt to unify the policies and laws across the sector. Under Chapter 8, 'customary land rights' have been recognized. The National Land Law is currently under preparation.

- the Master Plan for the Agriculture Sector (2000/2001 - 2030/2031) aims to convert around 4 million ha of 'wasteland' for private industrial crop production under rubber, oil palm, paddy, pulses, and sugar cane, primarily for export.

Rapid expansion in rice exports is a Government priority, as Myanmar aims to be competitive with countries such as Thailand, Vietnam, and India. The ADS promotes rice production for national economic growth, but also recognizes the constraints of rice intensification (typically low yields). Expansion of rice production has been identified as the main cause of mangrove loss. The Myanmar Rice Sector Development Strategy foresees 7.7 million ha under rice production by 2030. Farmers are moving to cash crops, such as pulses, oilseeds, fruits and vegetables, meaning that traditional ricebased farming systems will need to encompass a broad range of non-paddy options. This shift will require significant investment in water management and infrastructure.

The Agricultural Development Policy (2016) is the most recent sector policy statement of MoALI that led to the formulation of the Agricultural Development Strategy (ADS) and Investment Plan. The Policy also commits to the development of VFV and 'wastelands' into new crop land, though sets no targets for such development.

The ADS and Investment Plan (2018-22) includes investments for new irrigation (US\$15 million), irrigation rehabilitation (US\$249 million), and agro-processing (US\$1 million). The emphasis is on improving irrigation efficiency through rehabilitating reservoirs and irrigation schemes. Other measures in the Investment Plan to raise agricultural productivity include (i) effective agricultural research and extension; (ii) efficient use of agricultural inputs; (iii) efficient and sustainable practices and use of natural resources (land, water, soils, and forests); and (iv) increased resilience to climate change and natural disasters.

There is a focus on making agriculture more efficient to reduce the need for expansion of agricultural land. This has included the rehabilitation of large irrigation systems funded by:

- ADB: 36,000 ha in the Central Dry Zone (Magway, Meikhtila, Yamethin and Shwebo Districts);

- WB: 35,000 ha in east Bago, Naypyiyaw, Mandalay, and Sagaing Regions;

- JICA: 87,527 ha in west Bago and 200,000 ha in Thaphanseik.

A range of new agro-ecological approaches are being piloted in Myanmar, including the System of Rice Intensification, green water management, more efficient nitrogen use, conservation agriculture, agroforestry, and organic agriculture.

There is growing concern that the Farmland Law (2012) does not provide sufficient security of tenure for smallholders. Reform is needed to increase the coverage of the land use categories over which tenure can be secured, by extending the narrow concept of 'farmlands' under the Farmland Law (2012) to lands that are used for any agricultural activity, including aquaculture, livestock grazing, and shifting cultivation. This is required especially for ensuring community land rights and encouraging longer term investments in agroforestry, rotating agriculture, and industrial crops. This may involve simplifying the land use classification system for rural land to only four broad categories, for example; 1) agriculture, 2) forest, 3) VFV lands, and 4) other lands.

\subsubsection{Energy}

Myanmar's energy consumption in 2017 comprises 21,772 ktoe (75\%) biomass and waste, 2,621 (9\%) oil products, 2,932 ktoe (10\%) electricity, 442 ktoe (2\%) charcoal, and 1,083 ktoe (4\%) biomass (International Energy Agency 2017). Key energy targets include increasing national generation capacity by 500-1,000 MW per year to reach an installed capacity of 16,665 MW by 2030 and boosting the electrification rate from $38 \%$ of the population to $75 \%$ by $2021 / 2022$, and then to $100 \%$ by 2030 . 
The GoM is preparing an update to the National Electricity Master Plan with assistance from JICA. The Master Plan includes a strategy for new electric power generation plants to be constructed by 2030, based on an electricity generation mix of 53\% hydropower (13,194 MW), 15\% domestic gas $(3,836$ $\mathrm{MW}), 11 \%$ coal $(2,621 \mathrm{MW}), 11 \%$ LNG $(2,866 \mathrm{MW})$, and 10\% renewables (other than hydropower) $(2,420 \mathrm{MW}) .{ }^{10}$ This blend aims to reduce the country's reliance on hydropower, thereby improving supply reliability during the summer months (IFC, 2018).

Myanmar has identified climate mitigation actions and policies in the forestry and energy sectors, complemented by supporting policies in other sectors. These actions have been selected not only to deliver reductions in greenhouse gas (GHG) emissions, but also to bring significant development cobenefits. For example, actions in the energy sector emphasize off-grid electrification using renewables to reduce the use of diesel generators and woodfuels, as well as the dissemination of energy efficient cookstoves. Actions in the forestry sector, including expansion of PFE and PAs, will not only preserve one of the world's most important GHG sinks, but will also prevent soil erosion and thereby reduce the risk of floods and landslides.

Improving energy access amongst rural populations can relieve pressure on forest resources. Years of uncontrolled logging and overharvesting of wood for cooking and industrial use have contributed to forest depletion in Myanmar. With increasing rural electrification, there has been a decline in woodfuels as the primary cooking fuel in favor of electricity, but firewood and charcoal continue to be used to a high degree as supplementary fuels. Research commissioned as part of CFN development reveals that households in Myanmar typically continue the use of woodfuel in combination with electricity. Adoption of electricity for cooking may therefore reduce their woodfuel consumption only by less than $50 \%$, compared with households depending on firewood or charcoal alone. These dynamics of 'fuel stacking' are important for understanding that electrification or adoption of liquified petroleum gas (LPG) does not immediately eliminate woodfuel demand. While sustainable energy sources deployed for greater rural electrification can deliver improved local management of forest areas (GGGI, 2017), continued near-term investments in energy-efficient cookstoves remain important. GoM is committing to increasing the adoption of efficient cookstoves to reduce the amount of woodfuel used for cooking. This includes an indicative goal to disseminate approximately 260,000 units between 2016 and 2031. For improved results, the quality of locally produced stoves will need to be improved and investment in industrial manufacture needs to be encouraged by progressively reducing subsidy to create a level playing field.

\subsubsection{Water}

The National Water Policy (2015) states that the GoM will take sector-relevant measures to implement the policy and achieve its purpose by taking actions in six sectoral clusters, of which the most relevant for forestry are:

- Food and Water Security: maintain growth and productivity of food systems, including in agriculture; apply integrated water resource management through adaptation strategies to increase water storage and watersheds management, and

- Healthy Ecosystems: rehabilitate biodiversity and natural ecosystems to ensure the provision of ecosystem services; adopt environmentally sound technologies and good management practices, including ecosystem-based adaptation interventions, to improve and maintain the health and resilience of all ecosystems, including forest, water, land, and coastal ecosystems; ensure sustainable management of forests and land use planning.

\footnotetext{
10 MoEE and JICA, 2018. The Project for Capacity Development of Power Sector Development Planning. Presentation on the Optional Studies of Generation Mix.
} 


\subsubsection{Mining}

The provisions of the Mine Rules (2018) mirror those in the Environmental Conservation Law (2012) and the EIA Procedures (2015). The Mines Rules state that permit holders shall be responsible for all expenses relating to environmental conservation, foreseeing that proponents will establish an environmental conservation fund at a state-owned bank, with the amount of contribution to be based on the relevant Environment Management Plan for mineral exploration, mineral production, and/or mineral processing. MoNREC is in the process of setting up this Environmental Management Fund (EMF). Potential sources of revenue from the mining sector are:

- Compensation from polluters for environmental impacts. Under Subsection (o) of Section 7 of the Environmental Conservation Law and Section 30 of the Environment Conservation Rules (2014); and

- Contributions from organizations that obtain benefits from natural environmental services in the form of PES.

\subsection{Forest sector information related to Nationally Determined Contributions}

The Myanmar Climate Change Strategy and Action Plan (2016-2030) and its NDC set in 2017 spell out a broad vision of how to address climate change. Forestry is a key pillar of Myanmar's NDC, for both protection against extreme events and preservation of biodiversity. It recognizes the important role of forests in increasing resilience against extreme events, including the impact of floods and droughts, and for preserving biodiversity. Myanmar's NDC:

1. focuses on maintaining Myanmar's net GHG sink status by maintaining forest cover and investing in renewable power;

2. underlines the need to focus on adaptation, with the National Climate Change Strategy and Action Plan as a key tool; and

3. sets mitigation targets in the energy, forestry, industry, agriculture and urban sectors, opening opportunities for Myanmar to benefit from investment in low-carbon development.

Myanmar is currently updating its NDC and expects to submit the revised version to the United Nations Framework Convention on Climate Change (UNFCCC) in June 2020.

The environmental impacts of climate change in Myanmar are far-reaching and include increased risk of forest fires, plant pests and diseases, and desertification, particularly in the Central Dry Zone (CDZ), due to droughts and extreme temperatures; loss of vegetation in mountain regions as result of rapid-onset events such as floods and landslides; and destruction of coastal ecosystems due to strong cyclones, among others. The Myanmar Climate Change Strategy and Action Plan commits to: a) maintaining growth and productivity in agriculture, fisheries and livestock; $b$ ) adaptation strategies to increase water storage and watershed restoration and preservation; $c$ ) rehabilitation of biodiversity and natural ecosystems; and, d) sustainable management of forests.

Forests are essential for maintaining watershed health, reducing flood risk, erosion and landslides, preserving biodiversity and absorbing atmospheric carbon dioxide $\left(\mathrm{CO}_{2}\right)$. Although Myanmar has significant carbon sequestration capacity, high deforestation rates remain a critical issue. One of Myanmar's major challenges is to enhance the carbon sink potential of its forests, which can generate co-benefits such as adaptation.

Myanmar is still a net carbon sink as its forests have the capacity to uptake more $\mathrm{CO}_{2}$ than that emitted from human activities. Carbon sequestration by natural forests contributed 91 per cent to total $\mathrm{CO}_{2}$ removal in 2000 (MoNREC 2012a). However, $\mathrm{CO}_{2}$ removals by natural forests are gradually reducing due to land use change, especially the expansion of agricultural and temporary cropped areas. Over the period 1990-2011, the area of land under agriculture increased by 7.73 million ha (ADB 2015). 
Based on the revised Forest Reference Emissions Level submitted by Myanmar to the UNFCCC (November 2018), annual emissions are 53.8 Mt of $\mathrm{CO}_{2}$ equivalent for the period 2005-2015. The forest sector offers huge potential to sequester carbon through forest enhancement, conservation, and sustainable management. There is an urgent need to invest in these activities, as unplanned development will jeopardize Myanmar's net GHG sink status. Current targets from ongoing Government programs aim at sequestration of about $99 \mathrm{Mt}$ of $\mathrm{CO}_{2}$ from afforestation and reforestation on about 0.9 million ha of land between 2020 and 2031. In addition, Government targets to reduce deforestation by $50 \%$ by 2030 are estimated to result in avoided emissions of $176 \mathrm{Mt}$ of $\mathrm{CO}_{2}$.

Urban development may further drive land-use change and deforestation and undermine commitments to maintain forest cover to reduce global emissions. Deforestation can also increase the exposure of urban settlements to risks such as landslides, increased surface water run-off, and heat-island effects.

The National REDD+ Strategy is currently under development and will set out the management framework, drivers of deforestation, and mitigation strategy for the implementation of Reducing Emissions from Deforestation and Degradation as defined under the UNFCCC. The draft strategy has gone through a consultation process and is expected to be finalized in 2020 .

\subsection{Network of forest Protected Areas}

Myanmar has an ambitious goal for expansion of its forest PAs, as set out in the Forest Policy (1995) and the NFMP. The NFMP includes a target to increase PA coverage to 10 percent of national land area by 2030. The current National Biodiversity Strategy and Action Plans (NBSAP, 2015-2020) defines a strategy for establishing seven additional PAs, taking total coverage from 5.75 percent to 7.82 percent of land area by 2021.

Myanmar's forests are recognized globally for their biodiversity values. Forests are considered integral to the stability of the environment. Myanmar's huge altitudinal range (from the sea to the eastern Himalayas) and its position between major biomes make it highly important for biodiversity and wildlife. Myanmar is one of the world's biodiversity 'hotspots' with, for example, over 300 mammal species (including at least five that are endemic), 144 globally threatened species, ${ }^{11}$ and the greatest diversity of bird species in southeast Asia. Equally important is the use of Key Biodiversity Areas (KBAs), ${ }^{12}$ which extend well beyond the national PA system, to establish connectivity in biodiversity corridors and for protecting critical watersheds and catchments. KBAs currently cover $17 \%$ of the country, comprising 132 sites, but expansion to $41.2 \%$ comprising 194 sites is currently under review. Some KBAs overlap with existing PAs, including sites designated under international conventions. Others are small in size, scattered and are not yet under legal protection, but could be managed through community-based conservation measures (e.g., community-managed areas or locally managed marine areas).

Myanmar is a signatory to the UN Convention on Biological Diversity (CBD), through which the fiveyear NBSAPs are developed. The current NBSAP prioritizes:

- Launching an initiative to restore millions of hectares of forest that are commercially exhausted and subject to conversion to plantations or agriculture;

- Expanding the PA network to cover 15 percent of the country's coral reefs and key gaps in the terrestrial system, including mangrove forests, through both government and communitybased approaches; and

\footnotetext{
11 Myanmar CBD Country Profile: https://www.cbd.int/countries/default.shtml?country=mm.

12 KBAs are sites of global significance with clearly defined boundaries. They are nationally identified using globally standardized criteria and thresholds, and represent the most important sites for biodiversity conservation worldwide. Source: http://www.biodiversitya-z.org/content/key-biodiversity-areas-kba.
} 
- Ensuring that national laws recognize customary tenure as a way to protect indigenous knowledge and genetic plant resources, and to provide a practical incentive for community participation in biodiversity conservation and benefit-sharing.

The Biodiversity and Conservation of Protected Areas Law (2018) aims to implement government policy for PA conservation and to protect geo-physically unique areas, endangered wildlife, and their natural habitats. There has been public consultation on draft Rules to guide implementation of the law.

The Environmental Conservation Law (2012) and Rules (2014) also contain provisions for biodiversity conservation in PAs, and for establishing PES mechanisms. The EIA Procedure (2015) contains provisions for assessing the environmental impacts of agriculture, livestock and forestry development. 


\section{CONTRIBUTION TO LIVELIHOODS AND SUSTAINABLE DEVELOPMENT}

Myanmar's forests contribute to the national economy in a number of significant ways. They support basic household needs and livelihoods, commercial production, export earnings, and employment. They also contribute indirectly through a range of ecosystem services, particularly hydrological functions at the river basin level, storm protection on coastlines, pollination, soil nutrient recovery, biodiversity habitat (including for fisheries), and, increasingly important, disaster risk protection.

\subsection{Livelihoods, inclusion and poverty relevance of forests}

There appears to be a strong correlation between the World Bank Group's Multi-dimensional Disadvantage Index (MDI) ${ }^{13}$ and forest cover (World Bank 2018b). This is especially the case in upland ethnic areas, where a large majority of rural households rely on fuelwood as their primary energy source and 63 percent of rural land is either forest or woodland. The MDI is an index of disadvantage by township, constructed using 2014 census data. It allows for the mapping of townships with greaterthan-average, average, and lower-than-average disadvantage levels (World Bank 2018b). Figure 5 shows the MDI by township (greater-than-average disadvantages in red) and Figure 6 shows the area of remaining intact forests by township for comparison with the pattern of disadvantage.

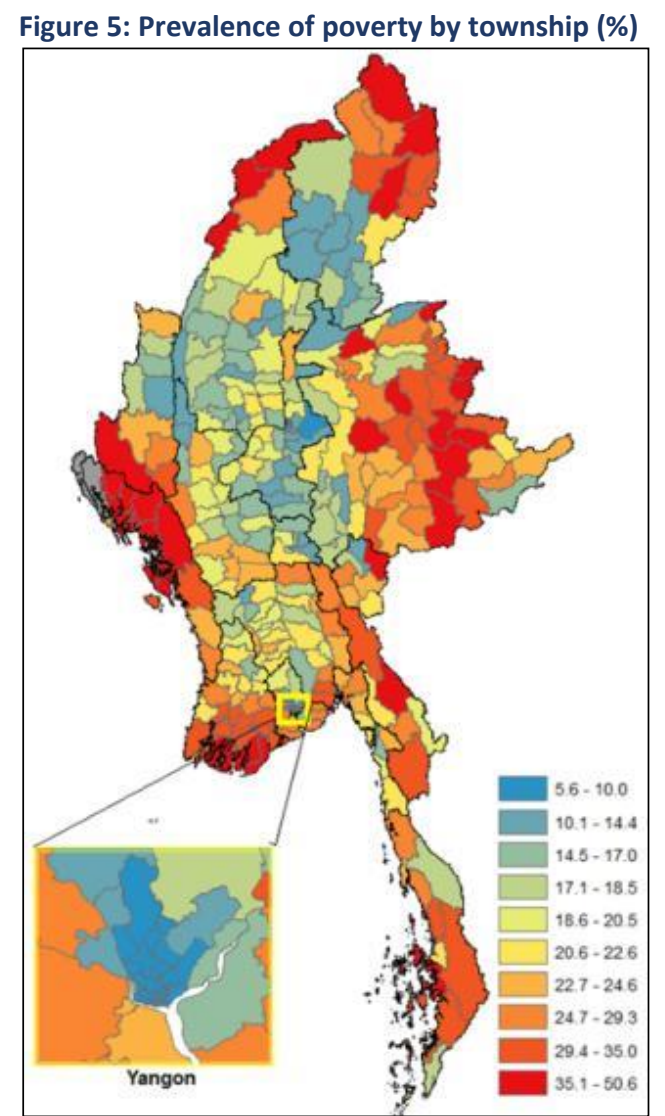

Source: World Bank 2018b; authors' calculations.

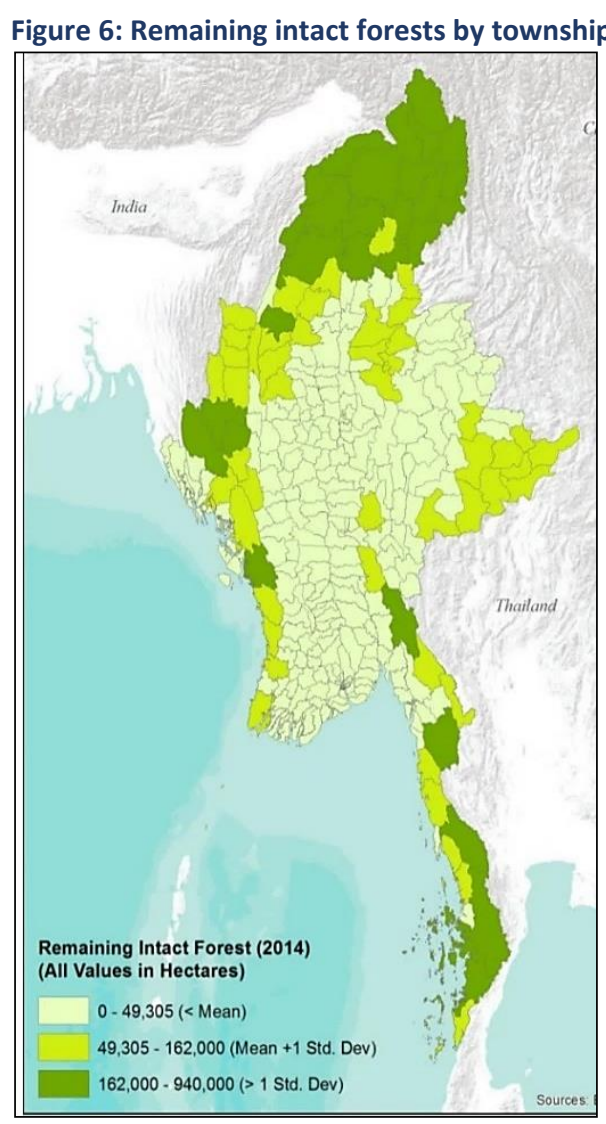

Source: Bhagwat et al. 2017

\footnotetext{
13 The MDI consists of 14 non-monetary indicators from 6 domains (education, employment, health, water and sanitation, housing, and assets) chosen through a consultative process and based on Myanmar Population and Housing Census data. The term 'disadvantage' refers to deprivations in a particular domain or indicator, i.e. a household is considered to have a disadvantage if its members fail to meet a defined cut-off in an indicator.
} 
Poverty is also more prevalent and severe in the hilly, mountainous, and coastal agro-ecological zones of Myanmar, compared with the Delta and Central Dry Zone. A recent natural capital assessment also suggests that the biophysical supply of key services - such as sediment retention, waterflow regulation, and flood control - is concentrated in the relatively poorer areas in the north and northwest of the country (Mandle et al. 2017; WWF 2016a).

There are no comprehensive studies of forest-dependent livelihoods in Myanmar. ${ }^{14}$ In 2012, however, it was estimated that around 520,000 households (or about $14 \%$ of all households) are located in and around forests (Emerton \& Aung 2013).

Rural households depend on forests for a range of material benefits, ecosystem services, and cultural values (Tint et al 2011). These include woodfuel, land for shifting cultivation, construction and timber poles, bamboo and rattans, fodder and forage for animals, wild foods, bush meat, medicines and other NTFPs, wood extraction, processing and sales, and cultural values. Woodfuel remains the most important energy source in rural areas, and NTFPs are a major source of income and housing materials for the poor.

Several regional studies illustrate the importance of forests for sustaining livelihoods across various agro-ecological zones:

- In uplands, there is a range of forest uses, including shifting cultivation, agroforestry, hunting, and gathering (Vicol 2018).

- In the Central Dry Zone, pastoralism is more widespread, so forage and fodder are important forest resources. A woodfuel deficit has led to illicit trade from the edges of the CDZ, putting extra pressure on resources there. With perceived increasing aridity, forests play important local ecosystem service functions for the local microclimate (Forsyth 2018; Zin et al. 2019).

- In coastal areas, mangrove forests play a range of roles, including maintaining juvenile fish habitats, protecting coastal zones from erosion, and providing specific forest products including roofing (nypa palm leaves) and charcoal. A recent study on livelihood use of mangroves in CFs found significant dependency on forests, particularly by the poorest, especially for woodfuel, timber, and NTFPs (Feurer et al. 2018).

The annual value of NTFPs was estimated to be around MMK 166,000 (US\$118) per household (Emerton \& Aung 2013). This would accrue to households in and around forests, giving an overall value to rural communities of US\$487 million for NTFPs harvested from terrestrial forests. Transferring evidence from other countries in the region for mangrove benefits, the study estimates an annual value of around MMK44,000 per ha, giving a total of around US\$20 million for benefits from mangrove forests.

\subsubsection{Peace and conflict}

Myanmar has been more deeply affected by subnational conflict than any other country in Asia, fueled in part by abundant natural resources. Across the country, there are at least 20 major ethnic armed organizations (EAOs) as well as hundreds of splinter groups and government-affiliated militias.

Around two-thirds of remaining forests are in ethnic areas, and in most of these areas there are strong grievances over past and even ongoing abuses (BMI 2018). These areas mostly remain militarized, either by the Tatmadaw, militias, or EAOs. Ongoing armed conflict is concentrated in Rakhine, Kachin, and Shan states (Figure 7). Kachin and Shan also have extensive areas of intact forest.

\footnotetext{
${ }^{14}$ This gap could be filled by using the Living Standards Measurement Survey (LSMS) forestry modules and the LSMS-ISA trees on farm module, which is especially useful for the agriculture-related perennial agroforestry activities.
} 
In 2016, it was estimated that 118 out of 330 townships in Myanmar had been affected by active or latent conflict (TAF 2017 ${ }^{15}$ ).

Figure 7: Presence of EAOs in Myanmar

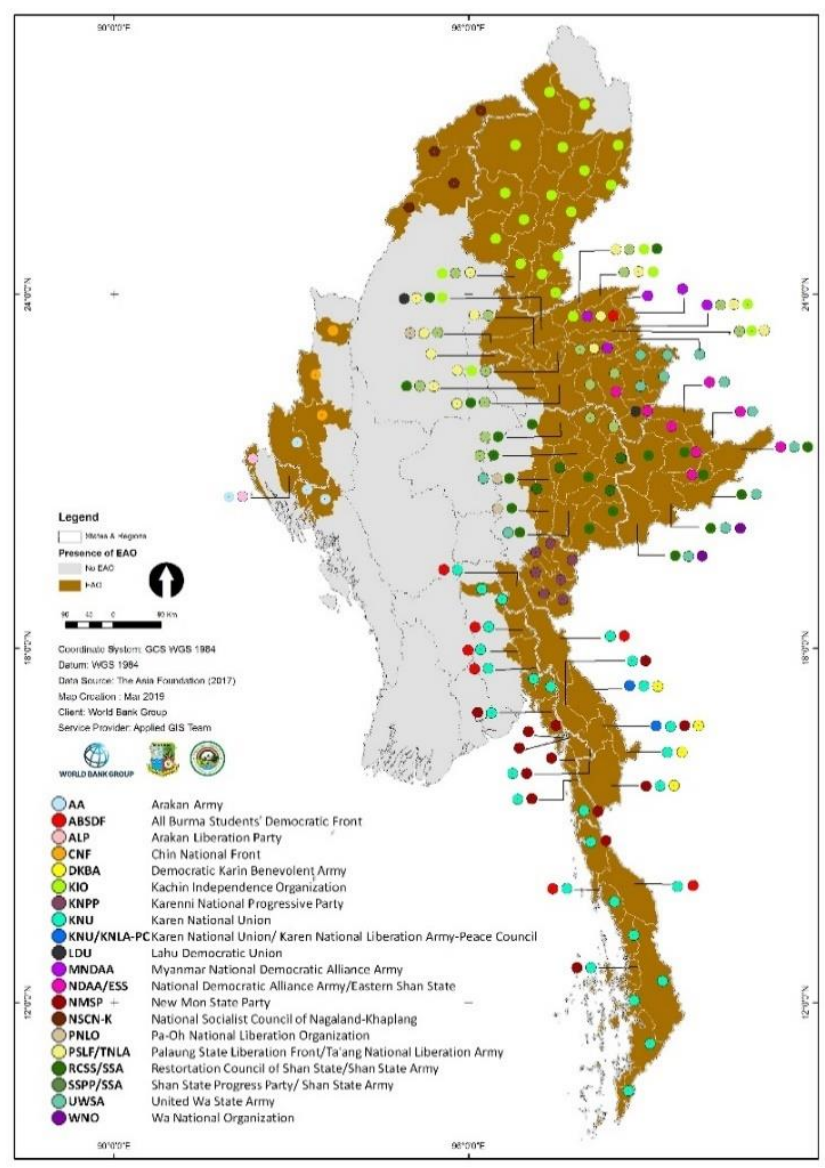

Source: The Asia Foundation 2017.

Forest resources can act as a 'resource curse' by encouraging conflict over the control of benefit flows, eroding peacetime institutions, and undermining the rule of law. Past militarization of forestry in contested areas, especially logging operations, has exacerbated conflict in some areas, and the military and EAOs have used logging as means of generating funds.

Governance of forests and other natural resources is one of numerous issues in the peace process. The key issues relate to ethnic groups' aspiration for federal decentralization of forest governance and more equitable benefit sharing between the Union, State, Region, and locality, already recognized in the Pyingdasu Accord (2017).

\subsubsection{Gender}

Women and men have differentiated roles and responsibilities in relation to forest resources, which structures their priorities and preferences in species choice for tree planting, and in the use and management of forest resources and access to forests. Women's roles in relation to the forest sector vary across the country, depending on local cultural traditions and livelihood transitions, as commercialization increases. While it is important to be cautious in assuming gendered forest use, it is generally the case that rural women are more engaged in subsistence forest product collection for domestic use, especially fuelwood and fodder collection. Men are often more focused on cash generation and employment and may even migrate away in pursuit of income opportunities, leaving women-headed households and a 'double burden' of domestic tasks and farm management. Men

${ }^{15}$ https://asiafoundation.org/2017/10/18/contested-areas-myanmar-key-findings-new-asia-foundation-study/. 
tend to be more involved in dealing with outsiders, including FD staff (e.g., as village 'headman'), and anecdotal evidence suggests that planning and species choices in community forestry may not always adequately reflect women's aspirations.

Ethnic minority women are traditionally engaged in various forest activities such as establishing nurseries for plantations; selecting seedlings and tree species; replanting timber trees; controlled burning to assist regeneration; and protecting germinating seedlings and new saplings, among other activities, and have thus contributed to the prevention of forest degradation. However, although most of the women are the primary users and managers of the forests, they do not have control over the forest resources as their rights have not been recognized in the statutory forestry related regulations. Instead, their views are mostly represented by their spouses, and their representation is mostly insignificant in forestry planning and management meetings, and in decision-making processes.

Consequently, in forest management and use, women are limited in active participation in decision making and leadership and tend to receive fewer benefits. The gender disparity in Myanmar's forestry sector is largely attributed to customary practices and gender norms. Patriarchal authority is common within the family and community, with men mostly acting as the decision-makers. In the case of ownership of forested land and forest resources, women's rights to own and access land and forest resources are generally ignored. One of the underlying causes is that social norms reinforce forestry as a male-dominated profession in which women's rights are secondary.

Men and women also play different roles in forest products value chains. Women's participation is usually limited to harvesting and small-scale retail trade, while men dominate larger businesses and higher-value supply chains. A large majority of women do not own land, reducing their opportunities to access credit facilities, training, and appropriate technology, which is critical in forestry sector investments. Women are also burdened more by household chores and responsibilities, reducing the time which can be allocated to forestry and agroforestry income-generating activities.

Since 2010, the GoM has revised its forest land and resource policies, laws, guidelines, and regulations to provide greater recognition of tenure security, including protecting the rights of ethnic communities and women through the Farmland Law 2012; NLUP 2016; Mines Law 2015; Myanmar Investment Law 2015; Forest Law 2018; CBPA Law 2018; Land Acquisition, Resettlement and Rehabilitation Law 2018; and revised CFI 2019.

Women are underrepresented in land-related matters. Customary land governance follows socially defined practices, and community institutions related to land and resources are largely represented by men. This is reflected in the membership of the committees established by government mechanisms too. This trend of male-domination continues despite NLUP provisions that recognize the importance of women's inclusion in land governance. Few women, minorities, or members of other potentially vulnerable groups serve as senior officials on any State/Regional committees. Lack of gender awareness among local officials dealing with land allocation, inheritance, and dispute settlement sustains a male bias that prevents women from enjoying their mandated rights.

There has been progress in protecting and recognizing women's rights to forest land and resources in policy and under the law, but enforcement is still lacking. The Constitution of 2008 includes a guarantee of equal rights and legal protection to all persons, men and women (Article 347), and does not discriminate on the basis of sex. Similar affirmations are made in the NLUP and other regulatory frameworks. However, widespread lack of awareness of such provisions across ministries and communities still challenges universal implementation and continues to deny women many of the fruits of Myanmar's formal commitments to participation, equality, and access to rights. At the same time, some customary traditions subtly encourage women to conform to traditional gender roles as primary caretakers of families. Women's participation in different local committees and attention to gender concerns in such committees and in peace negotiations are also limited.

\subsection{Economy: Job and wealth creation}


Myanmar's gross domestic product (GDP) was US\$67 billion in $2017 .{ }^{16}$ Real GDP growth has been declining from a relatively high rate of 8.4 percent in 2013/14 and is expected to be 6.2 percent in the 2018/19 fiscal year (FY). ${ }^{17}$ The contribution of agriculture, including forestry, to GDP has declined significantly over the same period, according to official data (Figure 8).

Figure 8: Myanmar real GDP growth and sector contributions

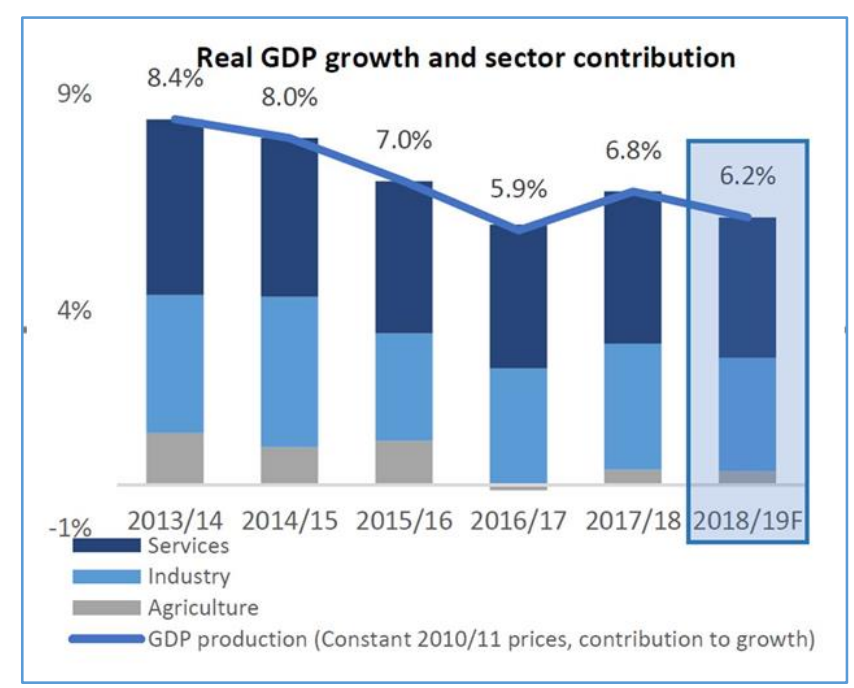

Source: World Bank 2018.

\subsubsection{Contribution to GDP}

The forestry sector has traditionally played a major economic role, dominated by commercial teak exports. Commercial timber has been extracted in huge volumes over the last century, especially in the period between 2010 and 2014. Today, forestry is less prominent in formal GDP estimates. In FY $2015 / 16$ it was just 0.2 percent or US\$130 million at constant 2018 prices, ${ }^{18}$ and timber exports earned some US\$95.68 million or 0.8 percent of total export earnings (MEITI 2019). However, the value of unlicensed or illegal timber exports is said to be significantly higher.

While forestry continues to make an important contribution to GDP, this contribution has fluctuated widely over recent years. Ministry of Planning and Finance (MOPF) data indicate a significant fluctuation and declining trend over the most recent five-year period. This can be explained by five interlinked factors: (a) forest exhaustion due to overharvesting; (b) a reduced Annual Allowable Cut (AAC); (c) the one-year logging ban introduced in 2015; (d) the 10-year logging ban in Bago Yoma since 2016; and (e) the introduction of the log export ban in 2014, requiring processing of wood products before export.

\subsubsection{Government revenue}

Total government revenues received from the forestry sector are significant. In FY 2015/16, they represented 8.3 percent (US\$583 million) of overall government revenues (MEITI 2019,). In FY 2017/18, total revenues from the forestry sector were US\$322 million (MEITI 2010), mainly from timber (Table 2). The revenue collection from NTFPs is less than 1 percent of the total revenues.

Table 2: Myanmar Forestry revenues by sub-sector (FY 2017/18)

\begin{tabular}{|l|l|l|l|r|r|r|}
\hline & & & & $\begin{array}{c}\text { Total } \\
\text { (MMK } \\
\text { Revenue stream }\end{array}$ & $\begin{array}{c}\text { Equivalent } \\
\text { in US\$ } \\
\text { million }\end{array}$ & \% \\
\hline Income tax & Reconciliation status & Paid by & Paid to & billion \\
\hline
\end{tabular}

16 https://data.worldbank.org/country/myanmar.

${ }^{17}$ Beck et al. 2018.

${ }^{18}$ All U.S. dollar values referred to in this section are expressed at constant 2018 U.S. dollar, deflated using the Consumer Price Index for that year and then converted at the 2018 exchange rate. 


\begin{tabular}{|c|c|c|c|c|c|c|}
\hline State contribution & Reconciled & MTE & TD & 41.21 & 30.40 & 9.44 \\
\hline Commercial tax & Reconciled & MTE & IRD & 16.57 & 12.22 & 3.80 \\
\hline Special Goods Tax & Reconciled & MTE & IRD & 15.95 & 11.77 & 3.65 \\
\hline Royalties & Reconciled & MTE & FD & 3.03 & 2.23 & 0.69 \\
\hline Other revenues & Unilateral disclosure & Private & FD & 2.03 & 1.50 & 0.46 \\
\hline Dividends & Reconciled & FPJVC & FD & 0.03 & 0.02 & 0.01 \\
\hline Total revenues from timber & & & & 130.33 & 96.13 & 29.85 \\
\hline Total revenues from NTFP \& others & Unilateral disclosure & Private & FD & 4.08 & 3.01 & 0.93 \\
\hline \multicolumn{4}{|c|}{ Subtotal I } & 134.41 & 99.14 & 30.78 \\
\hline Timber sales in USD (export) & Unilateral disclosure & Private & MTE & 186.68 & 137.69 & 42.75 \\
\hline Timber sales in MMK (local) & Unilateral disclosure & Private & MTE & 115.56 & 85.23 & 26.46 \\
\hline \multicolumn{4}{|c|}{ Subtotal II } & 302.24 & 222.92 & 69.22 \\
\hline \multicolumn{4}{|c|}{ Total } & 436.65 & 322.05 & 100 \\
\hline
\end{tabular}

Source: MEITI 2020. Figures in red added manually as per original source (not true sums).

Timber is now sold both at local and national open tender auctions by the Myanmar Timber Enterprise (MTE), although until recently the MTE would also engage in direct export. Logs sold at auctions may also be exported; but if sold as logs, they must now be processed before export. The total volume of timber sales in 2015/16 was US\$296.45 million (a drop from US\$402.46 million in 2014/15) (Table 3) (MEITI 2019). A gradual decrease of the forestry revenues was observed during FY 2014/15 to 2017/18 (Table 4) (MEITI 2020).

Table 3: Total volume of timber sales by forest products $2015 / 16$

\begin{tabular}{|l|r|l|r|r|}
\hline Type & Quantity & Unit & US\$ million & $\%$ \\
\hline Teak log & 113,395 & Hoppus tons & 140.06 & 51 \\
\hline Hardwood Log & $\mathbf{2 9 6 , 6 5 7}$ & Hoppus tons & 135.29 & 49 \\
\hline Total local & $\mathbf{4 1 0 , 0 5 2}$ & Hoppus tons & $\mathbf{2 7 5 . 3 4}$ & $\mathbf{9 3}$ \\
\hline Teak conversion & $\mathbf{8 , 5 6 2}$ & Cubic tons & 10.72 & 51 \\
\hline Hardwood conversion & 4,184 & Cubic tons & 7.73 & 37 \\
\hline Woodbase & 3,163 & Cubic tons & 2.66 & 13 \\
\hline Total local / export & $\mathbf{1 5 , 9 0 9}$ & Cubic tons & $\mathbf{2 1 . 1 0}$ & $\mathbf{7}$ \\
\hline & & Total sales & $\mathbf{2 9 6 . 4 5}$ & $\mathbf{1 0 0}$ \\
\hline
\end{tabular}

Source: MEITI 2019. Figures in red added manually as per original source (not true sums).

Table 4: Evolution of forestry revenues (FY 2014/15 to 2017/18)

\begin{tabular}{|l|c|c|c|c|c|}
\hline Forestry revenues & $2014 / 15$ & $2015 / 16$ & $2016 / 17$ & $2017 / 18$ & $\begin{array}{c}\text { CAGR* } \\
(2014 / 15-2017 / 18)\end{array}$ \\
\hline MMK billion & $\mathbf{6 5 5 . 1 7}$ & $\mathbf{5 8 4 . 9 4}$ & $\mathbf{4 9 . 0 5}$ & $\mathbf{4 3 6 . 6 5}$ & $\mathbf{- 1 2 . 6 5 \%}$ \\
\hline Exchange rate US\$/MMK & 995.26 & 1223.58 & 1260.60 & 1355.82 & \\
\hline US\$ million & $\mathbf{6 5 8 . 2 9}$ & $\mathbf{4 7 8 . 0 6}$ & $\mathbf{3 8 0 . 8 1}$ & $\mathbf{3 2 2 . 0 5}$ & $\mathbf{- 2 1 . 2 0 \%}$ \\
\hline
\end{tabular}

* - Compound Annual Growth Rate

Source: MEITI 2020

High levels of timber theft, irregularities, and underreporting result in loss of revenues. There is further room for improvement of the revenue management system (MEITI 2019). The importance of NTFPs for the rural society is largely underestimated as they are mostly traded in local markets and not registered.

Table 5: Teak and hardwood log extraction in Myanmar (FY 2008/09 to 2017/18) (hoppus tons)

\begin{tabular}{|c|c|c|c|c|c|c|c|c|c|c|c|}
\hline \multirow[b]{2}{*}{ Product } & \multicolumn{10}{|c|}{ Annual log extraction (hoppus tons) } & \multirow{2}{*}{$\begin{array}{c}\text { CAGR } \\
(\%) \\
13 / 14 \\
17 / 18\end{array}$} \\
\hline & 08/09 & $09 / 10$ & $10 / 11$ & $11 / 12$ & $12 / 13$ & $13 / 14$ & $14 / 15$ & $15 / 16$ & $16 / 17$ & $17 / 18$ & \\
\hline Teak & 194,481 & 158,110 & 182,618 & 225,639 & 235,685 & 258,643 & 100,704 & 55,627 & 1,247 & 15,416 & -50.59 \\
\hline Hardwood & $1,033,890$ & $1,136,986$ & $1,019,357$ & $1,103,575$ & $1,223,732$ & $1,008,784$ & 481,863 & 487,921 & 9,587 & 325,012 & -24.66 \\
\hline Total & $1,228,371$ & $1,295,096$ & $1,201,975$ & $1,329,214$ & $1,459,417$ & $1,267,428$ & 582,567 & 543,547 & 10,834 & 340,428 & -28.01 \\
\hline
\end{tabular}


Source: MEITI 2020. Headings and numbers as per original source except totals for 2013/14 and 2015/16, which were added manually (not true sums).

\subsubsection{Exports}

In 2015/16, the total value of Myanmar's wood exports was estimated at US\$443 million (FAO 2018a). Almost half of these recorded exports were 'roundwood', despite the 2014 export ban that should have resulted in roundwood exports falling to zero. This may reflect a delay in introduction of the ban and perhaps (illegal) export overland to China. The Myanmar Extractive Industries Transparency Initiative (MEITI) 2019 report gave an export value of US\$207 million for the same period, less than half the FAO figure. Such discrepancies confirm the need for more accurate data collection.

From 2010 to 2014, there was a huge increase in the value of wood and timber product exports, with an extreme peak in $\mathbf{2 0 1 1}$ of close to US\$2.2 billion. Figure 9 displays the trend of timber and wood product exports over the last 20 years. It shows a steady increase until 2009, with exports composed of mainly roundwood, with some sawn wood and other products. Since 2014, there has been a fall in export values caused by a decline in availability, the log export ban, and reduced AAC. Timber can now only be legally exported through Yangon (with a minor concession from Myeik port in southern Tanintharyi).

Figure 9: Myanmar timber and wood product exports (1997-2016)

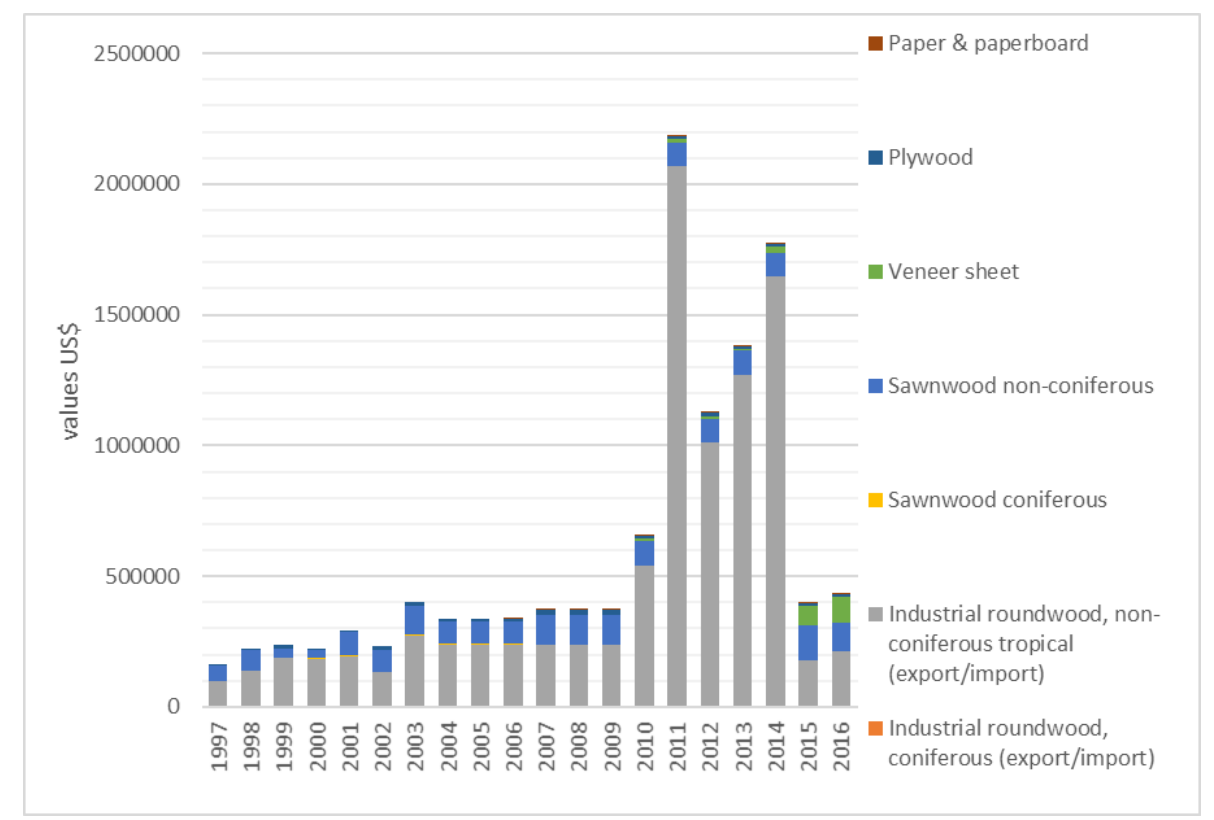

Source: FAO 2018

India and China are the two largest importers of timber products from Myanmar. India has recently become a major (official) importer country. However, if unofficial trade is considered, then China is also a major importer of forest products, including charcoal. In 2013, 94 percent of China's imports of timber products from Myanmar were registered in Kunming, the capital of Yunnan, a landlocked Chinese province bordering Kachin State in Myanmar. It is likely that all these imports were transported overland through trading posts along the Yunnan border (MEITI 2019).

\subsubsection{Timber processing}

The Forest Product Strategy (2015-2019), developed by the Ministry of Commerce, lays out an action plan to improve processing capacity in support of export-oriented companies. The lack of reliability, pricing, and quality of upstream supplies, poor skills and capacity of the industry, lack of transparency, and changing taxes were all identified as challenges. 
The MTE owns several sawmills and wood processing mills with old and inefficient processing technology, leading to high waste and inefficiencies (Blessing, 2018). The MTE has access to some of the highest value trees in the world. Improvements in material recovery and quality of outputs therefore have the potential to return much additional value.

At present, most wood processing is undertaken by small- and medium-scale enterprises (SMEs). Those SMEs suffer from lack of a cohesive business environment, lack of credit financing, and regulatory complexity. Access to timber is challenging, market information is scarce, and productive infrastructure (labor, skills, logistics, and electrification) is still poor. Accessing timber through timber auctions (from plantations, conversion forests, and RFs) provides uncertainty and challenges for longterm planning, as prices, quantities, and species are often unpredictable.

Lack of research, access to technology, and trained labor are additional challenges for SMEs in the wood processing sector. Procedures will need to be simplified and incentives introduced to encourage integrated industries (national and international) to invest in high-end technology and processing capacity in Myanmar. Additional research in priority areas is also needed (for example, lesser-used species, technology development, and market research).

\subsubsection{Contribution to formal employment}

The forestry sector's contribution to formal employment represents just 0.1 percent of the country's total 2015 labor force (about 32,000 persons), employed by FD, MTE, and selected companies. This compares to 0.5 percent in Vietnam and 0.6 percent in Thailand - both countries which have developed important secondary wood product industries based largely on plantations (FAO 2014). Formal jobs in Myanmar's forest sector generated up to MMK 143 billion in wage earnings in 2016. Myanmar's low formal employment in the sector reflects the minimal value-added processing of timber.

Estimates put the value of unlicensed or illegal timber exports at four times the documented value (Raitzer et al. 2015; UNODC 2013). In 2018, large volumes of timber were reportedly exported illegally to China through the Ruili route. Large volumes of timber were also not accounted for in the formal logging activities of subcontractors (EIA 2019). China maintains customs statistics that appear to indicate a virtual cessation of overland import of logs in the last two years (although the import of charcoal continues). So-called 'salvage logging' from infrastructure development and land conversion has also not always been accurately monitored (various sources).

GDP only measures the formal economy, while NTFPs and woodfuel largely operate in the informal economy. The value of woodfuel and NTFPs is therefore underestimated. Woodfuel remains the country's major energy source and is reported to be used for cooking and heating by 60-80 percent of households (although there is evidence that this is declining with the spread of electrification). It is also an important source of energy for small-scale industries. These significant sectoral contributions are not included in the GDP calculations, mainly due to lack of data.

Wood processing, in the GDP calculations, may be included in the category of 'industry' rather than 'primary sector - forestry' for the purpose of GDP calculation, and so neglected if the category is taken at face value. A more nuanced assessment of the forest sector and its contribution to the GDP should include industrial processing and value chain aspects.

\subsubsection{Forest ecosystem services}

The annual value of forest ecosystem services is extremely high and estimated to be US\$7.3 billion (Emerton \& Aung 2013). The largest contributions come from insect pollination supporting agriculture (37.4 percent) and mangrove fishery nurseries (15.5 percent) (Figure 10 and Table 6). Other forest ecosystem services include (a) carbon sequestration, (b) watershed protection, and (c) coastal 
protection. The benefits of ecosystem services recur in perpetuity, and while forest conversion for timber production may have short-term benefits, forest conservation provides long-term benefits.

Figure 10: Ecosystem services of forests

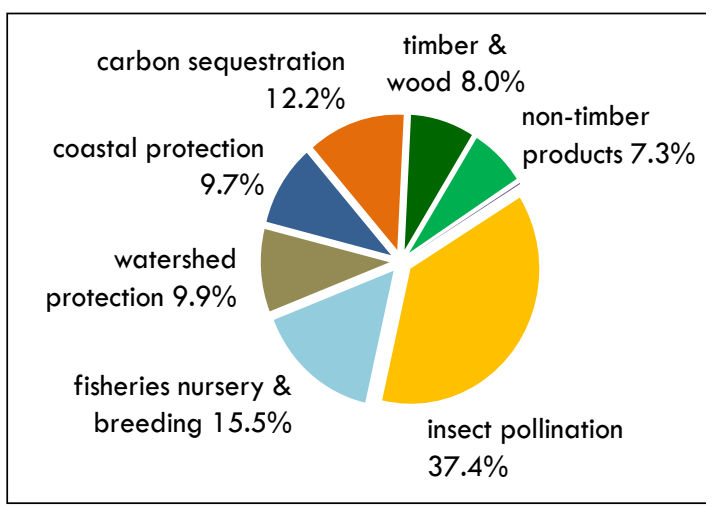

Source: Emerton \& Aung 2013
Table 6: Baseline values of forest ecosystem services

\begin{tabular}{|l|r|r|}
\hline Ecosystem service & MMK billion & USS million \\
\hline Timber \& wood products & 565.2 & 582.1 \\
\hline Non-imber forest products & 492.0 & 506.6 \\
\hline Forest elephants & 20.0 & 20.6 \\
\hline Terrestrial forest watershed protection & 700.1 & 721.0 \\
\hline Mangrove coastal protection & 686.6 & 707.1 \\
\hline Forest carbon sequestration & 863.9 & 889.7 \\
\hline Mangrove fisheries nursery \& breeding habitat & $1,097.6$ & $1,130.4$ \\
\hline Insect pollination & $2,649.2$ & $2,728.3$ \\
\hline Nature-based recreation \& tourism & 8.6 & 8.8 \\
\hline Total forest sector & $7,083.0$ & $7,294.6$ \\
\hline Of which: & 1,057 & $1,088.7$ \\
\hline Direct forest income & 3,755 & $3,867.5$ \\
\hline Value-added to production in other sectors & 1,407 & $1,448.6$ \\
\hline Domestic costs and damages avoided & 864 & 889.7 \\
\hline Gobal costs and damages avoided & & \\
\hline
\end{tabular}

In the hills and coastal areas in particular, forests help maintain stream flow in the dry season and retain sediments and thus purify water, particularly in the northern, mountainous part of the country. They also help mitigate the impact of climate change.

\subsection{Contribution of forests to other sectors}

Watershed protection services are another important ecosystem service, and in Myanmar, their annual value is estimated to be US\$721 million (Emerton and Aung 2013). They also have a key role in managing seasonal river flow fluctuations and in maintaining water quality. Watershed forests reduce disaster risk by absorbing precipitation and releasing it more slowly. This lowers the risk of flooding during the rainy season and ensures that water continues to flow during the dry season.

\subsubsection{Hydropower}

The IFC Strategic Environment Assessment (SEA) of the Hydropower Sector in Myanmar recognized that watershed protection can help maintain hydropower performance over time by maintaining or improving seasonal runoff distribution across the year and by minimizing erosion and sedimentation. The SEA recommends that watershed protection mechanisms could include: (i) developer-sponsored watershed management activities, and/or (ii) PES. PES is delivered by local communities to assist in the provision of an ecosystem service. The main environmental service local communities can offer hydropower plants is watershed protection (IFC, 2018). Land use upstream of hydropower plants has a significant role to play in moderating hydrological flows, soil erosion and sediment generation in the catchment (Figure 11).

Figure 11: Watershed protection for hydropower projects

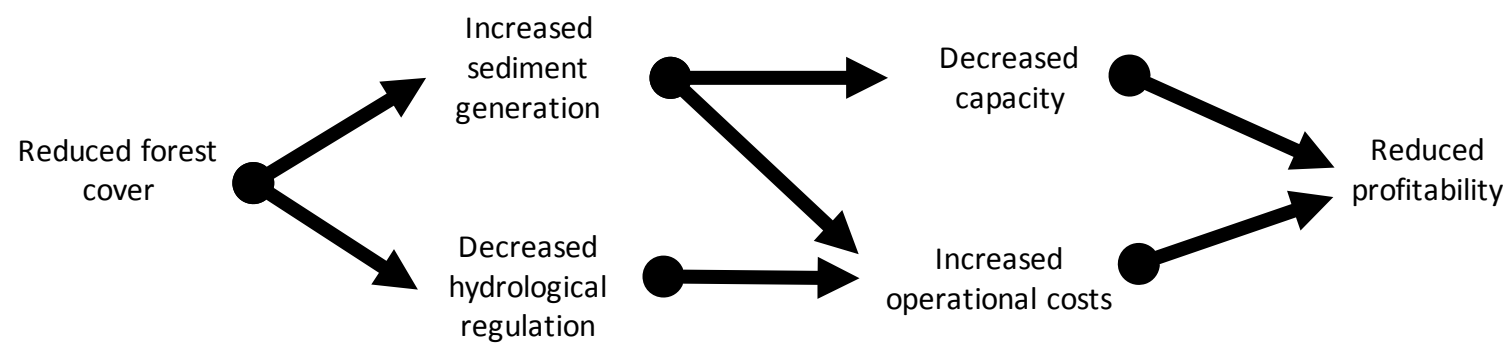

In the case of PES for watershed protection, Vietnam offers a good example. The main beneficiaries of watershed protection services offered by forest protection and broader catchment management are subject to a charge for these ecosystem services. PES systems in watersheds have been restricted 
to three user groups, i) water supply companies, which benefit from water availability and quality; ii) tourism enterprises benefiting from pristine natural environments, and iii) hydropower companies which benefit from enhanced operations, lower O\&M costs and a reduction in issues with reservoir sedimentation. ${ }^{19} 97 \%$ of watershed protection fees in Vietnam are garnered from hydropower plants.

In Vietnam, the watershed protection funds are managed by a central fund and disbursed through provincial forestry departments to forest user groups. A similar structure could be implemented in Myanmar based upon existing institutional arrangements within the FD. Activities could focus on forest rehabilitation, reforestation, prevention of illegal timber extraction and other prohibited land uses. Watershed protection can provide benefits for local communities, rehabilitate degraded forest and protect watersheds in basins with existing hydropower and irrigation reservoirs, e.g., the Sittaung and Ayeyarwady basins. The potential impacts of hydropower on forests is further explored in Chapter 3.

\subsubsection{Flooding and sedimentation}

Under the World Bank-supported Ayeyarwady Integrated River Basin Management Project, the GoM is developing a Decision Support System and Basin Master Plan for the Ayeyarwady River Basin. Some of the key findings related to forestry are around flooding and sediment:

- Flooding: Besides rainfall and climate change, floods are also influenced by land cover (e.g., deforestation) and reservoirs.

- Sediment: Deforestation is likely to give rise to additional soil erosion and increased sediment transport of particularly fine sediment in the river. The increased turbidity may affect fisheries negatively, increase the 'natural' fertilization of flood plains, and increase delta aggradation. Long term effects may include riverbed sedimentation and negative impacts on navigation (HIC 2019).

\subsubsection{Ecotourism}

Myanmar stands to benefit greatly from tourism-related revenue, but growth must be managed to avoid degradation and overexploitation of the country's environmental assets. As the largest country in southeast Asia, with rich natural and cultural heritage, Myanmar has the potential to generate high flows of tourism. In Myanmar, travel and tourism accounted for $6.8 \%$ of the country's GDP in 2018, creating around 1.3 million jobs or $5.9 \%$ of total employment (WTTC 2019). In the same year, some 3.5 million international visitor arrivals (Ministry of Hotels and Tourism, 2019) are estimated to have contributed MMK3,333.7 billion (US\$2.38 billion) to the national economy (WTTC 2019). Myanmar's tourism potential is still largely untapped and compared to international and regional trends, this data suggests there is plenty of room for expansion of visitor arrivals and the sector's contribution to GDP, foreign exchange earnings and employment. While tourism has practically halted due to COVID-19, it is expected to rebound and provide an opportunity for rapid growth and job creation. Managing this demand sustainably is key to ensuring that the sector supports the country's green growth. Aside from PAs specifically classified as ecotourism sites, many of Myanmar's top tourist destinations are in coastal and forested areas that can be significantly negatively impacted by uncontrolled mass tourism traffic (GGGI 2017).

Ecotourism and cultural tourism are important subcategories for which Myanmar is well suited. However, an appropriate management framework needs to be in place to take advantage of this potential income stream including: (a) basic infrastructure, including water, access, and others; (b) a revenue management stream, including mechanisms for benefit sharing; (c) improvements to overall PA governance; and (d) capacity building of rangers and local population to serve the ecotourism and cultural tourism markets.

\footnotetext{
${ }^{19}$ ADB, undated, Scaling up the Payment for Forest Environmental Services Program in Quang Nam Province: Final Report.
} 


\subsubsection{Disaster risk management}

Forest ecosystem services reduce Myanmar's vulnerability to climate change and natural disasters. Myanmar is one of the countries most vulnerable to cyclones, flooding, earthquakes, and tsunamis. It was ranked second in the 2017 Global Climate Risk Index ${ }^{20}$ and has the fourth highest level of natural risk in the INFORM Index for Risk Management. ${ }^{21}$ It is estimated that natural disasters cost Myanmar an average of US\$2 billion each year (3 percent of GDP).

Forests reduce flood and landslide risk, and recent modeling exercises have estimated that mangroves reduce the impact of natural disasters on the coast by an average of US\$165 million per year (Losada et al. 2018). The estimated cost of the damage from floods and landslides in the Ayeyarwady River Basin in 2015 alone was US\$1.51 billion (World Bank 2015a). This may be due to more extreme weather, but the upper Ayeyarwady catchment has suffered deforestation in recent years (especially upper Sagaing and Kachin), exacerbating flooding. There was significant subsequent flooding in 2016, 2018, and 2019.

Mangroves also play an important role in managing the risk of disaster. Mangroves are found in the coastal areas of Rakhine State and in Ayeyarwady and Tanintharyi Regions. They provide a range of production and protection services, including timber, fuelwood, NTFPs, nursery and breeding grounds for fish, and protection from cyclones and storm surges. Yet these mangroves are disappearing. From 2000 to 2014, an estimated 14,619 ha of mangroves were lost each year in Myanmar, with rice paddy expansion being the primary driver, with an economic loss of US\$2.4 million per year in mangrove ecosystem services values (Estoque et al. 2018).

\subsubsection{Agriculture}

Agriculture, rural livelihoods, sustainable forest management and food security are linked with climate change challenges. Myanmar adopted a climate smart agriculture strategy and developed a National Adaptation Program of Action to Climate Change in 2012 that highlights importance of the forestry sector for sustainable agricultural development. Despite national statements supporting protection of Myanmar's remaining forests, their conversion to agriculture has been occurring for many decades and a new set of land investment laws are still facilitating forest conversions into private agribusiness concessions. The FD only manages the PFE and PAs, while many forest conversion areas, particularly in ethnic states, are essentially outside their authority. Claims that agribusiness ventures bring employment and economic development to local communities are mostly not supported by evidence, which rather suggests that communities' farming lands and customary forests are being confiscated, and a large number of these cleared lands are still not planted and are not being managed with any social or environmental safeguards (Forest Trends 2015).

\footnotetext{
${ }^{20}$ https://germanwatch.org/en/download/16411.pdfAccessed February 14, 2018.

${ }^{21}$ Inter-Agency Standing Committee and European Commission 2019. https://drmkc.jrc.ec.europa.eu/inform-index Accessed February 25, 2019.
} 


\section{STATE OF THE FOREST SECTOR}

\subsection{Challenges and Drivers of Deforestation and Degradation}

It is estimated that about 26 percent of forest cover was lost between 1990 and 2015, with overextraction of timber being one of the main causes of forest degradation. Timber extraction has drastically declined in recent years partly due to the inevitable decline in availability of the most valuable species, but also due to regulatory reform that has reduced the AAC and banned log exports. The main drivers of deforestation and forest degradation are discussed below.

\subsubsection{Drivers of deforestation}

Land use conversion (primarily for agriculture and mining) is the primary driver of forest loss in Myanmar. An estimated 1 million ha, both within and outside the PFE, is estimated to have been converted for commercial plantations and mining between 2002 and 2014 (Lim et al. 2017). It is estimated that 27 percent of forest loss was attributed to large-scale plantation crops (oil palm, rubber, and sugar) (Bhagwat et al. 2017).

Uncontrolled forest conversion ${ }^{22}$ and conversion logging ${ }^{23}$ also lead to higher deforestation rates and invite illegal logs to be sold together with conversion timber. Conversion and salvage logs are considered legal and need to be appropriately licensed, monitored, and handled under the MTLAS.

Mining accounts for at least an estimated 46,000 ha of forest loss per year, almost all in Kachin, Sagaing, and Mandalay (Connette 2016). Development of roads and other infrastructure in closed forest and high-priority conservation areas is another key driver of forest loss.

\subsubsection{Drivers of forest degradation}

Conversion of forests to other land uses is the main cause of deforestation, and largely takes place in forests that are already degraded. Overlogging is often the first stage, rendered forests accessible through opening up of roads. Informal extraction of timber and fuelwood can follow, continuing the degradation process (Treue et al. 2016). Forest degradation is driven mainly by the following:

- Unsustainable extraction of timber. Since the 1970s, formal commercial timber extraction volumes, especially of teak, have exceeded the AAC.

- Illegal logging. Between 2001 and 2013, 10.2 million $\mathrm{m}^{3}$ of Myanmar logs exported to global markets were not authorized for harvest, which would equate to a $47.7 \%$ illegal logging rate (Enters 2017).

- Woodfuel production. The Food and Agriculture Organization (FAO) estimates total annual woodfuel consumption is 38.2 million $\mathrm{m}^{3}$ (FAO 2018a). In 2011, poorly regulated fuelwood extraction was estimated to account for 81.6 percent of all wood extraction. Data from the World Bank's recent assessment of Myanmar's woodfuels sector confirm these levels, with an estimate totaling 36.3 million $\mathrm{m}^{3}$. Household consumption of woodfuel significantly outweighs demand for industrial uses and commercial catering.

The permitted annual timber harvest has been reduced to around $523,000 \mathrm{~m}^{3}$ in $2019 / 20$ from around 2.7 million $\mathrm{m}^{3}$ in 2013/14 to allow the remaining natural forests time to recover. Of this, about 55 percent will be processed for export, leaving only about $235,000 \mathrm{~m}^{3}$ available for the domestic market. The current permitted harvest of teak (Tectona grandis) - Myanmar's premium species - is

\footnotetext{
22 Forest conversion is the removal of natural forests for other land use, such as agriculture, mining, infrastructure, and urbanization.

${ }^{23}$ Conversion logging refers to timber harvested (or salvaged) during land clearance (e.g., for mining, infrastructure such as road and electricity grid construction, or on areas expected to be flooded hydropower dam construction).
} 
only around $9,000 \mathrm{~m}^{3}$, about half of which is now planned to be extracted from mature plantations. There is little information on the age-class structure or quality of existing plantations, but these are unlikely to produce more than 2 million $\mathrm{m}^{3}$ per year at maturity.

The domestic consumption of non-fuel wood is estimated to be around 4 million $\mathrm{m}^{3}$ annually, ${ }^{24}$ indicating that most timber supplying the domestic market comes from other sources, including land cleared for other purposes, from old rubber plantations, imports of processed wood products and illegal logging in natural forests. Wood product exports have plummeted from around 4 million $\mathrm{m}^{3}$ roundwood equivalent prior to 2014 to about $700,000 \mathrm{~m}^{3}$ roundwood equivalent in 2018 . Fuelwood accounts for an estimated additional 36.3 million $\mathrm{m}^{3}$, compared to an allowable harvest from state forests of less than 1.8 million $\mathrm{m}^{3}$.

In recent decades, timber extraction has consistently exceeded the AAC. For 2015-2016, official extraction levels are stated as 60,052 hoppus tons for teak (just over 11 percent of the 2009/10 levels), and 619,742 hoppus tons for other tree species (around 23 percent of 2009/10 levels). Most of the recent extraction comes from (upper) Sagaing (66 percent of hardwoods and 46 percent of teak) (Figure 12) (MEITI 2019).

Figure 12: Timber extraction by state/region

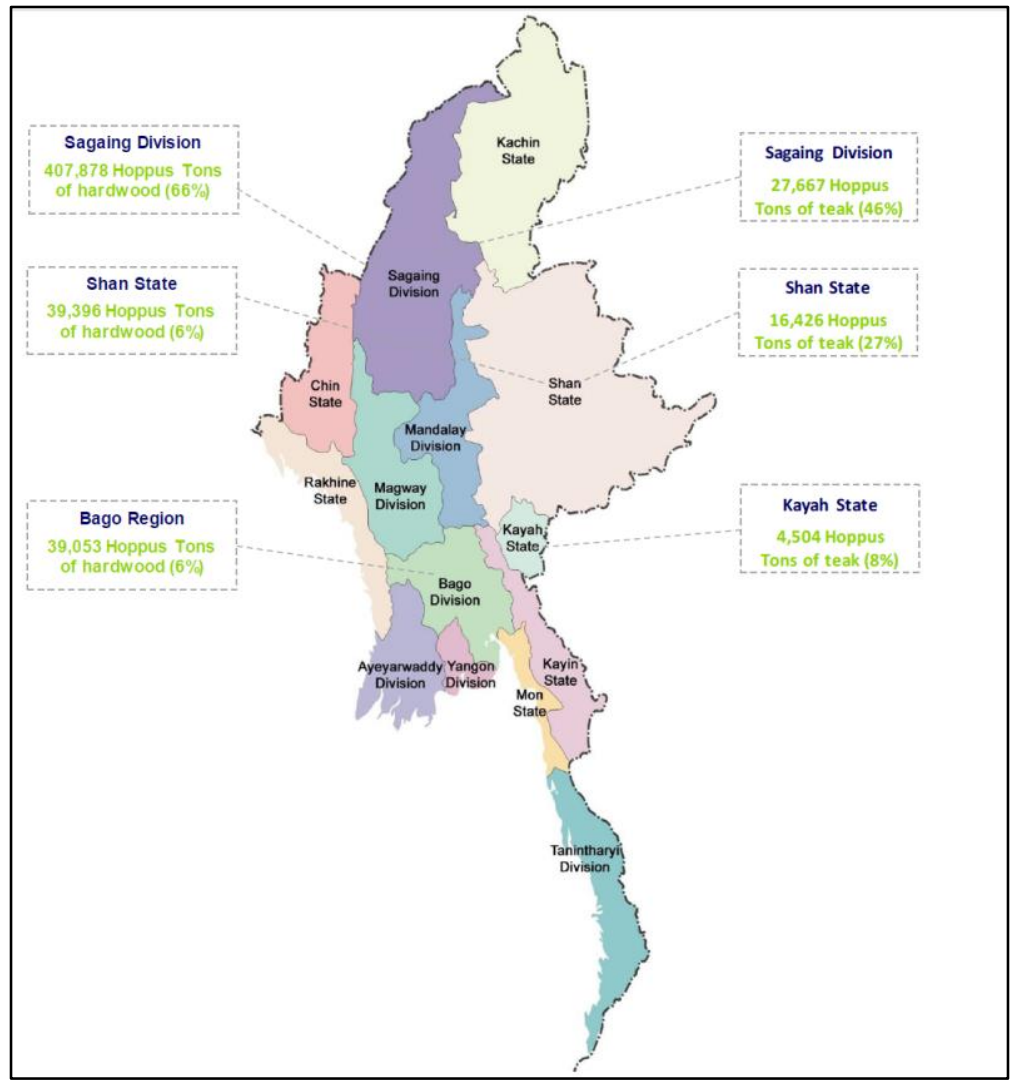

Source: MEITI, 2019

Teak has been the primary focus for commercial extraction in Myanmar. FD data on extraction volumes indicate that $700,000 \mathrm{~m}^{3}$ per year equivalent of teak was already being officially extracted by the 1920s. These levels were not reached again until the 1980s, by which time they exceeded the AAC, even excluding estimations of wastage and illegal extraction.

Figure 13 indicates a long history of severe over-extraction, as the estimated AAC was being exceeded by official extraction almost continuously from 1970 onwards for 45 years. When conservative

${ }^{24}$ Based on FAO Stat estimates. 
estimates of wastage and illegal logging are included, the AAC is far exceeded. Extreme levels of overextraction beyond the AAC were officially sanctioned in more recent years, before the start of democratic transition.

Figure 13: Official teak extraction (1918/19 to 2014/15)

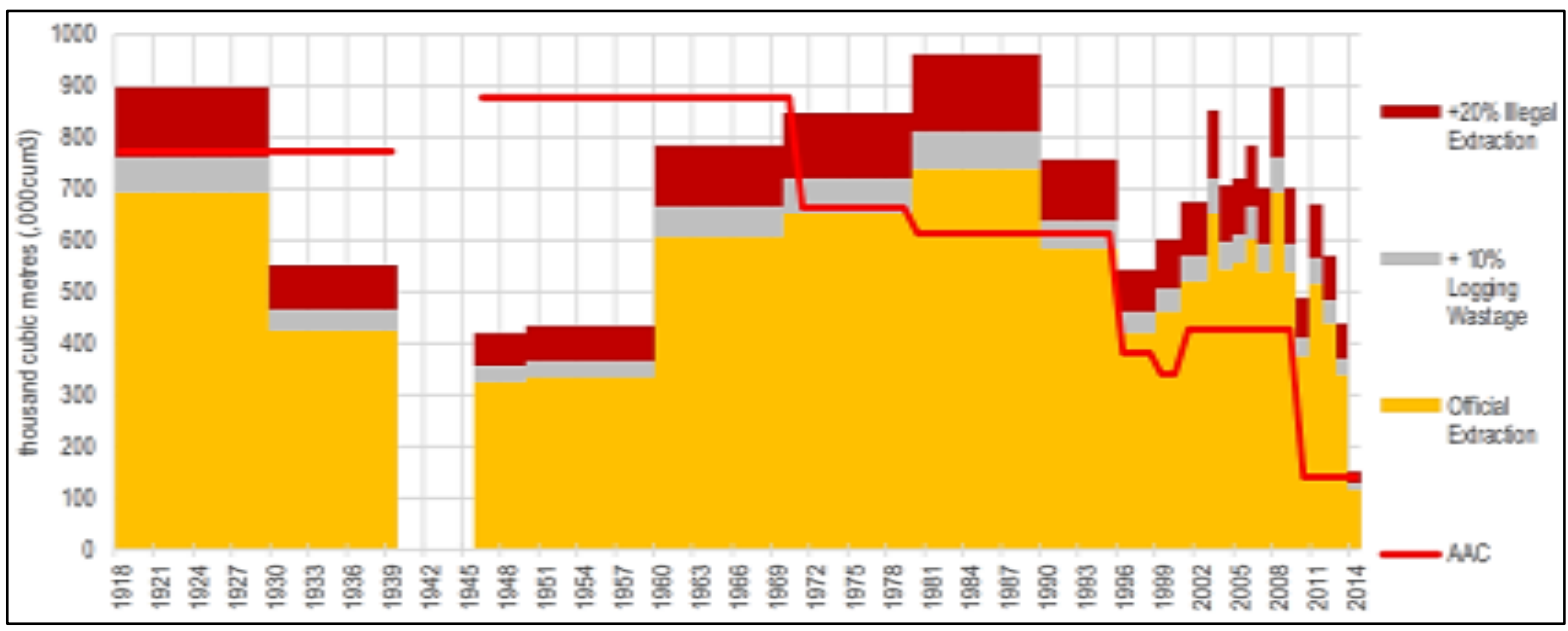

Source: Treue et al. 2016

The 'other hardwoods' category includes both very high-value timber (like rosewood) and low-value timber species. The extraction trend is different from teak due to more limited market development. Although total extraction levels are higher than they are for teak, they have been below the AAC until recently. By the end of the 1990s, the AAC was revised significantly downwards. However, extraction accelerated. ${ }^{25}$

Unless the gaps between demand and supply are closed, forest loss and degradation will continue.

\subsection{Competing uses of land and their impact on forests}

\subsubsection{Agriculture}

It is estimated that 1 million ha of the 2 million ha lost from intact forest (from 2002 to 2014) can be explained through conversion to non-forest land uses such as mining, agriculture, and infrastructure (Bhagwat et al. 2017). A further 0.54 million ha of the loss is attributable to plantation crops, such as oil palm, rubber, and sugar cane. Thus, a total of 1.54 million ha of the 2.0 million ha lost can be accounted for by land-use change. There are two main land-use changes related to agriculture:

- Large commercial land concessions (oil palm, rubber, sugar cane, banana, and other crops) have been widely promoted by MoALI policies and by staff of the GAD and the DALMS (formerly Settlements and Land Records Department). The aim has been to promote the commercialization of the agricultural sector, particularly beyond rice production areas. However, land concessions have been awarded with little reference to forest policy. There are many cases of large-scale, well-stocked forest being cleared and leading to illegal log marketing prior to land conversion. Some of these concessions are concentrated around Myeik, largely for palm oil.

- Between 2010 and 2013, the land area allocated to large-scale private agriculture concessions increased by an unprecedented $\mathbf{1 7 0}$ percent. According to official statistics, large-scale land acquisitions for commercial agriculture increased from nearly 2 million acres in 2010 to 5.2 million acres by mid-2013. Official 2013 agricultural statistics show that the government allocated over 800 domestic companies a total of nearly 750,000 acres of demarcated forest land for industrial agricultural production. These figures are an

\footnotetext{
25 Source: Forest Department information - unpublished.
} 
underestimate, as they are based only on agricultural concessions allocated by central government agencies and do not include additional concessions allocated by sub-national, military, and/or non-state authorities (Forest Trends 2015). In Kachin State and Tanintharyi Region - which are considered some of southeast Asia's last remaining high conservation value forests and also the location of over 60 percent of Myanmar's agribusiness concessions - only 12 and 19 percent, respectively, of total agricultural concession had been cultivated (Forest Trends 2015).

- Small-scale agricultural expansion. With continued population growth, and in the absence of land development planning, small-scale agriculture has expanded ad hoc into many forested areas. Populations have also been displaced because of civil conflict since the 1950s, and these have sometimes moved into forest areas. Displacement due to conflicts is still a problem.

While oil palm plantations are located only in Tanintharyi, other plantations such as rubber, betel nut, banana, and sugar cane are expanding throughout the country. Rubber has rapidly expanded throughout the region. MoALI estimates that the total area planted with rubber was 652,105 ha in 2015-2016. Mon, Tanintharyi, and Kayin account for 68 percent of rubber-growing area; Shan, Bago, and Kachin account for 24 percent. ${ }^{26}$ Due to low rubber prices and the relatively low quality of Myanmar's rubber products, area expansion has reduced and many rubber plantations are inactive. With the recent price decline, rubber wood from old plantations is being sold for woodchips and firewood.

There is a need for MoNREC coordination with other ministries, especially MoALI, in relation to the issue of 'Unclassified Forests' (also termed 'Wastelands'). The Master Plan for the Agriculture Sector (2001-2031) aims to expand cultivation by 4 million ha into areas termed 'wasteland', which seems to be unclassified forest land, much of which is likely to be customary land. The policy became articulated through the VFV Land Management Law (2018). MoALI, FD, and communities lack agreement on procedures to manage these lands. The FD is now also seeking to gazette unclassified forests where it can. Yet without a statutory legal category of customary land, it seems impossible to resolve the appropriate land category and many cases fail to recognize preexisting customary tenures.

Inconsistencies remain between policies and laws across sectoral ministries in relation to 'VFV' lands. For example, there are competing policy targets for VFV land between the DALMS, which encourages agricultural land use, and the FD, which seeks expansion of the PFE and CF. This is a particular challenge in Kachin State. The VFV Lands Management Law (2018) is primarily aimed at encouraging investment in commercial agricultural projects and is therefore a direct threat to the significant areas of forest that exist on these lands.

Shifting cultivation is sometimes referred to in relation to forest degradation. However, under normal circumstances, there is little evidence to substantiate the assumption that shifting cultivation is contributing to net forest degradation. Recent field assessments indicate that there is virtually no new shifting cultivation, and that almost all existing shifting cultivation systems either have apparently relatively stable fallow rotations (Heinimann et al. 2017) or that cultivators are moving rapidly away from shifting cultivation and towards niche agroforestry cash crops as rural markets have developed and domestic rice trading has become liberalized.

\subsubsection{Plantation}

In Myanmar, a minimum plantation area of $\mathbf{2}$ million ha would be required to meet a total domestic roundwood demand of 45 million $\mathrm{m}^{3}$ of fuelwood and industrial wood, assuming a conservative annual growth rate of $15 \mathrm{~m}^{3}$ per ha, and that a portion of fuelwood could continue to be sourced from natural forests, old rubber plantations, and farm-grown trees. If a large proportion of wood production were destined for export, more than 2 million ha of plantation areas would be needed.

26 Draft REDD+ Strategy for Myanmar 2019. 
After three years of implementing MRRP, less than 13 percent of the overall plantation target and less than 10 per cent of the private plantation target has been met. Total private sector planting (excluding rubber) on all land types is reported to be about 152,200 ha, although the locations and quality of these plantations are unclear. Teak is the most widely planted species by the private sector, with an area of about 60,000 ha reported, but there is an increasing focus on fast-growing industrial species, with 47,000 ha reported to have been established by mid-2019.

Reported progress with community forestry is somewhat better, with CF certificates issued covering about 63,800 ha (20 per cent of the target area). However, this does not necessarily equate to reforestation or restoration, and efforts are constrained by current government capacity, lack of defined delivery mechanisms to support development, and weak links to markets for CF produce.

There is interest in investments from private companies, but to tap into the full potential, policy reforms will need to be considered. Current and potential investors list a range of constraints to increased investment. These include: (i) availability of large contiguous blocks of land within RF, or lack of access to such areas; (ii) land tenure issues, especially informal occupation of forest land for farming; (iii) perception of difficulty of doing business; (iv) complicated procedures to acquire land and to harvest, transport, ship, process and trade timber; $(v)$ insufficient government staff able to promote and support forest sector investment; (vi) lack of enforcement capacity to prevent encroachment and illegal logging in plantation areas; (vi) lack of finance; and (vii) widespread availability of illegal timber, which depresses prices and reduces demand for plantation-grown logs.

To address these challenges, this CFN includes an assessment of enabling conditions and incentives for sustainable private sector investment in timber plantations (see Annex 2).

\subsubsection{Infrastructure}

There has been a general expansion of road networks in many forested areas in recent years. This has facilitated lower-cost extraction of wood, especially from hitherto remote areas, and has improved access for settlement, thus accelerating land-use change.

The development of dams and reservoirs has also had a negative effect on forests. Hydropower dams and irrigation reservoirs account for about 70,000 ha of the 2 million ha of intact forest lost from 2002-2014 (Treue et al. 2016). Most are small and medium multifunctional dams. However, there is concern that dams now under construction or planned threaten to inundate much larger areas. The International Finance Corporation (IFC) SEA estimates that 139,400 ha will be inundated by dams currently under construction, and a further area of 253,300 ha is planned to be inundated (IFC, 2017). 


\subsubsection{Wood-based energy}

Woodfuels - and biomass more generally - are a major source of energy in Myanmar. In fact, woodfuels represent $75 \%$ of the country's total final energy consumption, with $21.8 \mathrm{Mt}$ of oilequivalent per year, according to the International Energy Agency (Figure 14). ${ }^{27}$

Concerns around the scale of woodfuel extraction are supported by FAO data on annual production volumes of woodfuels versus industrial roundwood. ${ }^{28}$ While these estimates suffer from important uncertainties, the quantity of woodfuels (up to 40 million $\mathrm{m}^{3}$ per year) is significant and consistently represents nearly ten times the volume of industrial roundwood produced over the last 10 years.

Household demand accounts for the majority of total woodfuel consumption in the country (94 percent or $23.8 \mathrm{Mt}$ per year as per recent World Bank assessment), while the catering sector accounts for 4 percent and small-scale industries for 2 percent.

After firewood and electricity, charcoal is the country's third most common source of cooking energy, used by $9.4 \%$ of the population as their main cooking fuel in 2017 , compared with $13 \%$ in 2014. In 2014, 20\% of urban households and 9\% of rural households used charcoal as their main cooking fuel. By 2017, the percentage of households using charcoal as their main cooking fuel had decreased slightly to $17 \%$ and $6 \%$ in urban and rural areas, respectively. Charcoal is therefore more commonly used in urban areas, but also in rural parts of the southeast coastal zone. These areas have also been reported to be hotspots of charcoal production for export to Thailand, Malaysia and China (Mongabay 2017, 2019). Charcoal for Yangon comes mainly from hardwood trees, potentially contributing to forest degradation, while charcoal in the Central Dry Zone comes mainly from village land and farmland.

\footnotetext{
27 International Energy Agency (IEA), “Data \& Statistics," accessed February 5, 2020, https://www.iea.org/data-andstatistics/data-tables.

${ }^{28}$ As defined by FAO Stat, industrial roundwood includes logs used for manufacture of sawnwood, railway sleepers, and veneer, as well as poles and posts.
} 
It is important that forests

are managed more

sustainably for woodfuels,

and that woodfuel

processing and utilization

becomes as clean and

efficient as possible, and

that fuel switching

strategies are well-informed

and approached

strategically. The World

Bank's Myanmar Woodfuels

Figure 15 Framework for a modern, sustainable woodfuels sector

Assessment, finalized in June

2020, proposes several intervention options (see Figure 15 and Annex 3).

\subsubsection{Extractive industry}

Mining accounts for at least an estimated 46,000 ha of forest loss (Connette 2016), almost all in Kachin, Sagaing, and Mandalay (Figure 16). Poor governance of the mining sector, particularly jade, has led not only to deforestation but also to pollution and, in some cases, to social conflict. For example, most of the deforestation along the Uyu and Chindwin rivers in Homalin township was caused by legal and illegal surface mining (Bhagwat et al. 2017). The gemstone sector is governed by a different legal framework than the rest of the mining sector, with the Myanmar Gems Enterprise operating independently from MoNREC. Especially in the gemstone sector, the license area and tenure length are not sufficient for companies to develop adequate mine closure plans and implement rehabilitation. ${ }^{29}$ Substantial mining areas can also be found in Shan State, Tanintharyi and Bago Regions. Traditional small-scale gold mining in Eastern Bago Region and Kayin State has been replaced by industrial mining, proving extremely destructive to forest cover and the natural environment onsite and beyond. Downstream populations have reported riverine pollution due to mining operations and health impacts due to long-term mercury or methylmercury exposure (Myo Myanmar 2016). Large scale limestone mining in Kayin State and mineral mining in Tanintharyi Region are also leading to deforestation and water pollution. Although these mining operations create jobs for local communities, grievances over loss of land, displacement of traditional livelihoods and other social issues are leading to recurrent grievances (Frontier Myanmar 2019). ${ }^{29}$ The 2019 Gemstone Law allows 3 years for medium scale mining ( 5 acres), 2 years for small scale mining, and 1 year for
artisanal mining ( 1 acre). 
Figure 16: Estimated area of mining in Myanmar

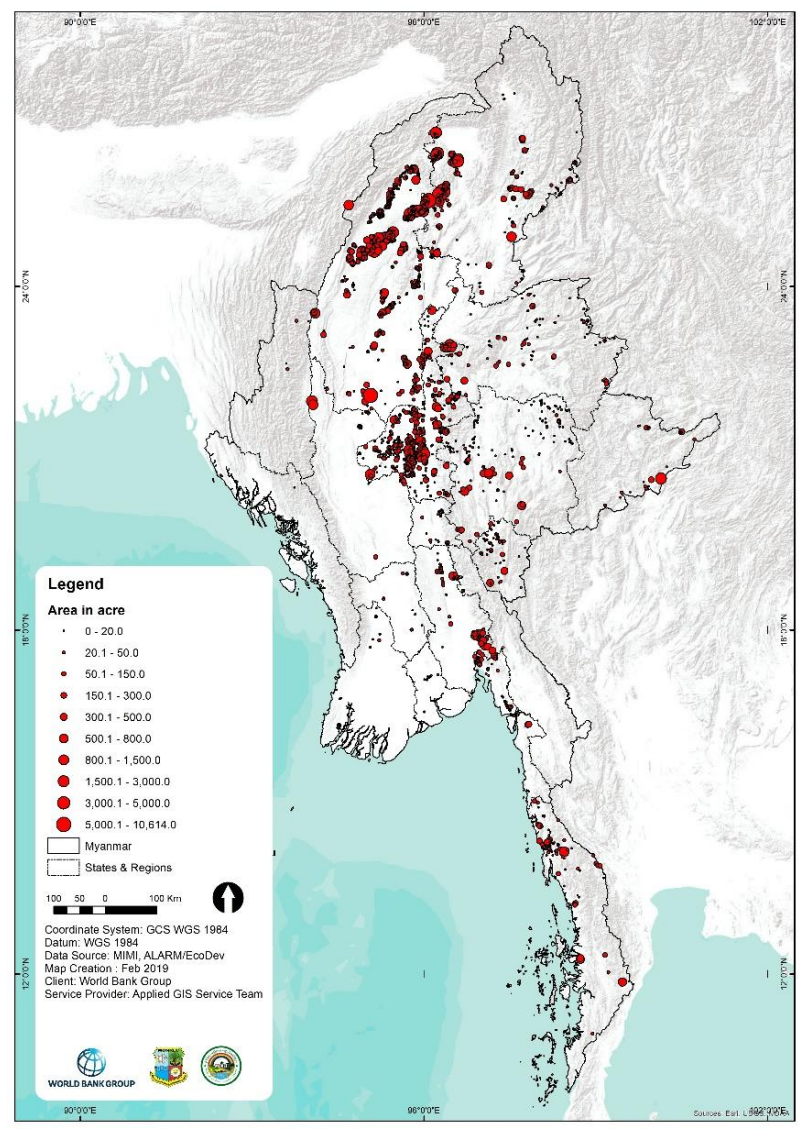

Source: Connette et al. 2016.

Mining has been brought under MoNREC, and the Mining Rules (2018) have been developed to improve governance. Stakeholders have received the Mining Law and Rules more positively than the more recent Gemstone Law (2019). Poor governance of the mining sector in the past, particularly jade mining, has led not only to deforestation, but also to pollution and - in some cases - to social conflict. Open-pit mining in northern Myanmar, often along streams and rivers, is another major cause of intact forest decline. For example, most of the deforestation along the Uru and Chindwin Rivers in Homalin township was caused by illegal (and legal) surface mining. Mining has negative impacts on local communities and biodiversity (Bhagwat et al. 2017).

The Myanmar Centre for Responsible Business has carried out Sector-Wide Impact Assessments in the mining sector. At several sites, deforestation was reportedly caused by forest clearing for mines and processing sites, as well as unsustainable and often illegal logging of wood for project use. One mining company estimated that $70 \%$ of the forest cover had been lost in the area in which the company operated (MCRB 2017). Lime powder production for gold processing and other mining processes also contributes to deforestation by requiring large amounts of firewood: The Sector-Wide Impact Assessment for the mining sector also analyzed a sample of Production Sharing Contracts. In relation to forestry:

- prior permission must be obtained from the FD if any trees are to be felled, including within the concession area; and

- land on the mined concession must be reforested by the private partner after mine operations end, or the private partner must pay compensation. 
It is not clear to what extent the process for tree felling in concession areas is enforced by the FD, if at all.

The Karen National Union (KNU) has developed Mining Licensing Rules and Regulations that apply in the KNU-controlled areas. The Rules require permit-holders to secure prior approval from the relevant KNU Forest Department where any trees are to be cut on forest land. Any trees cut from the concession must be purchased at a price set by the KNU Forest Department. KNU's mining permission is regulated annually, however, leading miners to accelerate extraction as much as possible with little regard for environmental and social impact.

Offsets: The ESIA for the expansion of the Shwe Taung Cement plant and coal mine in Mandalay Region requires the project proponent to develop a biodiversity offset plan. With support from the IFC, this biodiversity offset plan was developed although its implementation has not yet started.

\subsection{Governance challenges}

\subsubsection{Legal, regulatory, and institutional frameworks:}

The key policy and legal framework in the forest sector comprises primarily the Constitution of the Republic of Myanmar (2008), the National Forest Policy (1995), CFI (2019), the Forest Law (2018), Forest Rules (1995) and associated guideline, and the Conservation of Biodiversity and Protected Areas Law (2018).

In recent years, significant changes have been made to the legal and policy framework supporting CF in particular, resulting in a progressive enabling environment for the establishment of CF, CF User Groups (CFUGs), and CFEs. It can be argued that the legal environment for CF in Myanmar is more advanced than the legal frameworks found in other countries in southeast Asia (World Bank 2019d).

The key policy, legal, and regulatory frameworks in the forest sector include the following:

- Constitution (2008). Forests are included under Section 96, Schedule 1, as a matter for Union legislation, rather than the State and Region level.

- Forest Policy (1995). This provides the framework within which forests are governed by the Union administration.

- CFI 2019 revised (from 1995 and 2016). This is a detailed framework for the establishment and functioning of CF. The 2016 revision particularly emphasizes enterprise development and provides for commercialization of timber and non-timber CF products and services. The 2019 revision set out procedures for commercialization of CF products and their harvest, transport and sale.

- Forest Law (2018), Forest Rules (1995 - under revision), and associated guidelines. These confirm State control over the PFE, the trees that are there, and also the management categories. The Rules of the new Forest Law are currently being finalized following a series of public consultations facilitated by the FD with support from various NGO/INGOs.

- Conservation of Biodiversity and Protected Areas Law (2018). The objective is to implement the government policy for conservation of PAs. The rules to guide implementation of the law are currently being developed.

The FD under MoNREC is the primary agency responsible for forest management. The FD is responsible for sustainable forest management, biodiversity conservation, restoration of degraded forests, watershed protection, CF, mangrove conservation, and research and development.

The FD State / Regional offices are responsible for coordinating and implementing field activities within their respective areas. The FD State/Region offices are headed by Regional Directors and consist of rangers who are responsible for coordinating and implementing field activities. The 
administration is further devolved to districts (headed by Assistant Directors) and to townships (headed by Staff Officers).

The local FD Directors report to the FD Headquarters and also to the Regional Minister for Environmental Conservation regarding progress of forestry operations and incidents of timber illegal logging. The regional government, with the lead of the Regional Minister for Environmental Conservation, inspects illegal logging and illegal trade of timber and provides oversight to arrest related to timber illegal logging in their respective states / regions.

The roles and responsibilities of other key departments in MoNREC that relate to forestry are summarized below:

- MoNREC Union Minister's Office: coordinates and facilitates the tasks of the FD, as well as the MTE, DZGD, Environmental Conservation Department, and Survey Department as well as other line ministries' institutions. It mainly deals with policy matters and issues and is responsible for evaluating and monitoring the implementation of forest policies, production and work targets, short- and long-term planning, and the project achievements of the MONREC.

- Myanmar Timber Enterprise (MTE). The MTE is the only state-owned economic enterprise in the forest sector. It has responsibility for timber harvesting, milling and processing, and marketing (local and export). MTE has recently initiated elephant conservation-based tourism activities.

- Dry Zone Greening Department (DZGD): The DZGD was formed in 1997 with the specific aim of greening the Central Dry Zone, through rehabilitation of degraded forest lands, protection and conservation of remaining natural forest, and restoration of the environment.

- Survey Department produces maps (topographical and project related), including for boundary demarcation and inspection.

- Environmental Conservation Department is responsible for implementing National Environmental Policy, strategy, framework, planning, and action plan for the integration of environmental consideration into the national sustainable development process.

The State and Region governments / Chief Ministers / ministers have substantial formal and informal roles at the local level with regard to natural resources management, including land and forests. They chair the local land dispute committees and they are the first line of political engagement for all kinds of macro disputes. There are often conflicts between statutory law and customary rights over land ownership and land use. The land disputes and also applications for land use change such as VFV to CF or VFV to PFE are evaluated by the land management committee which is chaired by the regional Chief Minister. The FD is a member of the committee and provides comments if the land is under the authority of FD or is forested upon the application or submission of land disputes.

As per the Forest Law (2018), the township or district level officer from GAD serve as the Forest Settlement Officer in constitution of Reserved Forests. The GAD official/Forest Settlement Officer leads the scrutiny body appointed in respect to constituting the reserved forests and report to the Director General of FD after following the prescribed procedure.

\subsubsection{FD capacity}

FD staffing levels are significantly lower than needed to implement a sustainable forestry agenda. Permanent staffing of the FD is approximately 8,000 against a planned target of more than 15,000 (Table 7), due mainly to budgetary limitations. 
Table 7: FD staffing, planned and current (2018)

\begin{tabular}{|l|c|c|c|}
\hline Position & $\begin{array}{c}\text { Number planned in } \\
\text { organizational structure }\end{array}$ & $\begin{array}{c}\text { Currently } \\
\text { recruited }\end{array}$ & Vacant \\
\hline Officer & 538 & 482 & 56 \\
\hline Staff & 14,911 & 7,554 & 7,357 \\
\hline Total & $\mathbf{1 5 , 4 4 9}$ & $\mathbf{8 , 0 3 6}$ & $\mathbf{7 , 4 1 3}$ \\
\hline
\end{tabular}

Source: World Bank 2019b

The staffing levels, skill, and competencies of the FD need to be assessed to inform future composition, capacity building, and training plans. After decades of a highly centralized governance system and technical implementation of forest management by the FD, current programs will need to orient themselves towards partnership building with the private sector, civil society organizations (CSOs), communities, non-Bamar ethnic groups, and other stakeholders. This will demand a new set of skills, especially at State, Region, and local levels.

At the same time, MTE's overcapacity represents a challenge for the MoNREC. Staffing of the MTE is estimated to currently be around 15,000. There are also thousands of forest laborers. With declining availability of viable forest management areas and reduced AACs, the demand for forest extracting and processing had declined. The role of the MTE in the future may need to be reformed.

In the past, the FD has not had the capacity to effectively control illegal logging and over-extraction. Organized crime and illegal networks were, and to some extent still are, influential actors. As a result, many accessible forests have been stripped of their most valuable timber (both legally and illegally), and in some areas of almost all their trees (for example, western areas of Bago Yoma). There are several regional well-known (but difficult to tackle) hotspots of illegal timber trade, for example, crossborder traffic from timber harvested in Sagaing and Kachin exported illegally to China. Wildlife and charcoal trade are other illegal activities affecting sustainable forest management.

According to the CFI 2019, the FD must provide technical assistance to the CFUGs for management of Community Forest and harvesting forest products. FD has a dedicated Forest Extension Division, established in 1995, which carries out extension services. The Extension Division works under the national office, which develops and sends out awareness and training information to FD offices located in each state/region and township.

Effective control mechanisms as well as extension services will need additional field staff, logistical support, and training. They will also need improvement along the entire value chain, better information systems (including financial tracking), citizen engagement tools, strengthened collaboration with other national agencies judiciary, customs, police, and communities, and support from international collaborators.

\subsubsection{Rights and secure access to forested lands and resources:}

Community-based forest tenure prevails across the country. Historically, rights to land and forest resources were embedded in the social structure and governed by customary traditions. Customary tenure remains the dominant form of de facto access to and use of forest land and resources across Myanmar. Most locally accepted customary systems allow for a complex mix of individual, family, and community tenures even in urban and peri-urban areas. Across the country, more than half of all landholdings are held, without formal titles or certificates, in accordance with customary practices. ${ }^{30}$ However, the actual areas occupied/used/accessed largely remain unmapped, un-demarcated, unquantified, and frequently unprotected, with encroachment and 'illegal uses' reported in all areas.

\footnotetext{
30 There is no formal or reliable data available. However, field research completed by different institutions have generated 'proxy' data on which this estimate was based. In Myanmar, almost 50\% of privately held land parcels (excluding concessions and leases) are categorized as "customary rights" and include households residing inside or outside forest areas, where social traditions guide land tenure arrangements. In many rural areas, inheritance and sub-divisions are not registered but informally held.
} 
A complex policy and legal environment characterizes forest governance in Myanmar. The Forest Law (2018) and the Conservation of Biodiversity and Protected Areas Law (2018) are the primary laws regulating forests in Myanmar. Forested land outside the permanent forest estate is under the administration of other laws and ministries, most often the VFV Land Law (2018) while the forests and forests products are regulated by MoNREC under the Forest Law. MoNREC further regulates and limits use rights to national and regional lists of 'reserved species' including teak. Overall, at least 44 statutory laws and regulations govern the land and resources sector; 20 of these apply to forest administration and management. ${ }^{31}$ Adding to this challenging legal environment is the lack of a uniform land and land-use classification system, as at least three different sets of inconsistent and overlapping criteria classify land use (refer to categories in NLUP: farmland, forest land, and other lands). Additionally, multiple customary or informal tenure arrangements apply different land-use methods in upper and lower regions with many communities using local categories for identifying land uses.

Multiple agencies with similar or overlapping mandates and responsibilities administer and govern Myanmar's forest tenure. Currently, the FD/MoNREC, the GAD and DALMS/MoALI play a major role at all levels of non-forest land administration. The FD/MoNREC assumes primary responsibility in areas designated as forests and in protecting the land and resources under their jurisdiction from encroachment and squatting. At the state/region and township/district levels, the GAD acts as the union government's representative, helping to coordinate the work of different departments and agencies, and issuing grants/permits for specific land uses. These imprecise institutional arrangements have led to a perennial struggle between local communities, local leaders, and government officials, as communities continue to manage their resources through customary practices, and the government attempts to enforce formal laws.

As large parts of remaining forests are in ethnic areas, resolving conflicts is crucial for achieving effective enabling conditions for sustainable forest management. EAOs such as the Kachin Independence Army (KIA), KNU, and Karen National Liberation Army (KNLA) have a strong presence on the ground. Due to the ongoing conflict, EAOs have developed administrative mechanisms. These have recently been formulated into polices as follows: (a) KNU - Land Policy 2015 and Forest Policy 2015, (b) KNLA - Karenni Land Policy 2016, and (c) KIA - Kachin Land Forest Policy (draft). The KNU has also established CFs.

This CFN includes a detailed forest tenure assessment (see Annex 1).

\subsubsection{Effective protection of public forest lands (i.e. Protected Areas)}

Funding for the PA does not adequately cover all management needs. In the last decade, both government and international funding for PAs has increased significantly. Government funding rose by about 50 percent in real terms between 2010 and 2015, and externally funded grants and projects committed almost US\$20 million in 2014. However, funding gaps remain. Only half of PAs have a dedicated budget or staff. Even PAs that do receive regular funding are, for the most part, unable to cover the costs of basic infrastructure, equipment, maintenance, and operation. Comparative studies from other ASEAN countries suggest an annual budget of US\$130 per 100 ha is needed - three times the level of funding available to the PA system in Myanmar in 2015 (MOECAF 2015).

In addition, the current FD staff have limited capacity to manage the expanding PA network. The Nature and Wildlife Conservation Division (NWCD) has about 500 staff, of which 450 are on the ground in only 23 of the 43 existing PAs.

Private funding of biodiversity conservation has been largely absent, with the prominent exception of the Tanintharyi Nature Reserve established in 2005. The reserve is funded by the gas companies that run three pipelines across the area. Their main aim is to compensate for impacts on biodiversity

\footnotetext{
${ }^{31} \mathrm{~A}$ list of Policies, Laws and Regulations affecting the land sector in general and forest land and resources in particular has been compiled for the Myanmar Forest Tenure Assessment, carried out between October 2019 and February 2020.
} 
caused by the pipelines and support facilities. ${ }^{32}$ This serves as an example for accessing alternative funding sources for maintaining PAs.

PES is another important mechanism that can be explored. Most important, the Biodiversity and Conservation of Protected Areas Law (2018) includes a provision for the FD to "determine a system for Payment for Ecosystem Services derived from the ecosystems within a PA." It will be important to provide the causal link between conservation and impact, to argue for PES.

PAs also provide great economic opportunities in the form of ecotourism and cultural tourism. Many areas in Myanmar are highly attractive for further developing this kind of tourism. The Greater Mekong Subregion has received increasing volumes of ecotourists, and it is important to put Myanmar's PAs on the tourism operators' map. At the same time, the appropriate management framework needs to be in place to take advantage of this potential income stream: (a) provide basic infrastructure, including water, access, and others; (b) build a revenue management stream, including benefit sharing; (c) support overall PA governance; and (d) build capacity of rangers and local populations.

\subsubsection{Forest management including concessions}

The FD holds the mandate to manage land in the PFE and also to manage forest on other land. NonPFE land is administered by a number of agencies, including the DALMS, DZGD, and the GAD under the Ministry of President Office (formerly the Ministry of Home Affairs).

Forest areas in the PFE are managed by forming Working Circles under District Forest Management Plans. The distribution of forest by Working Circle is shown in Figure 17. The 'Production' Working Circle has the largest allocation of forests (31.5 percent), mainly natural RF managed for timber is managed under the Myanmar Selection System (FAO 2015).

The next largest category is local supply/ CF (18.5 percent), which is mainly PPF, although also RF, and sometimes even unclassified forests, managed for local needs. Other Working Circles include PA, Mangrove, Watershed, and Non-Wood Forest Products. Those forest areas not included in a Working Circle make up around 21.8 percent of all forests.
Figure 17 FD Working Circle categories (including planned PAs)

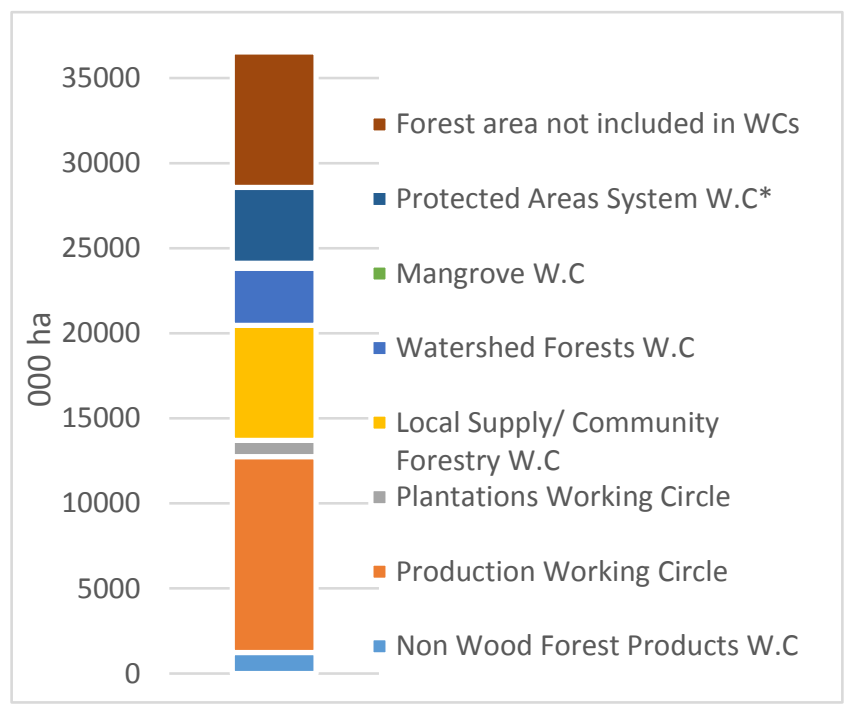

Figure 18 Official timber flow system

\footnotetext{
32 http://www.tnrpmoecaf.gov.mm/about.
} 


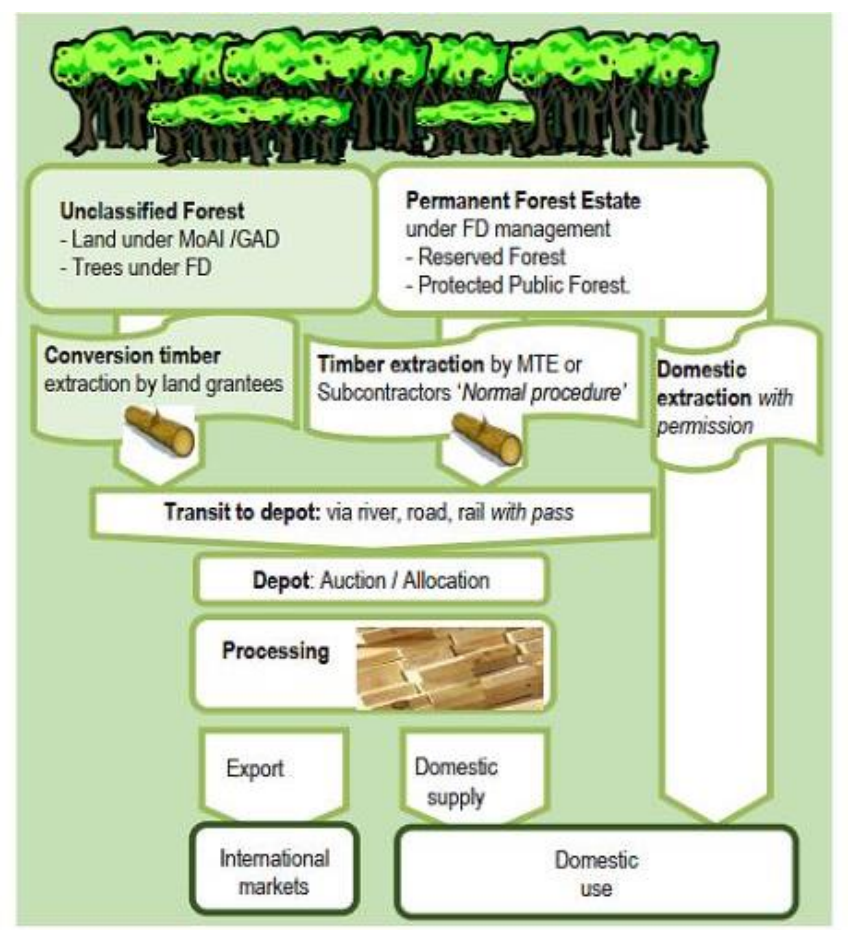

Timber production in Myanmar is regulated based on the following rules and regulations:

- $\quad$ Logging Rules (1936)

- Extraction Manual (1948)

- $\quad$ State Timber Board Act (1950)

- Standing orders for Extraction Staff of MTE (1970)

- National Code of Forest Harvesting Practices (2000)

Timber is supposed to be produced and extracted according to the 10-year District Forest Management Plans, which are based on systematic inventories of the forest stands. An inventory allows calculation of the notional annual increment in timber volumes, which is then converted into an ACC that would ensure sustainability.

RFs are typically divided into $\mathbf{3 0}$ compartments which are logged according to a $\mathbf{3 0}$-year rotation, as long as only trees above girth limits are marked for extraction. This is the original Brandeis Selection System first introduced in 1856, subsequently the Myanmar Selection System.

FD and MTE staff both visit the compartment and record the suitable trees marked for felling and estimate their volumes. Extraction has been the sole responsibility of the MTE, although, due to capacity constraints, extracting has often been subcontracted in the past.

Overharvesting (beyond AACs) and lack of accurate site-specific inventories have led to extraction of unsustainable volumes of timber in some forest areas. The fact that the AAC is theoretically based on the entire country, but in practice has been applied to only a fraction of Myanmar due to lack of access to conflict and ethnic areas, has further compounded overharvesting (Castrén 1999).

\subsubsection{National Forest Inventory}

Myanmar has a long tradition of carrying out forest Inventories and is among the first countries in the world that had historically established, sample-based, large-area forest inventories with strip sampling in teak forests during the 1850s. The first attempt at a national-scale forest inventory began in 1980/81 and ended in 1992 but was never completed. Since then, the FD has carried on with district level inventories for periodic management planning purposes, including the definition of AAC and the development of stand and stock tables at the forest management unit (FMU) level, at the scale of forest districts or compartments where harvesting operations would take place.

Current initiatives aim to support the development of a comprehensive National Forestry Inventory that can generate major forest type maps and detect changes. This system would be based on a combination of remote sensing and site-specific inventories in permanent sample plots. It would provide important information on the extent and quality of the forest resources and form the basis for good forest planning, management, and policy development.

FAO, under the UN-REDD Program, has supported Myanmar in developing a new design for the NFI, together with efficient and feasible approaches and methodologies for data collection and analysis. The new methodologies were tested in the field in different regions of the country. In 2015, a National Forest Monitoring System Action Plan was developed by the Forest Department with support by FAO as part of the UN-REDD program in Myanmar. 


\subsubsection{In June 2020, Finland signed an agreement with the FD to finance the NFI, to be implemented by FAO. ${ }^{3}$ Use of ICT in forest monitoring}

The Forest Department has started using ICT tools for forest conservation and biodiversity protection. With the support of the World Bank and FAO, and in cooperation with OneMap, the FD is setting up a database for regular collection of information and monitoring of CFs. In some PAs, with the support of development partners, FD uses SMART software for wildlife monitoring. The FD needs to strengthen ICT application nationwide to support field activities, beneficiary engagement practices and ultimately for improved forest management and governance.

FD has a remote sensing section and produces forest/land cover maps nationwide. However, the remote sensing analytical software application and access to high-resolution imagery are limited. The FD currently issues forest cover information based on the FAO's forest cover assessment.

\subsubsection{Forest products and value chain}

Before the introduction of the log export ban, roundwood exports, especially teak, were the dominant commercial forest product in Myanmar. Since 2014, teak and other species have been required to be processed before export. The Forest Product Strategy 2015-19, developed by the Ministry of Commerce lays out an action plan to improve processing capacity in support of exportoriented companies. The lack of reliability, pricing and quality of upstream supplies, poor skills and capacity of the industry, lack of transparency, and changing taxes were identified as challenges.

Teak is the most recognizable and relatively fast-growing species with significant, albeit long-term, investment opportunities. Over-extraction and a global supply gap are driving high demand and high prices, both internationally and nationally. However, there is concern over low product quality and poor silvicultural practices. In addition, buyers consider the quality of plantation teak to be significantly lower than teak from natural forests.

At present, most wood processing is undertaken by SMEs. These smaller processing industries suffer from lack of a cohesive business environment, lack of credit financing, and regulatory complexity. Access to timber is challenging, market information is scarce, and productive infrastructure (labor, skills, logistics, and electrification) is still poor. Accessing timber through timber auctions (from plantations, conversion forests, and RF) does not provide the possibility for long-term planning, as prices, quantities, and species are often unpredictable.

Myanmar has around 1,783,800 ha of natural bamboo forest areas (either pure stands or mixed with forests). These are found particularly in Bago Yoma (819,500 ha), Rakhine (777,000 ha), and Tanintharyi $(187,300$ ha). Bamboo is also cultivated in many areas by farmers and grows widely in disturbed forest areas. It is estimated that bamboo grows across a total of over 14,300,000 ha. There are 18 species of bamboo of commercial importance in Myanmar. Internationally, demand for bamboo is increasing for application in diversified products such as flooring, chopsticks, charcoal, and construction material.

\subsubsection{Participation of stakeholders in decision making}

Stakeholder participation in decision making is still a new approach for natural resource sectors in Myanmar. The governance system in the forestry sector has been historically bureaucratic with management systems often still following those developed during the British colonial period.

\footnotetext{
33 https://www.forestdepartment.gov.mm/news/26887.
} 
Starting with the formulation of the National Land Use Policy, the FD adopted public consultations and pursued development of participatory legal framework as part of the development of the Forest Law, and its Forest Rules (draft), and the Conservation of Biodiversity and Protected Area Law and its Rules (draft). The FD's commitment to expanding CF and setting up a multi-stakeholder Community Forestry National Working Group demonstrates commitment to advancing community-based conservation and management of forests.

The FD, with the support of the UN-REDD+ Program, is drafting guidelines for an approach to ensure Free, Prior, Informed and Consent in implementation of Myanmar's National REDD+ Strategy and other initiatives affecting forests. These guidelines are expected to become mainstreamed into the FD's regular operations and management systems. 


\section{OPPORTUNITIES AND PROPOSED INTERVENTIONS}

\subsection{Opportunities for forest sector reform}

The World Bank's Program on Forests (PROFOR) ${ }^{34}$ projects an increasing timber supply gap over the coming years based on increasing demand for wood products. This is confirmed for Myanmar by a recent assessment of the enabling conditions for private plantations (summarized in Annex 2). At the same time, loopholes for illegal timber import will be closing as producer countries commit themselves to timber legality assurance systems (TLAS). Major consumer markets, including China, are pushing in the same direction. Although this is should be good news for Myanmar's forests, it also means that key policy reforms need to be advanced to meet sustainability and traceability standards.

Myanmar has huge potential to become a more important player in regional and global timber markets and to respond to the demands of a $\mathbf{2 1}^{\text {st }}$ century wood-based economy. There is an opportunity to transform and improve the performance of the sector, including uplifting wood-based timber industries with technology transfer and modernization.

Myanmar holds the largest expanse of natural forest in the region, providing a strong basis for sustainable forest management of its unique high-value timber stock. This rich natural resource has the potential to benefit the economy, boost job creation, contribute to livelihood sustenance, and provide critical environmental services.

To leverage Myanmar's potential for reviving its legendary forest sector, business as usual is no longer viable and significant transformation and modernization of the sector is needed. The impetus for such transformation is already present, and the need for reform is recognized. In the case of the MTE, which monopolized timber extraction and constrained innovation in the productive value chain, the need for a reform process is particularly apparent.

$\mathrm{CF}$, as well as new community-based conservation models proposed through recent policy reform, provides opportunities for large-scale forest restoration through a multi-purpose landscape approach that better reflects Myanmar's diverse range of social, institutional, land, and resource conditions. Landscape approaches offers a more people-centric model of forest restoration, taking into account mixed forestry and agriculture livelihood models that create increased social benefits, while also restoring ecosystem functions. Strengthened legal and institutional foundations, particularly for productive use and value-added enterprise development from CF products and services, have resulted in significant uptake of CF over the last few years, with the total area under CF doubling since 2016 after decades of slow progress.

Despite the recent dynamics in support of CF, Myanmar's national target of 3 percent of total forest area under community-based management is still comparatively low when compared to international best practice. Globally, almost one-third of the world's forest area is now estimated to be under some form of community management, and regional data show that 34 percent of total forest is under community-based management regimes in East Asia and the Pacific (FAO 2016c).

Expanding and accelerating CF and other community-based conservation models must be a priority. These models have huge potential to engage local communities in efforts to meet national policy targets for forest rehabilitation, reforestation, and forest conservation. At the same time, they increase communities' security of land and resource tenure over their customary lands and protect local livelihood assets. This is particularly urgent for mangrove ecosystems, which have declined dramatically over recent decades and have higher average annual loss rates (2.2 percent) than other forest types. With in-country evidence showing improved community-led governance of mangroves as a result of $\mathrm{CF}$, there is an opportunity to curb current mangrove loss through community-based management and protection.

${ }^{34}$ https://www.profor.info/sites/profor.info/files/Productive percent20forests percent20booklet percent20-updated.pdf 
At present, only 41 percent of Myanmar's forest is located inside the PFE, with a majority of forest located on land designated as VFV under the administration of DALMS. These unclassified forests on VFV land are typically under customary community management. However, without statutory recognition of customary tenure, they are at risk of land use change through expansion of agricultural concessions and appropriation through VFV laws, as well as from informal extraction. CF provides a means to provide tenure security for these unclassified forests for a 30-year renewable term, although approval of CF on VFV land has proven to be challenging in the context of overlapping authority between DALMS and the FD. Similar ambiguity remains regarding competing policy targets for expansion of agriculture on VFV land versus expansion of the PFE, including for protection purposes.

Cultural and nature-based attractions provide the foundation for tourism development. PA assets and attractions embrace landscapes, wildlife, vegetation, historical sites and indigenous culture, which inspire investors to develop tourism products and services, including accommodation, catering, retail outlets, and a myriad of visitor activities (such as birdwatching and sports) that help grow a country's economy through job creation and revenue generation.

Myanmar's PAs have a range of high-value tourism assets, including remarkable landscapes, seascapes and wetlands that are home to tigers, leopards, marble cats, elephants, gibbons, bears, deer, rare and endemic birds, orchids, mangroves and more. While visitor numbers to PAs such as Moeyungyi, Indawgyi and Inle have grown rapidly in recent years, pilgrims to Alaungdaw Khattapha and Popa have also grown, offering opportunities to diversify the visitor experience and raise national awareness of the role of PAs in national economic development as well as global sustainability and climate change mitigation.

Building stronger relationships between government, civil society, and other actors, including the private sector, will be essential to promote peaceful and sustainable governance on forests across the landscape. Multi-stakeholder processes that are inclusive, participatory, and cognizant of local conflict dynamics are needed to prevent tensions arising from forest conservation and restoration initiatives. In this context, a considerable shift in skills development will be needed to develop and implement a more people-centric public sector culture that emphasizes outreach and engagement, and to develop models for improved the sharing of benefits from forests with local communities in a more equitable way. The process for developing such models will need to include special emphasis on women, and on vulnerable and marginalized groups. Although gender issues are being increasingly considered in the practical implementation of policy initiatives, women and marginalized groups continue to be disadvantaged in participation, decision-making and leadership processes in forest management, as well as in the development of new livelihood and enterprise opportunities. Genderresponsive measures will need to inform roll-out of forest reform. Extension services will need to proactively target, women, youth, and marginalized groups.

Globally, PA authorities recognize that management costs can be alleviated through the strategic selection and promotion of forms of tourism suited to individual PAs. Beyond direct income, tourism can contribute to PAs as part of a wider global conservation strategy, including meeting Aichi Targets related to conservation, community development, and public awareness. Focusing on local communities, tourism incomes give households a reason to value and preserve their natural resources.

Ethnic communities' aspirations for peace, self-determination, cultural preservation, and environmental sustainability are reflected in local initiatives supported by ethnic organizations. Many conservation and forest management initiatives exist under the administration of ethnic groups, some of which demonstrate a strong track record and readiness for implementation. The means by which such self-governed ethnic initiatives could be recognized is worth exploring in the context of the country's vision for creating a peaceful, prosperous, and democratic Myanmar.

While recent policy reforms have set the stage for the important process of change across the forest sector, implementation will depend on the capacity of existing institutions to deliver these reforms. 
Given the overlapping responsibilities across different sectoral agencies and different land categories, overstretched forest sector institutions operating at sub-optimal staffing levels, extension services significantly constrained by resource and budget limitations, the institutional accountability and governance framework highly centralized, and monitoring and reporting not yet fully digitized and managed through a forest information system that allows easy data compilation and analysis, spatial planning and integration, significant investments will be needed in capacity building. A functional review will be critical for informing measures to improve institutional alignment and functionality, boost human resources in terms of skills and planning capacity, but also in quantity, emphasize more collaborative and inclusive management models, and put in place partnership arrangements to fill institutional gaps. Such functional review will also be important to enhance cross-sectoral collaboration, and to consolidate and improve existing coordination mechanisms to advance dialogue with other critical sectors, including agriculture, mining, energy, and infrastructure.

\subsection{Recommendations and proposed interventions}

The GoM has initiated a range of important forest policy actions over the past years to address forest loss and degradation and foster greater community involvement in forest conservation and restoration. The anticipated transformation of the sector from an extraction-based forest economy to a more plantation-based forest economy, and the ongoing shift from a predominantly publicly dominated forest management model to a more inclusive and integrated forest landscape management and restoration model that includes community ownership and potentially more private sector involvement, will need to be underpinned with alignment of institutional functions and capacities.

Recommendations and proposed interventions to support further reform and transformation of the sector are summarized below (and captured in more detail in Annex 4).

\subsubsection{Institutional strengthening and reform for improved forest management and governance}

Complete the National Forest Inventory and establish a more robust forest information system as a basis for forest management and conservation across different land categories.

The FD has embarked on the implementation of a National Forest Inventory, which will provide information on the current status of Myanmar's forests and form the basis for updated forest management plans.

Building on the NFI, it will be important to develop a more robust GIS-referenced forest information system, including mapping and validation of existing boundaries of land in different forest categories and under different management regimes. With only $41 \%$ of forest area currently gazetted as forest land, it will be important to review land categorization for forested land outside the PFE. This could help identify options for protecting such forest through different approaches, depending on local circumstances, e.g., community-managed areas, lease agreements, expansion of gazetted forest land, etc. This is particularly important given that most forest outside the PFE is located on VFV-designated land, and hence available for development, including for agricultural purposes. Any lease of VFV forested land should ensure that tree cover is not lost. Perverse incentives for forest destruction through VFV leases should be removed.

The overlapping and conflicting authority of MoNREC and MoALI related to management and administrated of forest outside the PFE (e.g., on VFV land) overlaps further with customary tenure, which has not yet been properly recognized in the NLUP 2016 and VFV Amendment 2018, leading to further social grievances. It will be critical that preexisting customary tenure in ethnic areas is recognized and that a legal framework for statutory recognition of customary tenure is developed. Dialogue between all agencies and stakeholders will need to continue, to support rural livelihood security and to address long-standing grievances. 
Carry out a functional review of forestry sector institutions and invest in capacity building, with an emphasis on management efficiency and adoption of innovative technology

A functional review of the forestry sector institutions is required, with a focus on the FD as the apex agency responsible for forest management, to guide development and reform of the sector in order to help meet agreed policy and program targets. This is particularly important considering the complex policy and legal environment, and the overlapping mandates that exist between sectoral agencies.

Building on the findings of the functional review, skills development and capacity building will need to be prioritized. This may include re-orientation of staffing across FD's functions and more reliance on decentralized structures, including partnerships with the private sector, CSOs, communities, ethnic groups and other stakeholders. Capacity will need to be enhanced, particularly at state/region, district, and township level, to support a more collaborative forest management approach that emphasizes citizen engagement and partnership building. New skillsets supporting livelihood development, improved benefit-sharing, SME development, and bottom-up land use planning across the forest landscape will need to be developed. Capacities for participatory approaches, social inclusion, and grievance mechanisms will need to be improved. In addition, digital transformation for monitoring and reporting will be necessary to improve real-time data analysis, planning, and adaptative management. Digitalization of data systems should be linked to ongoing efforts to include spatial data dimensions (GIS-based information). Finally, critical staffing gaps that are undermining effective forest management and protection will need to be addressed, both through improved re-alignment of staff functions, and through recruitment to fill gaps and vacancies.

It will also be important to continue to address important knowledge and data gaps, including (but not limited to): i) improved data on linkages between poverty and forest uses, and better understanding of the importance of timber and NTFP for household incomes in rural areas; ii) improved quantification of drivers of deforestation and forest degradation for more targeted and concentrated mitigation efforts; and iii) disaggregation of data by gender and vulnerability markers.

Strengthen forest governance through improved accountability, transparency, and law enforcement capacity, including detection and collaboration for prosecution

New measures will be needed to increase transparency, accountability, and citizen engagement to address irregularities and challenges in governance, which have resulted in leakage of forest resources to organized crime and shadow markets.

Government will need to strengthen forest sector governance and tackle illegal logging through more effective anticorruption measures, and collaborative efforts through the Extractive Industries Transparency Initiative, FLEGT, and others. Continued illegality is undermining not only sectoral targets for increased forest cover through both conservation and restoration efforts, but also investor confidence for plantation development.

In addition to tackling illegal logging, improved transparency in timber legality assurance and traceability are key aspects for improving Myanmar's reputation, and critical for attracting investment in plantations and to gain and maintain access to increasingly demanding export markets.

Increase supply of legal wood products by strengthening the framework for timber legality assurance International timber markets are becoming increasingly regulated to ensure the legality of timber supply. China - the largest timber importing country - is also bringing into force in July 2020 a new forest law to curb illegal timber and strengthen verification systems. Myanmar will need to further develop and strengthen the MTLAS to meet the requirements of regional and international markets, and to create an investment climate for high-value production and export. It will be necessary to align MTLAS framework with the requirements of key consumer countries, to implement national certification standards that align with regional and international standards, and to consider third-party verification for increased transparency. 
Likewise, the private sector should be encouraged to seek national or international certification standards for forest plantations as part of lease agreements. Fiscal incentives should be considered to stimulate the adoption of certification.

Improve the long-term management and sustainability of state-owned plantations

State-owned plantations have been a cornerstone of the FD's forest restoration efforts, but have suffered from high mortality rates, timber theft, and inadequate long-term maintenance, for which budgets are often lacking. In addition, the establishment of new state-owned plantation has fallen short of targets under the MRRP. While ensuring adequate budgets for establishing, maintaining and protecting state-owned plantation should be a long-term aspiration, it will be critical to consider private sector investment, public-private partnership models, and private-public-community partnerships in the near-term. These alternative approaches for meeting the Government's plantation targets can support not only new plantations, but also the maintenance of existing government plantations to avoid loss to encroachment and illegal logging.

\subsubsection{Toward a more inclusive and participatory forest management approach}

Develop a comprehensive delivery mechanism to accelerate the expansion of CF and ensure tangible benefits from CF tenure to communities

Much of Myanmar's denuded or degraded forest is suitable for establishing timber plantations, including through CF, thereby providing opportunities for scaling up forest restoration and community-level forest enterprise development. CF, as well as new community-based conservation models supported by recent policy reform, also provide opportunities for a more people-centric approach to forest conservation. To accelerate roll-out of CF, the slow CF registration process and limited handover capacity will need to be addressed. While the approval process will need to be simplified and accelerated, measures should also be introduced to ensure that CF establishment ensures equity and inclusiveness and avoids elite capture. To accelerate expansion of CF, a more efficient delivery mechanism will be needed, through a combination of skills development and training for local FD staff, combined with additional facilitation through a cadre of service providers and community facilitators to help fill shortfalls in extension services. Such enhanced delivery mechanisms will need to be supported with an improved communication program and underpinned with an open access CF database that provides transparent information about status, progress, challenges, and other data, not only for management and coordination purposes, but most importantly also for knowledge exchange and learning purposes across the network of CFUGs. As a first step, existing CF data platforms and data collection mechanisms managed by the Community Forestry Unit of the FD should be harmonized, and a stock-taking exercise on the status of all originally created CFUGs carried out.

Based on the findings of the stocktaking exercise, and taking into consideration the changes needed for effective community support, the CF Strategy (2018-2020) should be reviewed and updated.

Support establishment of CF networks to facilitate learning and knowledge exchange

Critical knowledge and capacity constraints are hindering the full impact and benefit that CF can provide. It is recommended that a network of CFUGs be formed at district, regional, and national levels to help address such gaps and facilitate learning and exchange among CFUG members, as well between CUFGs and government, private sector, and CSOs. Such networks could further be used to raise awareness on recent policy changes as well as changes in the CF Instructions that many CFUGs (and even local FD staff) may not yet be fully aware of. Such networks would also provide a platform for coherent bottom-up input to policy processes and implementation.

Strengthen access to finance through community-led financial mechanisms

Although the new CFI provides a stronger framework for CFE establishment, CFUGs continue to face a barrier in securing access to finance, especially small loans to invest in CF and value addition. An immediate opportunity is provided by the current legal framework that allows CFUGs to open institutional bank accounts and to establish CF Development Funds as a vehicle to strengthen access 
to funds that support livelihood development, investments in CF management, and product development. It will be critical to scale up the establishment of CF Development Funds, not only to facilitate enterprise development and sustained interest and benefits from CF for communities, but also to provide opportunities for short-term livelihoods support and motivation from CFUGs in the absence of quick returns from timber-based enterprise development. As part of the roll-out of CF Development Funds, different pilot models should be carefully assessed and guidance for appropriateness of different models developed.

Additional measures should be introduced to support access to finance for business development in the medium term, including developing favorable financing operations with microfinance institutions, providing technical support to producer groups, and providing CFE/SME incubator support programs.

Minimize risks and maximize opportunities through cooperatives and similar mutualistic enterprise organizations, and strengthen market access through private sector-community cooperation

To overcome barriers that are currently hindering CF enterprise development, including access to information, resources, and markets, CFUGs should be supported to build groups or cooperatives that strengthen their negotiating position, increase efficiencies, and provide economies of scale. Lessons from successful experiences in neighboring countries (e.g., bamboo cooperatives in China) may provide important lessons. Emerging CFEs should also be supported to form mutually beneficial partnerships with the private sector, regardless of whether they are organized as cooperatives or as otherwise associated groups with shared bargaining power, or individually. A market analysis of opportunities for CFE development, timber and NTFP products, and potential partnerships should be carried out and a CF product platform could be created to help facilitate connection between CFUGs, CFEs, and private sector actors. For example, active cooperation in plantation development between communities and commercial investors can strengthen the sustainability of community-level forest enterprise development. An emerging model in Myanmar is so-called 'clusters' of CFUGs that form partnerships with investors with processing facilities. Investors supply seedlings and technical advice to CFUGs and provide a market for their products, while CFUGs expand the supply of raw material for processing by the investors. It will be important to encourage industries that can promote vertical integration in cooperation with smallholders, promoting technology transfer and skill enhancement for processing and handling to SMEs. As referenced above, SME development will need to be supported with an enhanced enabling environment for SME development in the timber industry.

Mainstream CF rollout across different land classifications, including in reserved forests, mangrove forests and VFV lands, and explore ways to promote CF services to ethnic communities to support effective customary forest management.

Expansion of CF has typically focused on handing over encroached or degraded forest areas with insufficient stock to sustain viable forest enterprise. CF provides an opportunity also for sustainable community-led forest management as well as conservation-based enterprise development (e.g., community-based tourism/ecotourism) and other conservation-based benefit accrual. CF should thus be proactively expanded across different land classifications and forest types, to provide opportunities not only for restoration, but also for community-led forest protection. This is particularly relevant for coastal mangrove areas, buffer zones around and corridors between Protected Areas, currently unprotected areas of high conservation value. It will be critical to strengthen the dialogue with ethnic communities to recognize and enable pre-existing customary tenures and management, and where appropriate and agreed by communities, promote CF, including on VFV land. To recognize customary tenure systems, different forms of community-based forest management beyond CF should also be explored and the most practical models identified, including Community Protected Areas and Indigenous and Community Conserved Area (CPAs/ICCAs), where appropriate.

\subsubsection{Transform to a plantation-based forest economy with more private sector engagement}

Develop and implement a plantation strategy to enable private sector investments 
While Myanmar has introduced some policies aimed at encouraging private sector investment, a coherent plantation strategy is needed to support a much larger switch to plantation forestry and meet domestic timber needs, sustain export needs and take pressure of natural forests. A plantation strategy will need to consider what level of investment is needed to meet Myanmar's domestic wood product demands and those of its export markets, taking into account employment ambitions, and to adequately respond to investor concerns and perceived constraints. Suggested reforms and actions should be categorized and prioritized depending on how readily they can be implemented, including different plantation models that could be phased in over time (e.g., expanding from current models of greenfield plantations on leased, denuded or degraded land, to also include existing governmentplantations, and potentially natural forest management leases in the future).

To guide the development of this comprehensive plantation strategy and reform process, a multistakeholder body that includes relevant government agencies, private sector representatives, CSOs representing community interests, and legislators should be created. Deliberations and decisions of the multi-stakeholder working groups should be supported with further technical, social, and economic analysis and data collection to address data gaps.

Increase transparency and community engagement to address social risks and reduce potential conflict, as well as other risks

Social risks, especially those related to land tenure and the potential for related conflict, are a major issue for all land-based investment in Myanmar. Adequate social and environmental safeguards need to be put in place and implemented, to ensure full consultation in land use allocations, including seeking local communities' Free Prior Informed Consent before commencing investment to avoid later problems. Partnership models or other approaches for cooperation with local communities should be encouraged, to help ensure those communities benefit from investments, while at the same time reducing social risk for plantation investors. Such approaches could include commercial arrangements with local community-based forestry enterprises on adjacent RF or VFV land, contract tree growing by farmers on nearby private land, or establishing tree rows at wide spacings to allow intercropping between rows - also possibly incorporating sharing of the proceeds from the harvested timber.

Biophysical risks, including those that may arise through climate change, can be addressed to a degree through species choice, appropriate surveillance and management flexibility.

Identify and make available information about areas available for investment

There is a severe lack of information for potential investors on the land areas potentially available for plantations. The most suitable areas in terms of land area, access, site quality, and other supporting infrastructure should be identified, but combining land surveys, remote sensing analysis, and consultation with prospective investors and other stakeholders. Once information is available, better publicity should help promote plantation investment for the available sites.

Review and improve lease terms and licensing processes for plantation establishment

Area limits for plantation leases are currently too small, the current 30-year plantation lease length is generally too short, and procedures for acquiring leases are complex and cumbersome. The terms for plantations leases should therefore be reviewed and the processes for licensing and decision-making should be streamlined. Investors will need lease terms that provide assurance for multiple plantation rotation, as per current limitations, in particular to attract associated investments in downstream processing. Longer lease terms are also critical for increasing the confidence of potential institutional investor or financiers who would be seeking investment opportunities with a secure future, thus allowing them an exit strategy.

Once established, information about streamlined procedures and regulations for the acquisition and management of plantation leases should be compiled in guidance documents and made available not only in Myanmar language, but also translated. 
Lighten and streamline transport requirements for plantation timber and bamboo

Regulations covering timber harvesting and transport, originally designed for natural forests, are unnecessarily onerous for plantation forestry. The requirements for harvesting and transporting plantation products and bamboo should be streamlined to reflect the lower risk of illegal harvesting and the opportunity to collect revenue. Similarly, more streamlined requirements should be considered for plantation timber legality assurance systems.

Consider a range of external financing sources in the short term as well as adaptation of domestic financial products in the medium term to respond to lack of finance for plantations

A key obstacle to investment in plantation development is the lack of suitable financing products through state or commercial banks. Equity finance therefore seems to be the only viable option at present. A range of external financing sources should be considered, including: a) equity finance in joint ventures of partnerships with local companies from foreign institutional and industrial investors, including international investment funds and Development Finance Institutions (DFIs); b) loan financing to private investors, including through DFls; and c) multilateral development bank loans to Government, routed to investors though state-owned banks. Development finance would also require borrowers to meet environment and social performance standards. These financing sources could be blended and supplementary options explored from international climate funds, voluntary carbon markets, and investment funds that support green businesses.

\subsubsection{Support expansion of forest protection and seek financial viability of Protected Areas}

Expand area under protection to meet national targets, with increased focus on community-based conservation models and improved stakeholder engagement and benefit-sharing.

To achieve Myanmar's targets of land under protection, community conservation models as defined by recent policy reform (2018 Biodiversity Law), but for which rules and more detailed instructions are still pending, should be promoted. Multi-stakeholder dialogue and engagement should continue on the implementation of community-based conservation models as well as collaborative arrangements for buffer zone management.

Where appropriate, gazettement of planned PAs should be advanced only where dialogue and engagement with communities and civil society is assured.

The ongoing process of development and renewal of PA management plans should continue, including more multi-stakeholder engagement and dialogue on buffer zone management. Where appropriate, plans for sustainable tourism should be developed to support increased revenue collection and benefit-sharing.

Improve financial sustainability of the Protected Areas system with a multi-pronged approach

Improved resource mobilization and revenue generation is needed to support the financial viability of the national PA system, which is currently constrained by insufficient funding for planning, capacity development, monitoring, operating costs, and engagement and benefit-sharing with communities. Nature-based tourism has the potential to leverage Myanamar's high-value eco-tourism assets, promote investment in (and revenue generation for) PAs, while creating jobs and opportunities for increased benefit-sharing with local communities to incentivize conservation.

Operating standards and mandatory requirements need to be put in place to ensure responsible tourism development and management that benefits PAs and local communities. Regulation and enforcement of sustainable behavior can be achieved through construction permits, licensing, and environmental impact assessments, as well as by putting in place a concession management framework and related contracts. This can be further supported through voluntary mechanisms to crowd-in responsible tourism operators and enhance sustainability of the sector, including through award schemes, sustainability certification, codes of conduct, and consumer feedback platforms. 
Most importantly, a review of the benefit sharing opportunities and mechanisms will be needed to guide development of a benefit-sharing system for local communities from PA revenues.

Additional financing opportunities should be revised and operationalized to support forest conservation, including PES schemes, the Biodiversity Fund, and potential REDD+ payments.

Consider concession agreements with private enterprises (e.g., ecotourism, forest plantations) in PAs Concession agreements with private enterprises (e.g., ecotourism, forest plantations) in selected, less sensitive zones of PAs should be considered to support revenue generation and contribute to the financial viability of PAs, while creating employment for local communities. A functional safeguard system will need to be in place before commercial activities in PAs can be pursued, to avoid unintended negative impacts on biodiversity, the environment, and local people.

\subsubsection{Cross-cutting forest management issues}

Address woodfuel as a major national energy source and contributor to forest degradation

Woodfuels meet the energy needs of most households in Myanmar as well as those of important commercial and industrial sectors. With diminishing forest resources, it is essential that remaining resources are sustainably managed and enhanced, that woodfuel processing and use becomes as clean and efficient as possible, and that fuel switching strategies are well-informed and strategic.

Recommended actions to increase the use of appropriate alternative fuels include:

i) promote liquified petroleum gas (LPG) for household cooking, including through potential subsidies, awareness and information campaigns;

ii) support rice husk pellets and briquettes as a low-carbon alternative for heat and steam production for industrial consumers through financial incentives for boiler modifications; and

iii) support charcoal briquettes for commercial catering to increase efficiency, with technical assistance for improved production and marketing for briquette producers.

Considering that fuelwood plantations offer no return on investment, woodfuel production will need to be re-imagined as a byproduct, rather than as a primary purpose of plantations, to be viable and sustainable. Recommendations to promote the production of sustainable woodfuels, include:

i) re-use of harvesting and processing residues from large-scale plantations, including further feasibility studies to understand the economic and regulatory environment,

ii) mixed-purpose plantations (e.g., agroforestry) at household level for areas in high woodfuel deficit, where mixed species plantation can provide multiple benefits (fruit, fodder windbreak, nutrient fixing, etc.); and

iii) enhanced supply from sustainably managed community forestry, including support for market access to compete with illegally produced woodfuels that suppress price and competitiveness.

Finally, with most charcoal produced illegally, there are no incentives for investing in greater sustainability and reducing energy loss through the value-chain. Yet, at the same time, enforcement of strict rules remains virtually impossible. The following recommendations are based on the premise of bringing the industry into the formal economy by encouraging compliance with licenses and output limits, and to facilitate good law enforcement:

i) Offer training on modernized charcoal production to reduce high inefficiencies.

ii) Promote cleaner and more efficient woodfuel use, starting with a national cookstove strategy to harmonize guidelines on subsidies to address current market distortions, and support local producers in high quality manufacturing and marketing.

Scale-up nature-based solutions for disaster resilience

Ecosystem restoration is a key measure to reduce the vulnerability of local populations to disasters, including storm surges, flooding, landslides, and droughts, as well as to increase resilience to the 
effects of climate change. Specific investments within the forest sector can support more resilient landscapes, including mangrove restoration in exposed and densely populated coastal and delta areas, productive agroforestry, green infrastructure such as buffer strips, forest restoration on slopes, and watershed restoration. Conservation, restoration and improved management of mangroves will provide important benefits in terms of natural, social, and financial capital.

Address multi-sectoral causes of deforestation

With many drivers of deforestation and forest degradation originating from outside the forest sector, it will be critical to break down sectoral silos in public sector administration and strengthen safeguards for activities that impact forest lands. Potential entry points for intersectoral coordination, policy formulation, and collaborative implementation are presented in section 4.3 below.

\subsection{Entry points for cross-sectoral opportunities and interventions}

The drivers of deforestation and forest degradation are intimately linked and will require crosssector planning, multi-stakeholder dialogue and development of a joint vision on the role of forests in Myanmar's development. The key sectors for preserving the country's remaining forests and potentially restoring the degraded forests are the agricultural, mining, infrastructure, and energy sectors. This is not to diminish the critical role of the forestry sector itself in forestry reform, but it does highlight the urgent need for cross-sector dialogue and a nationally integrated approach to preserving the country's remaining intact forests and restoring those that are severely degraded.

This section (Table 10) highlights key entry points and opportunities for further support to the GoM in promoting intersectoral collaboration on forests and forest-smart solutions, i.e. interventions that minimize the impact of other sector activities on forests. These may be supported by the World Bank and by other groups.

Table 9: Entry points for improved cross-sectoral planning for forest-smart development

\begin{tabular}{|c|c|}
\hline Sector & Cross-sectoral entry points \\
\hline Agriculture & $\begin{array}{l}\text { - Prioritize and proactively strengthen mechanisms for intersectoral coordination, } \\
\text { coordinated policy formulation, and collaborative implementation with MoALI, } \\
\text { with an emphasis on high-level coordination. } \\
\text { - Build budgeted partnership arrangements with MoALI to promote coordinated } \\
\text { extension services for agroforestry, in particular in CF and on agricultural land. } \\
\text { - Remove ambiguity related to overlapping authority of MoNREC and MoALI on } \\
\text { VFV land, to prevent conversion of unclassified forest land without due } \\
\text { application of stakeholder consultation and safeguards. } \\
\text { - As part of a transition to cash crops and crop diversification, include agroforestry, } \\
\text { crop combinations (e.g., rubber and coffee or cocoa), and multi-cropping systems } \\
\text { that include annuals and perennials. } \\
\text { - Incorporate interventions to increase canopy cover around cropped areas in } \\
\text { agricultural projects. } \\
\text { Offer and promote opportunities for agroforestry initiatives, Community-Driven } \\
\text { Development projects or value chain specific investments with recognition of } \\
\text { multiple cropping. Investments to be accompanied by technical assistance and } \\
\text { improved extension services for affected households. } \\
\text { - Identify opportunities for agroforestry in predominantly rice-producing areas. } \\
\text { Where possible, incorporate reforestation as part of agricultural investment } \\
\text { packages. } \\
\text { Provide access to micro-finance/low interest credit to facilitate investments and } \\
\text { technology to increase agricultural productivity for farmers who might otherwise } \\
\text { expand cultivated areas into forested land. }\end{array}$ \\
\hline
\end{tabular}




\begin{tabular}{|c|c|}
\hline Sector & Cross-sectoral entry points \\
\hline & $\begin{array}{l}\text { - Ensure that leases of forested VFV land avoid tree cover loss where possible, and } \\
\text { do not provide perverse incentives for forest clear-cut. } \\
\text { - Identify more efficient and simplified procedures for coordinating CF } \\
\text { establishment on VFV land with MoALI. } \\
\text { - Identify opportunities for PES schemes, e.g., downstream agricultural irrigation } \\
\text { schemes or reservoir operations paying for watershed protection efforts. } \\
\text { - Link to agro-ecotourism to incentivize farmers regarding the value of forests and } \\
\text { provide additional avenues of income to reduce deforestation attempts; explore } \\
\text { carbon financing linked to maintained forest cover. }\end{array}$ \\
\hline Energy & $\begin{array}{l}\text { - Accelerate rural electrification and promote sustainable off-grid electricity } \\
\text { solutions, including biomass/mini-hydro/solar, particularly in forest degradation } \\
\text { hotspots without immediate prospects for grid connectivity. } \\
\text { - Promote off-grid solutions as part of the National Community-Driven } \\
\text { Development Project (financed by the World Bank) to reduce pressure on forests } \\
\text { to meet local energy needs currently met by woodfuel. } \\
\text { - Promote development of fast-growing tree species for woodlots. Explore the role } \\
\text { of bamboo plantations as feedstock for charcoal or industrial heat. } \\
\text { - Incentivize sourcing of biomass energy from sources other than natural forests, } \\
\text { including residues from wood processing, support development of distribution } \\
\text { networks for sustainably source biomass energy, and reduce regulatory } \\
\text { requirements to enhance compliance and mainstream the woodfuel industry. } \\
\text { Strengthen the application of environmental and social safeguards to ensure that } \\
\text { the impact on forests of large electricity (hydropower) investments are avoided, } \\
\text { minimized, mitigated, and offset. Specifically, implement the EIA guidelines for } \\
\text { hydropower projects developed for Ministry of Electricity and Energy (MoEE) and } \\
\text { MoNREC as part of the } 2018 \text { Strategic Environmental Assessment (SEA) of the } \\
\text { hydropower sector, and integrate SEA provisions into the existing EIA procedure, } \\
\text { recognizing the weak legislative and procedural instruments for social safeguards } \\
\text { in medium- to-large-scale developments such as hydropower. }\end{array}$ \\
\hline Water & $\begin{array}{l}\text { - Identify priority areas for reforestation to counter flooding and landslides (e.g., } \\
\text { through watershed protection plantations) and strategic forest restoration to } \\
\text { prevent riverbank erosion and sedimentation of hydropower and irrigation } \\
\text { reservoirs. } \\
\text { - Focus on catchment management as it impacts the existing and proposed built } \\
\text { water assets, as per the Ayeyarwady River Basin Master Plan (under } \\
\text { development), building on interest from GoM to pilot improved management in } \\
\text { selected catchments (e.g., Myitnge or Bago). In this context, identify ways to } \\
\text { integrate reforestation/watershed management activities into the Decision } \\
\text { Support System newly established in the Hydro-Informatics Center, to take } \\
\text { advantage of capacity for scientifically based decision support within the basin. } \\
\text { - Explore opportunities for PES schemes, especially for watershed protection for } \\
\text { irrigation and hydro power. } \\
\text { Deepen understanding and recommendations of how good governance can be } \\
\text { strengthened across sectoral agencies, including water sector agencies. }\end{array}$ \\
\hline Land & $\begin{array}{l}\text { - Advance the National land law as it would provide framework for management of } \\
\text { forests on VFV lands; amend current land laws to expand the roles of farmers and } \\
\text { community members in land use decision making; }\end{array}$ \\
\hline
\end{tabular}




\begin{tabular}{|l|l|}
\hline Sector & Cross-sectoral entry points \\
\hline & $\begin{array}{l}\text { Continue dialogue between agencies and stakeholders toward statutory } \\
\text { recognition of ethnic customary land and resource tenure systems, as proposed } \\
\text { under the NLUP } 2016 \text { and Pyidaungsu Accord 2017. }\end{array}$ \\
\hline - $\begin{array}{l}\text { Recognize customary tenures in ethnic areas according to NLUP } 2016 \text { and VFV } \\
\text { Amendment 2018, and develop the legal framework for their statutory } \\
\text { recognition. }\end{array}$ & $\begin{array}{l}\text { Prioritize cadastral surveys in areas of agricultural expansion and encroachment } \\
\text { in high value conservation forests. }\end{array}$ \\
\hline Mining & $\begin{array}{l}\text { Continue to strengthen EIA review, approval, and implementation to reduce } \\
\text { mining impacts on forests. Place emphasis on capacity building. Differentiate } \\
\text { between large-scale mining and artisanal and small-scale mining to improve mine } \\
\text { closure and rehabilitation. }\end{array}$ \\
\hline - Foster discussion on opportunities for PES or setting up an environmental \\
management fund in the mining sector. \\
Identify and promote opportunities for increased use of Biodiversity Offset Plans \\
by mining projects. \\
Identify opportunities for mining companies to fund reforestation activities as \\
part of corporate social responsibility measures.
\end{tabular}

\subsection{Next steps}

The recommendations presented above (refer also to Annex 4 for a detailed table of recommendations) is intended to serve as basis for prioritizing interventions within the sector, facilitating discussions related to cross-sectoral issues, and identifying specific interventions and policy initiatives as part of the Forest Department's engagement with political and technical decision makers, private sector, development partners, communities, and civil society.

This framework can also serve the Government in their dialogue with development partners, donors, and other collaborators to programmatically request and define assistance that maximizes complementarity and synergies.

A critical next step will be to sequence recommendations to what is actionable and achievable in the short- and medium-term, based on both the direction of future forest sector reforms public budgets as well as ongoing and planned development cooperation. Several recommendations are fully aligned with the government's ongoing sectoral programs, such as the Myanmar's MRRP. Other 
recommendations are being picked up as priority areas for external support with projects from development partners under preparation.

For example, a large World Bank investment project, the Forest Restoration, Development and Investment Project (FREDIP), is under preparation by the FD to contribute to:

i. Strengthening and expanding CF and CF enterprise development, thus directly supporting MRRP targets for community-led forest restoration and SME development along the forest value chain, while at the same time creating direct benefits, including financial revenues and tenure security for rural communities;

ii. Restoring forest cover with an emphasis on re/afforestation in community forests, but also by creating enabling conditions for establishment of private plantations;

iii. Strengthening the PA system and expanding it through establishment of Community Protected Areas with an emphasis on creating opportunities for collaborative management, community-led conservation and creating economic opportunities through ecotourism development;

iv. Improving the enabling conditions for forest-based revenue generation and for improved access to profitable markets.

Cognizant of the need to strengthen the FD's capacity to implement a challenging reform process and to shift to a more service-oriented delivery model, FREDIP includes funding for a functional review of the forest sector with focus on FD as the apex agency responsible for forest management. More specifically, the project will support an institutional assessment of the FD structure vis-à-vis its existing capacity for fulfilling its mandate efficiently and effectively, and provide recommendations for functional reform to deliver on objectives of the wider forest sector reform. Project-supported capacity building will invest in strengthening the FD's capacity according to the identified needs, through provision of training, equipment, and technology support.

Finally, several recommendations are critically important to underpin ongoing and planned investments in the restoration and reforestation agenda in the long-term and highly relevant to meet higher-level objectives and vision for forest protection and production. Many recommendations oriented toward governance, institutions, and management will need a longer-term perspective, and will need to be refined and revised as the forest sector reform evolves and the peace process and the dialogue with ethnic communities advances. 


\section{REFERENCES}

ADB (Asian Development Bank). 2014. Myanmar: Unlocking the Potential Country Diagnostic Study. Manila: ADB, Economic and Research Department.

ADB, ed. 2016. Gender Equality and Women's Rights in Myanmar: A Situation Analysis. Manila: ADB.

-- - 2017. Myanmar Energy Consumption Surveys Report. Mandaluyong City, Metro Manila: ADB.

Adeogun, Adeniyi Ganiyu. 2018. Cost Effectiveness of Sediment Management Strategies for Mitigation of Sedimentation at Jebba Hydropower Reservoir, Nigeria.

Allendorf, T. D., M. Aung, K. K. Swe, and M. Songer. 2017. "Pathways to Improve Park-People Relationships: Gendered Attitude Changes in Chatthin Wildlife Sanctuary, Myanmar." Biological Conservation 216: 78-85. https://doi.org/10.1016/j.biocon.2017.10.005.

Aung, T. T., Y. Mochida, and M. M. Than. 2013. "Prediction of Recovery Pathways of Cyclone-disturbed Mangroves in the Mega Delta of Myanmar." Forest Ecology and Management 293: 103-113. https://doi.org/10.1016/i.foreco.2012.12.034.

Bauer, A., A. Hein, K. S. Htay, M. Hamilton, and P. Shortell. 2018. State-Owned Economic Enterprise Reform in Myanmar: The Case of Natural Resource Enterprises. NRGI/Renaissance Institute: Washington, DC.

Bauer, A., N. Kirk,and S. Sahla. 2018. Natural Resource Federalism: Considerations for Myanmar. New York: Natural Resource Governance Institute.

Béné Christophe, Newsham Andrew, Davies Mark, Ulrichs Martina, and Godfrey-Wood Rachel. 2014. "Review Article: Resilience, Poverty, and Development." Journal of International Development 26: 598-623. https://doi.org/10.1002/jid.2992.

BEWG (Burma Environmental Working Group). 2017. Resource Federalism - Road Map for Decentralised Governance of Burma's Natural Heritage. Yangon: BEWG.

Bhagwat, T., A. Hess, N. Horning, T. Khaing, Z. M. Thein, K. M. Aung, K. H. Aung, P. Phyo, Y. L. Tun, A. H. Oo, A. Neil, W. M. Thu, M. Songer, K. L. Connette, A. Bernd, Q. Huang, G. Connette, and P. Leimgruber. 2017. "Losing a Jewel-Rapid Declines in Myanmar's Intact Forests from 20022014." PLOS ONE 12 (5): e0176364. https://doi.org/10.1371/journal.pone.0176364.

Blessing, D. 2018. Options to Restructure and Reform Myanma Timber Enterprise. Final Report to Management of MTE and MONREC. Dan Blessing, Forester, Fulbright Specialist.

Burma News International. 2018. Myanmar Peace Monitor: Ethnic Grievances [WWW Document]. http://mmpeacemonitor.org/background/ethnic-grievances (accessed April 30, 2018).

Boori, M. S., K. Choudhary, M. Evers, and R. Paringer. 2017. "A Review of Food Security and Flood Risk Dynamics in Central Dry Zone Area of Myanmar." Procedia Engineering, 3rd International Conference "Information Technology and Nanotechnology", ITNT-2017, , Samara, Russia 201, 231-238. April 25-27,2017. https://doi.org/10.1016/i.proeng.2017.09.600.

Borras, S. M., and J. C. Franco. 2018. "The Challenge of Locating Land-Based Climate Change Mitigation and Adaptation Politics within a Social Justice Perspective: Towards an Idea of Agrarian Climate Justice." Third World Quarterly 1-18. https://doi.org/10.1080/01436597.2018.1460592.

Brakenridge, G. R., J. P. M. Syvitski, E. Niebuhr, I. Overeem, S. A. Higgins, A. J. Kettner, and L. Prades. 2017. "Design with Nature: Causation and Avoidance of Catastrophic Flooding, Myanmar." Earth-Science Reviews 165: 81-109. https://doi.org/10.1016/j.earscirev.2016.12.009. 
Business Innovation Facility. 2015. A Political Economy Analysis of the Myanmar Bamboo Sector. Yangon: Business Innovation Facility, DFID.

Cashore, B., and M. W. Stone. 2012. "Can Legality Verification Rescue Global Forest Governance? Analyzing the Potential of Public and Private Policy Intersection to Ameliorate Forest Challenges in Southeast Asia." Forest Policy and Economics, Emerging Economic Mechanisms for Global Forest Governance 18: 13-22. https://doi.org/10.1016/i.forpol.2011.12.005.

Challender, D.W.S., S. R. Harrop, and D.C. MacMillan. 2015. "Towards Informed and Multifaceted Wildlife Trade Interventions." Global Ecology and Conservation 3: 129-148. https://doi.org/10.1016/j.gecco.2014.11.010.

Cheng, S. H., S. Ahlroth, S. Onder, P. Shyamsundar, R. Garside, P. Kristjanson, M. C. McKinnon, and D. C. Miller. 2017. "What is the Evidence for the Contribution of Forests to Poverty Alleviation? A Systematic Map Protocol." Environmental Evidence 6: 10. https://doi.org/10.1186/s13750$\underline{017-0088-9}$

Colfer, C. J. P. 2011. "Marginalized Forest Peoples' Perceptions of the Legitimacy of Governance: An Exploration." World Development 2147-2164. https://doi.org/10.1016/j.worlddev.2011.04.012.

Connette, K. L. 2016. Mining in Myanmar: Remote Sensing of Mining Change between 2002 and 2015. Yangon: ALARM.

Cornish, G., and V. Vivoda. 2016. "Myanmar's Extractive Industries: An Institutional and Regulatory Assessment." The Extractive Industries and Society 3: 1075-1083. https://doi.org/10.1016/j.exis.2016.08.002.

Cowling, P., K. DeValue, and K. Rosenbaum. 2014. Assessing Forest Governance:A Practical Guide. Washington, DC: PROFOR and FAO.

D'Arrigo, R., J. Palmer, C. C. Ummenhofer, N. N. Kyaw, and P. Krusic. 2011. "Three Centuries of Myanmar Monsoon Climate Variability inferred from Teak Tree Rings." Geophysical Research Letters 38. https://doi.org/10.1029/2011GL049927.

Dong, M., and J. He. 2018. "Linking the Past to the Future: A Reality Check on Cross-border Timber Trade from Myanmar (Burma) to China." Forest Policy and Economics 87: 11-19. https://doi.org/10.1016/j.forpol.2017.11.002.

ECDF. 2016. Our Customary Lands: Community Based Sustainable Natural Resource Management in Burma. Yangon: Ethnic Community Development Forum.

Ei Ei Toe Lwin. 2011. "Villagers Shun Community Forest Plan." The Myanmar Times. https://www.mmtimes.com/national-news/1865-villagers-shun-community-forest-plan.html

EIA (Environmental Investigation Agency). 2014. Data Corruption: Exposing the True Scale of Logging in Myanmar [WWW Document]. http://www.illegal-logging.info/sites/default/files/EIA-DataCorruption-FINAL.pdf (accessed 10.23.14).

--- 2015. Organised Chaos: The Illicit Overland Timber Trade between Myanmar and China. London: Environmental Investigation Agency.

- - - 2019. State of Corruption: The top-level conspiracy behind the global trade in Myanmar's stolen teak. London: Environmental Investigation Agency.

Eleven Myanmar. 2015. "700 'Corrupt’ Forestry Officials Targeted.” Eleven Media Group, Myanmar.

Elson, D. 2016. Strategic support for Community Forestry Enterprise development (unpublished: Pyoe Pin, Yangon). 
Ellison, D., C. E. Morris, B. Locatelli, D. Sheil, J. Cohen, D. Murdiyarso, V. Gutierrez, M. Noordwijk, I.F. van, Creed, J. Pokorny, D. Gaveau, D. V. Spracklen, A. B. Tobella, U. Ilstedt, A. J. Teuling, S. G. Gebrehiwot, D. C. Sands, B. Muys, B. Verbist, E. Springgay, Y. Sugandi, and C. A. Sullivan. 2017. "Trees, Forests, and Water: Cool Insights for a Hot World." Global Environmental Change 43: 51-61. https://doi.org/10.1016/i.gloenvcha.2017.01.002.

Emerton, L., and Y. M. Aung. 2013. The Economic Value of Forest Ecosystem Services in Myanmar and Options for Sustainable Financing. Yangon: International Management Group.

Enters, T. 2017. Drivers of Deforestation and Forest Degradation in Myanmar. Yezin: UNREDD/Myanmar Programme.

Estoque, R. C., S. W. Myint, C. Wang, A. Ishtiaque, T. T. Aung, L. Emerton, M. Ooba, Y. Hijioka, M. S. Mon, Z. Wang, and C. Fan. 2018. "Assessing Environmental Impacts and Change in Myanmar's Mangrove Ecosystem Service Value due to Deforestation (2000-2014)." Global Change Biology 24: 5391-5410. https://doi.org/10.1111/gcb.14409.

FAO (Food and Agriculture Organization).. 2014. Contribution of the Forestry Sector to National Economies, 1990-2011. FAO Forest Finance Working Paper, FSFM/ACC/09 (http://www.fao.org/3/a-i4248e.pdf).

-- . 2015. Global Forest Resources Assessment 2015 - Myanmar Country Report. Rome: FAO.

-- - 2016a. Data Book with the Results of the Project "Strengthening Myanmar's National Forest Monitoring System - Land Use Assessment and Capacity Building" (TCP/MYA/3501). FAO.

- - -2016b. Forty years of community-based forestry - A review of its extent and effectiveness. Forestry Paper No. 176. Food and Agriculture Organisation of the United Nations (FAO), Rome. http://www.fao.org/3/a-i5415e.pdf

-- - 2018. FAOSTAT [WWW Document]. http://www.fao.org/faostat/en/\#data/FT (accessed May 17, 2018).

FAO (Food and Agriculture Organization) and PROFOR. 2011. Framework for Assessing and Monitoring Forest Governance. Rome: FAO.

Feurer, M., D. Gritten, and M. Than. 2018. "Community Forestry for Livelihoods: Benefiting from Myanmar's Mangroves." Forests 9: 150. https://doi.org/10.3390/f9030150.

Foran, T., L. Kiik, S. Hatt, D. Fullbrook, A. Dawkins, S. Walker, and Y. Chen. 2017. "Large Hydropower and Legitimacy: A Policy Regime Analysis, applied to Myanmar." Energy Policy 110: 619-630. https://doi.org/10.1016/i.enpol.2017.08.043.

Forest Trends. 2013. Tackling Timber Regulations: A Guide for Myanmar. Washington, DC: Forest Trends.

Forsyth, T., 2018. Is resilience to climate change socially inclusive? Investigating theories of change processes in Myanmar. World Development 111, 13-26. https://doi.org/10.1016/i.worlddev.2018.06.023

Freudenthal, E., 2017. Burning down the house: Myanmar's destructive charcoal trade. Mongabay Environmental News.

Giri, C., E. Ochieng, L. L. Tieszen, Z. Zhu, A. Singh, T. Loveland, J. Masek, and N. Duke.n.d. "Status and Distribution of Mangrove Forests of the world using Earth Observation Satellite Data." Global Ecology and Biogeography 20: 154-159. https://doi.org/10.1111/i.1466-8238.2010.00584.x.

Giri, C., Z. Zhu, L. L. Tieszen, A. Singh, S. Gillette, and J. A. Kelmelis. 2007. "Mangrove Forest Distributions and Dynamics (1975-2005) of the Tsunami-Affected Region of Asiat." Journal of Biogeography 35: 519-528. https://doi.org/10.1111/j.1365-2699.2007.01806.x. 
Global Witness. 2015. Jade: Myanmar's "Big State Secret." London: Global Witness.

GoM (Government of Myanmar). 1995. Forest_Policy - Republic of the Union of Myanmar.

- - . 2008. Constitution of the Republic of the Union of Myanmar.

--- 2017. Citizen's Budget 2017-2018.

Gordon, S., Mortimer, K., Grigg, J., and J. Balmes. 2017. "In Control of Ambient and Household Air Pollution - How Low should We Go?" The Lancet Respiratory Medicine 5: 918-920. https://doi.org/10.1016/S2213-2600(17)30393-4.

Gritten, D., S. R. Lewis, G. Breukink, K. Mo, D. T. T. Thuy, and E. Delattre. 2019. "Assessing Forest Governance in the Countries of the Greater Mekong Subregion." Forests 10 (1): 47.

Hamilton, S. E., and D. Casey. 2016 "Creation of a High Spatio-temporal Resolution Global Database of Continuous Mangrove Forest Cover for the 21st Century (CGMFC-21)." Global Ecology and Biogeography 25: 729-738. https://doi.org/10.1111/geb.12449.

Harvard, CID. 2018. The Atlas of Economic Complexity [WWW Document]. http://atlas.cid.harvard.edu/explore/?country=143\&partner=undefined\&product=undefined \&productClass=SITC\&startYear=undefined\&target=Product\&year=2016 (accessed May 17, 2018).

Heinimann, A., O. Mertz, S. Frolking, A. E. Christensen, K. Hurni, F. Sedano, L. P. Chini, R. Sahajpal,M. Hansen, and G. Hurtt. 2017. "A Global View of Shifting Cultivation: Recent, Current, and Future Extent." PLOS ONE 12: e0184479. https://doi.org/10.1371/journal.pone.0184479.

Hoare, A. 2015. Tackling Illegal Logging and the Related Trade. London: Chatham House.

Hong, E. 2017. "Scaling Struggles over Land and Law: Autonomy, Investment, and Interlegality in Myanmar's Borderlands." Geoforum 82: 225-236. https://doi.org/10.1016/j.geoforum.2017.01.017.

Hougen, H. P., H. D. Petersen, J. Lykke, M. Mannstaedt, and B. Ussing. 2000. "Death and Injury caused by Land Mines in Burma." Science and Justice 40: 21-25. https://doi.org/10.1016/S13550306(00)71929-0.

IASC (Inter-Agency Standing Committee) and European Commission. 2019. (accessed February 25, 2019)

http://www.informindex.org/Portals/0/InfoRM/2019/Inform\%202019\%20WEB\%20spreads\%20(3).pdf?ver=201 9-02-07-113610-123.

Irrawaddy. 2019. '143,000 Tons of trafficked timber seized' https://www.irrawaddy.com/news/burma/143k-tons-trafficked-timber-seized-3-years.html

KCSN. 2018. Analysis-Paper - Ongoing Burma Army Logging Threatens Peace Efforts in Karenni State.

Kenney-Lazar, M., G. Wong, H. Baral, and A. J. M. Russell. 2018. “Greening Rubber? Political Ecologies of Plantation Sustainability in Laos and Myanmar." Geoforum 92: 96-105. https://doi.org/10.1016/i.geoforum.2018.03.008.

Khaine, I., S. Y. Woo, M. Kwak, S. H. Lee, S. M. Je, H. You, T. Lee, J. Jang, H. K. Lee, H. C. Cheng, J. H. Park, E. Lee, Y. Li, H. Kim, J. K. Lee, and J. Kim. 2018. "Factors Affecting Natural Regeneration of Tropical Forests across a Precipitation Gradient in Myanmar." Forests 9: 143. https://doi.org/10.3390/f9030143.

KNU (Karen National Union). 2015a. Forest Policy - Karen National Union [WWW Document]. http://karennationalunion.net/index.php/burma/departments/forestry (accessed July 11, 2018). 
-- - 2015b. Land Policy - Karen National Union.

KWAT. 2018. "Burma Army Commits War Crimes against Kachin IDPs: Blocking Access to Refuge, Using as Human Shields and Minesweepers, Indiscriminate Shelling, Looting | Kachin Women's Association Thailand." http://kachinwomen.com/burma-army-commits-war-crimes-againstkachin-idps-blocking-access-refuge-using-human-shields-minesweepers-indiscriminateshelling-looting/ (accessed July 14, 2018).

Leimgruber, P., Kelly, D.S., Steininger, M.K., Brunner, J., Müller, T., Songer, M., 2005. Forest cover change patterns in Myanmar (Burma) 1990-2000. Environmental Conservation 32, 356-364. https://doi.org/10.1017/S0376892905002493

Lim, C. L., G. W. Prescott, J. D. T. De Alban, A. D. Ziegler, and E. L. Webb. 2017. "Untangling the Proximate Causes and Underlying Drivers of Deforestation and Forest Degradation in Myanmar: Forest Degradation in Myanmar." Conservation Biology 31: 1362-1372. https://doi.org/10.1111/cobi.12984.

LIOH. 2015. Destroying People's Lives:The Impact of Land Grabbing on Communities in Myanmar. Yangon: Land In Our Hands Network.

Liu, J. 2016. "Economic Contribution of Non-timber Forest Products (NTFPs) to Rural Livelihoods in the Tharawady District of Myanmar." International Journal of Sciences 2: 12-21. https://doi.org/10.18483/iiSci.904.

Lin, T., K. T. Htun, D. Gritten, and A. Martin. 2019. "Contribution of Community Forestry to Climate Change Adaptation: Examples from the Dry Zone of Myanmar." Paper submitted to International Forestry Review.

Macintosh, D. J. 2016. Meinmahla Kyun Wildlife Sanctuary Conservation Programme. Yangon: FFI. Forestry Report of an Advisory Mission. IIED/FFF/Forest Connect.

Mandle, L., N. Bhagabati, H. Helsingen, P. Hamel, R. Bartlett, A. Dixon, R. Horton, C. Lesk, D. Manley, M. De Mel, D. Bader, S. Myint, W. Myint, and M. Mon. 2017. "Assessing Ecosystem Service Provision Under Climate Change to Support Conservation and Development Planning in Myanmar." PLoS ONE 12 (9): e0184951.

Maraseni, T. N., N. Bhattarai, B. S. Karky, T. Cadman, N. Timalsina et al. 2019. "An Assessment of Governance Quality for Community-based Forest Management Systems in Asia: Prioritisation of Governance Indicators at Various Scales." Land Use Policy 81: 750-761.

Mehta, L., G. J. Veldwisch, and J. Franco. 2012. "Water Grabbing? Focus on the (Re)appropriation of Finite Water Resources." Water Alternatives 5: 15.

Milton, A. H., M. Rahman, S. Hussain, C. Jindal, S. Choudhury, S. Akter, S. Ferdousi, T. A. Mouly, J. Hall,and J. T. Efird. 2017. "Trapped in Statelessness: Rohingya Refugees in Bangladesh." International Journal of Environmental Research and Public Health 14: 942. https://doi.org/10.3390/ijerph14080942.

Ministry of Forestry. 1995. Myanmar Forest Policy.

Ministry of Health, Department of Traditional Medicine. n.d. Medicinal Plants Of Myanmar. Yangon: Ministry of Health.

Ministry of Information. 2017. Pyidaungsu Accord.

Ministry of Planning and Finance. 2016. Myanmar Statistical Yearbook 2016. Nay Pyi Taw: Government of the Republic of the Union of Myanmar.

Moe Aung, M. 2017. "Myanmar Ponders Ways to Make Bamboo Forests More Profitable." The Myanmar Times.

MOECAF (Ministry of Environmental Conservation and Forestry). 2011a. Forestry in Myanmar. 
--- 2015. Myanmar National Biodiversity Strategic Action Plan 2015-2020. Nay Pyi Taw: MOECAF.

Ministry of Hotels and Tourism. 2019. Myanmar Tourism Statistics 2018. https://tourism.gov.mm/wpcontent/uploads/2019/08/Myanmar-Toursim-Statistics-2018.pdf

Mon, M. S., N. Mizoue, N. Z. Htun, T. Kajisa, and S. Yoshida. 2012. "Factors Affecting Deforestation and Forest Degradation in Selectively Logged Production Forest: A Case Study in Myanmar." Forest Ecology and Management 267: 190-198. https://doi.org/10.1016/i.foreco.2011.11.036.

Mongabay Environmental News, October 26, 2017. Burning down the House: Myanmar's Destructive Charcoal Trade Emmanuel Freudenthal. https://news.mongabay.com/2017/10/burningdown-the-house-myanmars-destructive-charcoal-trade/

Mongabay Environmental News, April 18, 2019. Illegal Charcoal Trade Threatens Myanmar's Remaining Mangroves. Wudan Yan. https://news.mongabay.com/2019/04/illegal-charcoaltrade-threatens-myanmars-remaining-mangroves/

MoNREC (Ministry of Natural Resources and Environmental Conservation). 2018. Forest Reference Emission Level (FREL) of Myanmar (Submission to UNFCCC). Nay Pyi Taw.

MoNREC (Ministry of Natural Resources and Environmental Conservation)/IUCN/Mangroves for the Future. 2016. National Strategy and Action Plan (Coastal Zone and Mangroves). Nay Pyi Taw: MONREC.

MRBEA (Myanmar Rattan and Bamboo Entrepreneurs Association). 2015. Myanmar Bamboo Sector Competitiveness Study. Yangon: MRBEA.

Myanmar Environmental Rehabilitation-conservation Network (MERN). 2015. Project for Coastal Livelihood and Environmental Assets Restoration in Rakhine (CLEARR) Final Report. Yangon: MERN.

Myanmar Peace Monitor. n.d. Ethnic Grievances [WWW Document]. http://mmpeacemonitor.org/background/ethnic-grievances (accessed May 17, 2018).

Myanmar Extractive Industries Transparency Initiative (MEITI) Report for the Period April 2015-March 2016, Forestry Sector. MEITI 2019.

Myanmar Extractive Industries Transparency Initiative (MEITI) Fourth EITI report for the fiscal year 2017/18, Forestry Sector. MEITI 2000.

Myat Moe Aung. 2018. "Govt Allows Exports of Raw Timber Produced in Private Plantations." The Myanmar Times, July 9, 2018.

Myint Aung, U. 2007. "Policy and Practice in Myanmar's Protected Area System." Journal of Environmental Management 84: 188-203. https://doi.org/10.1016/j.jenvman.2006.05.016.

National Reconciliation and Peace Centre. 2017. 27 points signed as part of Pyidaungsu Accord. http://www.nrpc.gov.mm/en/node/226

NEPCon. 2013. Myanmar Forest Legality Analysis. Copenhagen: NEPCon.

Nijman, V., and C. R. Shepherd. 2015. "Trade in Tigers and Other Wild Cats in Mong La and Tachilek, Myanmar - A Tale of Two Border Towns." Biological Conservation 182: 1-7. https://doi.org/10.1016/j.biocon.2014.10.031.

Nijman, V., M. X. Zhang, and C. R. Shepherd. 2016. "Pangolin Trade in the Mong La Wildlife Market and the Role of Myanmar in the Smuggling of Pangolins into China." Global Ecology and Conservation 5: 118-126. https://doi.org/10.1016/j.gecco.2015.12.003. 
Phelps, J., and E. L. Webb. 2015. “'Invisible' Wildlife Trades: Southeast Asia's Undocumented Illegal Trade in Wild Ornamental Plants." Biological Conservation 186: 296-305. https://doi.org/10.1016/j.biocon.2015.03.030.

Prescott, G. W., W. J. Sutherland, D. Aguirre, M. Baird, V. Bowman, J. et al. 2017. "Political Transition and Emergent Forest-Conservation Issues in Myanmar." Conservation Biology 31: 1257-1270. https://doi.org/10.1111/cobi.13021.

Raitzer, D., Samson, J.N., Nam, K.-Y. 2015. Achieving Environmental Sustainability in Myanmar (SSRN Scholarly Paper No. ID 2709328). Social Science Research Network, Rochester, NY.

REACH. 2015. A Socio-ecological Assessment of Mangrove Areas in Sittwe, Pauktaw, Minbya and Myebon Townships, North Rakhine State. Assessment Report. REACH, Geneva, Switzerland. http://www.reachresourcecentre.info/system/files/resourcedocuments/myanmar_sea_report_nov2015.pdf

RECOFTC. 2018. Scaling Up Community Forestry in Myanmar (SUComFor). Final Report. RECOFTC - The Center for People and Forests. Bangkok, Thailand.

Richards, D. R., and D. A. Friess. 2016. "Rates and Drivers of Mangrove Deforestation in Southeast Asia, 2000-2012." PNAS 113: 344-349. https://doi.org/10.1073/pnas.1510272113.

Romijn, E., C. B. Lantican, M. Herold, E. Lindquist, R. Ochieng, A. Wijaya, D. Murdiyarso, and L. Verchot.2015. "Assessing Change in National Forest Monitoring Capacities of 99 Tropical Countries." Forest Ecology and Management, Changes in Global Forest Resources from 1990 to 2015 352: 109-123. https://doi.org/10.1016/i.foreco.2015.06.003.

Rustad, S. C. A., J. K. Rød, W. Larsen, and N. P. Gleditsch. 2008. "Foliage and Fighting: Forest Resources and the Onset, Duration, and Location of Civil War." Political Geography 27: 761-782. https://doi.org/10.1016/i.polgeo.2008.09.004.

RRI. 2015. "Who Owns the World's Land?" Rights \& Resources Initiative, Washington D.C.

Sampson, C., J. McEvoy, Z. M. Oo, A. M. Chit, A. N. Chan, D. Tonkyn, P. Soe, M. Songer, A. C. Williams, K. Reisinger, G. Wittemyer, and P. Leimgruber. 2018. "New Elephant Crisis in Asia-Early Warning Signs from Myanmar." PLOS ONE 13: e0194113. https://doi.org/10.1371/journal.pone.0194113.

Saw, A .A., and M. Kanzaki. 2015. "Local Livelihoods and Encroachment into a Mangrove Forest Reserve: A Case Study of the Wunbaik Reserved Mangrove Forest, Myanmar." Procedia Environmental Sciences, The 5th Sustainable Future for Human Security (Sustain 2014) 28: 483-492. https://doi.org/10.1016/i.proenv.2015.07.058.

Sein Win Tun, K., J. Di Stefano, and L. Volkova. 2016. "Forest Management Influences Aboveground Carbon and Tree Species Diversity in Myanmar's Mixed Deciduous Forests." Forests 7: 217. https://doi.org/10.3390/f7100217.

Shimizu, K., O. S. Ahmed, R. Ponce-Hernandez, T. Ota, Z. C. Win, N. Mizoue, and S. Yoshida, S. 2017. "Attribution of Disturbance Agents to Forest Change Using a Landsat Time Series in Tropical Seasonal Forests in the Bago Mountains, Myanmar." Forests 8: 218. https://doi.org/10.3390/f8060218.

Shyamsundar, P., S. AhIroth, P. Kristjanson, and S. Onder. n.d. Understanding Forests' Contribution to Poverty Alleviation: A Framework for Interventions in Forested Areas. Policy Research Working Paper 8462, World Bank Group, Washington, DC.

Smith, M. 2011. State of Strife: The Dynamics of Ethnic Conflict in Burma, Policy Studies. East-West Centre, Washington, DC. 
Smithsonian Institute. 2003. A Checklist of the Trees, Shrubs, Herbs, and Climbers of Myanmar. Contributions from the United States National Herbarium. Washington, DC: Smithsonian Institute.

Sovacool, B. K. 2013. "Confronting Energy Poverty behind the Bamboo Curtain: A Review of Challenges and Solutions for Myanmar (Burma)." Energy for Sustainable Development 17: 305-314. https://doi.org/10.1016/i.esd.2013.03.010.

Springate-Baginski, O. 2017. "Rethinking Shifting Cultivation in Myanmar: Policies for Sustainable Upland Livelihoods and Food Security." (pp. 226-241) In Shifting Cultivation Policies: Balancing Environmental and Social Sustainability, edited by Malcom Cairns. Wallingford: CABI.

Springate-Baginski, O., and M. M. Than. 2011. Community Forestry in Myanmar: Some Field Realities. Yangon: ECCDI/UEA.

Springate-Baginski, O., A. K. Thein, A. Neil, W. M. Thu, and F. Doherty. 2014. "Democratising Timber: An Assessment of Myanmar's Emerging 'Forest Law Enforcement, Governance and Trade' (FLEGT) Process." Forest Policy and Economics. https://doi.org/10.1016/i.forpol.2014.09.004.

Sunderland, T., R. Achdiawan, A. Angelsen, R. Babigumira, A. Ickowitz, F. Paumgarten, V. Reyes-García, and G.Shively. 2014. Challenging Perceptions about Men, Women, and Forest Product Use: $A$ Global Comparative Study. World Development, Forests, Livelihoods, and Conservation 64, S56-S66. https://doi.org/10.1016/i.worlddev.2014.03.003.

Swiss Reinsurance Company Ltd. 2009. "Natural catastrophes and man-made disasters in 2008: North America and Asia suffer heavy losses" p. 24. https://www.preventionweb.net/files/8841 Sigma22009e.pdf.

Tantipisanuh, N., T. Savini, P. Cutter, and G. A.Gale. 2016. "Biodiversity Gap Analysis of the Protected Area System of the Indo-Burma Hotspot and Priorities for Increasing Biodiversity Representation." Biological Conservation 195: 203-213. https://doi.org/10.1016/j.biocon.2015.12.043.

Tint, K., O. Springate-Baginski, and M. K. K. Gyi. 2011. Community Forestry in Myanmar:Progress and Potentials. Yangon: ECCDI/UEA.

Tint, K., O. Springate-Baginski, D. Macqueen, and M. K. K. Gyi. 2014. Unleashing the Potential of Community Forest Enterprises in Myanmar. Edinburgh: International Institute for Environment and Development.

TNI (TransNational Institute). 2017. Beyond Panglong: Myanmar's National Peace and Reform Dilemma (Myanmar Policy Briefing series). TNI, Amsterdam/Yangon.

Tordoff, A. W., M. R. Bezuijen, J. W. Duckworth, J. R. Fellowes, K. Koenig, E. H. B. Pollard, and A. G. Royo.2011. Ecosystem Profile - Indo-Burma Biodiversity Hotspot. Washington, DC: Critical Ecosystem Partnership Fund.

Treue, T., O. Springate-Baginski, and K. Htun. 2016. Legally and Illegally Logged Out: An Analysis of Land Use Change in Myanmar's Forest Sector. Yangon: ALARM/EcoDev.

The Asia Foundation. 2017. "The Contested Areas of Myanmar." The Asia Foundation, Yangon.

UN Comtrade. 2018. International Trade Statistics [WWW Document]. https://comtrade.un.org/data (accessed May 17, 2018).

UNDP (United Nations Development Program). 2013. A Regional Perspective on Poverty in Myanmar. Yangon: UNDP.

Unocha, V. 2018. Myanmar Humanitarian Needs Overview. Yangon: UN Humanitarian Team.

UNODC. 2015. Criminal Justice Response to Wildlife and Forest Crime in Myanmar - A Rapid Assessment. United Nations Office on Drugs and Crime. 
Vicol, M., B. Pritchard, and Y. Y. Htay. 2018. "Rethinking the Role of Agriculture as a Driver of Social and Economic Transformation in Southeast Asia's Upland Regions: The View from Chin State, Myanmar." Land Use Policy 72: 451-460. https://doi.org/10.1016/j.landusepol.2018.01.009.

Webb, E. L., N. R. A. Jachowski, J. Phelps, D. A. Friess, M. M. Than, and A. D. Ziegler. 2014. "Deforestation in the Ayeyarwady Delta and the Conservation Implications of an Internationally-engaged Myanmar." Global Environmental Change 24: 321-333. https://doi.org/10.1016/i.gloenvcha.2013.10.007.

Weber, S. J., L. Keddell, and M. Kemal. 2014. Myanmar Ecological Forecasting: Utilizing NASA Earth Observations to Monitor, Map, and Analyze Mangrove Forests in Myanmar for Enhanced Conservation. Hampton: NASA.

Whittle, M. J. 2017. Evaluation of the Dry Zone Greening Department 1997-2017. Nay Pyi Taw: DZGD.

Win, Z. C., N. Mizoue, T. Ota, T. Kajisa, S. Yoshida, T. N. Oo, and H. Ma. 2018. "Differences in Consumption Rates and Patterns between Firewood and Charcoal: A Case Study in a Rural Area of Yedashe Township, Myanmar." Biomass and Bioenergy 109: 39-46. https://doi.org/10.1016/j.biombioe.2017.12.011.

Woods, K. 2010. Community Forestry in Cease-Fire Zones in Kachin State, Northern Burma: Formalizing Collective Property in Contested Ethnic Areas. Siem Reap: CAPRi.

-- - 2013. Timber Trade Flows and Actors in Myanmar: The Political Economy of Myanmar's Timber Trade. Washington DC: Forest Trends.

World Bank Group. 2015. Myanmar Empowering People for Inclusive Growth: Myanmar Country Partnership Framework for the Period 2015-2017. World Bank. https://doi.org/10.1596/23129.

World Bank. 2017. An Analysis of Poverty in Myanmar. Yangon.

-- - 2018. "Myanmar Economic Monitor: Navigating Risks (English).” Myanmar Economic Monitor. Washington, DC: World Bank Group.

---. 2019. Myanmar Country Environmental Analysis - Forestry Resources Report. Washington, DC: World Bank Group.

- - - 2019. Myanmar Country Environmental Analysis - Assessing the Opportunities for Scaling up Community Forestry and Community Forestry Enterprises in Myanmar. Washington, DC: World Bank Group.

- - - 2020. An Assessment of Forest Tenure in Myanmar: Securing Forest Tenure for Sustainable Livelihoods. Washington, DC: World Bank Group.

- - . 2020. Incentivising Sustainable Private Sector Investment in Timber Plantations in Myanmar. Washington, DC: World Bank Group.

- - . 2020. Myanmar Woodfuels Sector Assessment. Washington, DC: World Bank Group.

WTTC (World Travel \& Tourism Council). 2019. Myanmar: Annual Research: Key Highlights. https://wttc.org/Research/Economic-Impact

WWF (World Wild Fund for Nature). 2016. "Capturing the Value of Nature: Advancing Natural Capital Accounting in Myanmar." WWF Myanmar, Yangon.

Zhang, M., A. Gouveia, T. Qin, R. Quan, and V. Nijman. 2017. "Illegal Pangolin Trade in Northernmost Myanmar and its Links to India and China." Global Ecology and Conservation 10: 23-31. https://doi.org/10.1016/i.gecco.2017.01.006. 
Zin, W. Y. L., P. Teartisup, and P. Kerdseub. 2019. "Evaluating Traditional Knowledge on Climate Change (TKCC): A Case Study in the Central Dry Zone of Myanmar." Environment and Natural Resources Journal 17: 1-29. https://doi.org/10.32526/ennri.17.2.2019.09. 


\section{ANNEX 1: ASSESSMENT OF FOREST TENURE}

\section{Methodology}

The Myanmar Forest Tenure Assessment was undertaken by the FD of MoNREC between September 2019 and February 2020 to help consolidate understanding of how forest tenure reforms have progressed in Myanmar, and to outline an improved approach and policy roadmap to strengthen forest tenure. The team made use of the global Forest Tenure Assessment framework that was developed by the World Bank's Program on Forests (PROFOR). The assessment consisted of four phases: (i) Review and revision of the global Forest Tenure Assessment framework to match the country context; (ii) Review of existing research; (iii) Regional and national multi-stakeholder consultation workshops with civil society organizations and government representatives; and (iv) finalization of the report. The assessment was structured around six key themes; of which the main findings are summarized below.

\section{Background}

In 2020, Myanmar completed a decade of historic transition. Since 2011, simultaneous transformations have been taking place in the country's institutional, land, and forest governance structures, reforming its economic, political, and social spaces and seeking peaceful solutions to civil conflicts and the long-running demand for tenurial reforms. These shifts are part of a well-negotiated long-term process, and progress includes adoption of the National Land Use Policy (NLUP, 2016), new Forest Law, and Conservation of Biodiversity and Protected Areas (CBPA) Law (2018). However, several reform measures have been widely contested, as rural people continue to demand protection and recognition of customary tenure and shifting cultivation practices.

Community-based forest tenure prevails across the country. Historically, rights to land and forest resources were embedded in the social structure and governed by customary traditions. Customary tenure remains the dominant form of de facto access to and use of forest land and resources across Myanmar. Most locally accepted customary systems allow for a complex mix of individual, family, and community tenures, even in urban and peri-urban areas. More than half of all landholdings are held without formal titles or certificates, in accordance with customary practices. ${ }^{35}$ However, the actual areas occupied/used/accessed largely remain unmapped, un-demarcated, un-quantified, and most frequently, unprotected, with encroachment and 'illegal uses' reported in all areas.

Ongoing peace negotiations include seeking agreement between the Union Government and EAOs on power-sharing agreements and division of responsibilities over forest land and natural resource governance. For ethnic groups and EAOs, building a stronger 'independent, stand-alone' tenureadministration system (both for forest and non-forest) is desirable and consistent with their political pursuit of local autonomy under the proposed federalist structure. In contrast, the Union Government sees replacing local systems with a unified national system as a path towards unification. It has been argued that neither position, however, would bridge the gaps in tenure security.

A complex set of laws regulates forest tenure in Myanmar. The Forest Law and the CBPA Law are the primary legislation regulating forests in Myanmar. Forested land outside the PFE is under the administration of other laws and ministries, most often the VFV Land Law (2018), while the forests and forests products are regulated by MoNREC under the Forest Law. MoNREC further regulates and limits use rights to national and regional lists of 'reserved species', including teak.

\footnotetext{
35 There is no formal or reliable data available. However, field research completed by different institutions have generated 'proxy' data on which this estimate was based. In Myanmar, almost 50\% of privately held land parcels (excluding concessions and leases) are categorized as "customary rights" and include households residing inside or outside forest areas, where social traditions guide land tenure arrangements. In many rural areas, inheritance and sub-divisions are not registered but informally held.
} 
Since 2010, the GoM has revised its forest land and resource policies, laws, guidelines, and regulations to provide greater recognition of tenure security, including protection of rights of ethnic communities and women [Farmland Law, 2012; NLUP 2016; Mines Law of 2015; Myanmar Investment Law 2015; Forest Law 2018; CBPA Law 2018; Land Acquisition, Resettlement and Rehabilitation Law of 2018, revised CFIs of 2016 (further amended in 2019)]. In addition, it established the NLUP Council (2018) to move forward on broader sectoral agenda. These initiatives aim to generate economic and social gains and incentivize sustainable forest use and management.

\section{Findings}

Theme 1: Policy and legal context and environment for improving forest tenure. As stated above, Myanmar's forest land and resource policy/regulatory framework has multiple overlapping regulations and guidelines, creating ambiguous, often contradictory provisions. These create administration and management systems with overlapping authority and jurisdictions for governing forest tenure in PFE and non-PFE areas. That said, Myanmar's forest policy is gradually shifting from promoting trade in forest products to balancing sustainable production of forest products with addressing tenure rights, biodiversity, and climate change. Despite efforts at national-level governance, traditional community-based traditions and practices in tenure management continue to guide forest tenure. Further, the absence of a uniform land and land-use classification system has created numerous challenges in confirming the tenurial rights of communities and in allocating land for development. The control, management, and ownership of land and natural resources are central to peace negotiations, power sharing between states/regions and union governments, and federalism.

Theme 2: Institutional arrangements for administering/managing/governing forest tenure. Myanmar's forest land and resource governance is characterized by multiple agencies with similar or overlapping mandates and responsibilities. These imprecise institutional arrangements have led to a perennial struggle between local communities, local leaders, and government officials, as communities continue to manage their resources through customary practices, and the government attempts to enforce formal laws. Revision of laws means both the legal framework for the forestry sector and implementation procedures are in flux, as enforcement of legal instruments is awaiting the adoption of rules for the Forest and CBPA Laws. Weak governance frequently leads to 'conflict of interest' in administering natural resources. In addition, women are underrepresented both in community institutions and in committees established by government mechanisms, despite the NLUP recognizing the importance of female representation, as customary land governance follows socially defined practices, and community institutions related to land and resources are largely represented by men.

Theme 3: Exercising rights to forest land and resources. There are several categories under which rights to access and use forest land and resources are granted: (a) limited-period permits are granted for using land for development and production/extraction; (b) forest land is 'encroached' by communities or investors (probably using force or political authority) without due process or compensation; or (c) land is accessed, used, or acquired through a largely faulty process. Clarifying forest tenure is thus important to ensure that local and ethnic communities can access vital livelihood resources. It is equally important to understand forest tenure types, formal and informal. Different government entities have issued several types of land-use permits for agricultural development, plantations, and mining operations. Many small-scale plantations and mining operations have no formal document, but operate on locally understood traditions and practices. Only permits/grants are registered whereas other types of informal or quasi-formal forest tenure are not well registered and secured. Access and land holding rights for customary holdings are recorded only at community levels, but there is no standard, no update, and no harmonization of data with other overall forest land use. In the absence of an integrated land register for each village or group of villages, it is difficult to monitor ongoing land-use and protect and manage resources sustainably. Formal mapping standards and procedures are heavily tilted towards State engagement. The Farmland Law, VFV Law, and CFIs assign responsibilities for mapping and surveying to different government departments. On the other 
hand, participatory land-use mapping is gradually gaining acceptance at the community level but still lacks formal recognition. The government has acknowledged that participatory mapping allows early recording and rudimentary analysis of rights and their links to tenure as local residents are engaged in mapping customarily held lands.

Theme 4: Forest tenure data/records management. Most FD inventories on concessions (or mining) provide only limited information. Data on permits and grants is primarily based on information extracted from relevant agreements or contracts, and therefore only has details from the time of signing the concession. Approved licenses are usually stored in (often not centralized) paper-based archives. The current land-information system lacks reliable and updated land information, and access to it is limited. At present, at least seven different government agencies are involved in mobilizing data on forest land and tenure-related aspects. There is no 'mining cadaster' in place, and permits for mining minerals, gemstones, and construction materials are independently processed and issued; data is manual and paper-based and details on permits issued are maintained via an MS Excel file. With no prudent IT-based license management system in place, reliable data on updates and changes are difficult to obtain. However, in recent years, the government has taken several steps to adopt modern technology and develop geospatial infrastructure and services in Myanmar. This vision and priority are broadly framed in NLUP and the e-Governance Master Plan (eGMP 2016-2020).

Theme 5: Modes/mechanisms to resolve grievances, disputes and conflicts over forest tenure. Although land is always the central and obvious conflict issue, it often disguises other political-societal conflicts. Disputes related to forest tenure are often difficult to resolve and could trigger further social instability. Conflict over the control of land and natural resources is particularly pressing in Myanmar's resource-rich ethnic territories and along its borders with China and Thailand. Policy and legal provisions for dispute resolutions are complex, characterized by legal pluralism with a wide range of justice providers, different co-existing legal systems, and varied justice perceptions, and accessible and affordable formal dispute-resolution mechanisms are lacking. Myanmar has multiple authorities to adjudicate disputes over forest land and resources, but most disputes remain unresolved. Formal dispute-resolution mechanism is limited to administrative arrangements. Available data (along with field reports) show that only a small number of disputes reach administrative bodies and even fewer cases reach the judiciary. Trust, familiarity, and shared identity form the basis for communitymediation in forest tenure disputes. Community-based dispute resolution has existed for long in Myanmar and is still the preferred modality for managing and resolving conflict in rural areas, maintaining harmony within the community, and establishing and maintaining security. There is no referral and appeal system between community-level mechanisms and official courts. In formal terms, the law stipulates that leaders at community or village/ward level should collaborate with local authorities in information gathering and judicial processes in case of disputes reviewed and adjudicated by courts. However, these provisions are not institutionalized and resourced.

Theme 6: Public participation, social inclusion, and safeguards. The assessment has brought forward a general perception that current instruments such as the Environmental Impact Assessment/Social Impact Assessment (EIA/SIA) are unable to provide accessible, affordable, real, and achievable safeguards to protect communities' tenurial rights. Over the years, state-connected land acquisition has often failed to keep promises, sometimes even reducing real access to fair compensation for those with tenurial claims. The newly adopted Forest Law and relevant regulations have yet to elaborate guidelines to protect 'safeguards' provisions for tenure security of local and ethnic communities and informal settlers. In addition, there is no clear provision to account for non-market values such as social, cultural, religious, spiritual, and environmental values. In support of the Land Acquisition, Resettlement, and Rehabilitation Act of 2019, enforceable procedures and guidelines in case of expropriation remain to be developed. The Law therefore needs to strike an important balance between protecting landowner and land-user rights, and ensuring an effective and equitable process for compulsory acquisition in the public interest. There has been progress in protecting and recognizing women's rights to forest land and resources, but enforcement is still lacking. The 
Constitution of 2008 includes the guarantee of equal rights and legal protection to all persons, men and women (Article 347). Similar affirmative provisions have been made in NLUP and other regulatory frameworks. However, widespread lack of awareness of the policy and regulatory frameworks across ministries and communities still challenges universal implementation and continue to deny women many of the fruits of Myanmar's formal commitments to participation, equality, and access to rights.

\section{Recommendations}

The assessment demonstrates that protection and recognition of forest tenure rights is critical if forest-dependent communities are to play an increasingly important role in forest and biodiversity preservation. Such a measure will also enable regulated use of forest resources and respect for customary and traditional practices and laws. The assessment also recognizes some pro-people and pro-reforms work done by the GoM and its agencies. It is almost impossible to achieve forest management (economic, environment, and social) objectives without dealing with policy and capacity gaps, and without involving local communities in the protection and management of forests. Most importantly, the government and other stakeholders should recognize the role of the community in protection and management of national forests.

To address the above-mentioned challenges, the assessment concludes with the following recommendations for government, civil society, and development partners, urging all actors to involve local and ethnic communities in all processes:

Adopt and enforce a comprehensive policy and legal framework as the first and critical step in reforming forest tenure. The government should be encouraged to reiterate its commitment to implement a comprehensive legal framework that protects tenure security and promotes equal access to tenure for local and ethnic communities, women, the rural poor, and other socially vulnerable groups. This in turn will promote the protection of rights to forest land and resources.

Mainstream forest tenure of local and ethnic communities. The government should initiate systematic strategies to safeguard and promote the rights of forest-dependent communities to land and resources in forest areas in the most cost-efficient and effective manner.

Engage all stakeholders and political leadership in the implementation of forest tenure reforms, to ease the shift from isolated measures to coordinated governance strategies. The establishment of a network of civil society and community leaders, under government responsibility, will play such a role and keep the track of reform implementation.

Improve local capacities (of government, community and civil society actors) to gather information on forest land holding patterns and socio-cultural factors affecting them. Sufficient information must be gathered on pre-existing use and ownership conditions. A thorough classification and analysis of available information could help enhance local and ethnic communities' claims on forest land and resources.

Development partners are urged to support (i) Capacity building to enable government (union and states/regions and local authorities) and local communities to engage in a dialogue on forest land and resource administration and management; (ii) Strengthening of national research capacities and public and independent expertise likely to contribute to knowledge of the issues at stake and policy formulation and monitoring; and (iii) Initiatives to debate forest land and resource tenure policies, using inclusive approaches to do so. 


\section{ANNEX 2: ASSESSMENT OF ENABLING CONDTIONS FOR PRIVATE PLANTATIONS}

\section{Methodology}

This study was commissioned by the World Bank to examine the need to increase commercial forest plantation establishment in Myanmar. It assessed the opportunities and constraints that result from the current policy environment, and presents options and approaches that should be considered with the aim of incentivizing a significant increase in private sector investment. The policy and investment recommendation derive from interviews with the FD, key stakeholders, and from a workshop with private and public entities including NGOs.

\section{Myanmar's reforestation strategy}

In Myanmar, a minimum plantation area of $\mathbf{2}$ million ha is required to meet domestic wood demand. This would be sufficient to meet a total roundwood demand of 45 million $\mathrm{m}^{3}$ of fuelwood and industrial wood, assuming a conservative annual growth rate of $15 \mathrm{~m}^{3}$ per ha, continued souring of some woodfuel from natural forests, old rubber plantations and farm trees, and no timber export.

Much of Myanmar's denuded or degraded forest is suitable for establishing timber plantations, either as commercial plantations or through CF. However, more than half of the 1 million ha of plantations established through past efforts are reported to have failed due to lack of resources for protection and maintenance.

The Government aims to restore or reforest about 884,000 ha on RF and PPF land under the MRRP. The bulk of this - about 312,000 ha - will be through CF, some of which is expected to involve tree planting for commercial use. The MRRP also includes establishment of around 226,500 ha of commercial plantations, to which the private sector is expected to contribute more than half. However, progress has been slow, and after three years of implementation, less than 13 percent of the overall plantation target and less than 10 percent of the private plantation targets have been met. Reported progress with CF is somewhat better, with CF certificates issued covering about 63,800 ha 20 per cent of the target area. This does not necessarily equate to reforestation or restoration, however, and efforts are constrained by current government capacity, lack of defined delivery mechanisms to support development, and weak links to markets for CF produce.

There are opportunities for the private sector to help address CF constraints by assisting farmers to establish plantations, providing quality planting material and technical advice, and guaranteeing markets or providing market links for both timber and non-timber forest products. Advantages to private sector entities from such arrangements include augmenting their own raw material supplies and reducing potential conflicts and consequent damage to their plantations.

The Government has prepared a draft strategy to increase reforestation that recommends four strategic areas for action: (i) creating enabling conditions - necessary institutions, policies, laws, instructions and procedures; (ii) establishing responsible institutional participation structures; (iii) developing benefit-sharing systems; and (iv) ensuring sustainable financing mechanisms. These are essential elements in framing a commercial plantation strategy and creating favorable conditions for private sector investment.

There are two categories of State-owned land available for establishing private sector forest plantations or community forests: forest land, which includes RF and PPF, and VFV land. The terms of private sector leases vary depending on the size of area and the species planted, with special conditions for teak. Areas between 100 acres and the maximum of 1,000 acres (40.5- $405 \mathrm{ha}$ ) are subject to competitive tender. For VFV land, up to 3,000 acres (1,214 ha) can be leased, after excluding areas with remaining good forest and those occupied by farming 
There is interest in investments from private companies, but to tap into the full potential, policy reforms will need to be considered. Current and potential investors list a range of constraints to increased investment. These include: (i) availability of large contiguous blocks of land within RF, or lack of access to such areas; (ii) land tenure issues, especially informal occupation of forest land for farming; (iii) perception of difficulty of doing business; (iv) complicated procedures to acquire land and to harvest, transport, ship, process and trade timber; $(v)$ insufficient government staff able to promote and support forest sector investment; (vi) lack of enforcement capacity to prevent encroachment and illegal logging in plantation areas; (vi) lack of finance; and (vii) widespread availability of illegal timber, which depresses log prices and reduces demand for plantation-grown timber.

Other investor requirements relate to location of areas close to potential processing sites and transport infrastructure linked to export facilities, free choice of joint venture partners, and the ability to repatriate profits or capital on exit. To provide early income, acquisition of management rights to existing timber resources, in combination with new plantations, is likely to be more attractive than starting plantations on greenfield sites.

\section{Proposed interventions}

Myanmar could explore a wider range of possible plantation models or combinations of models, to attract sustainable investments:

a) Establishment of greenfield plantations on leased denuded or degraded RF land (current model);

b) Establishment of greenfield plantations on leased denuded or degraded VFV land, or conversion of VFV land currently under agricultural crops to timber plantations (also currently practiced);

c) Management leases, including timber harvest rights, for existing government-owned plantations (including degraded or failed plantations) in combination with new plantation establishment on adjacent RF land; and

d) Management leases, including timber harvest rights, for natural forest in RF or VFV land in combination with new plantation establishment on adjacent RF and VFV land.

In all cases, arrangements with local communities and/or farmers are likely to be necessary to reduce the potential for conflicts, encroachment, and timber theft. These could include support for and commercial arrangements with local community-based forestry enterprises on adjacent RF or VFV land, contract tree growing with farmers on nearby private land, or establishing tree rows at wide spacings and allowing intercropping between rows - also possibly incorporating sharing the proceeds from the harvested timber.

A range of external finance sources could be considered. These include:

a) Equity finance in joint ventures or partnerships with local companies, from foreign institutional and industrial investors, including international investment funds and DFIs;

b) Loan financing to private investors, including through DFIs; and

c) Multilateral development bank loans to the government, routed to investors through local stateowned banks.

A blend of different financing sources is possible. International climate funds, voluntary carbon markets, and investments funds to support green businesses are other interesting options to explore.

There is a need to develop and implement a coherent action plan to develop a sustainable commercial plantation strategy, including policy reforms, investment incentives, infrastructure, finance and trade aspects. Categorizing the changes needed as follows could be considered:

a) Those that can be made by decision at the departmental level within existing capacity and through issuance of instructions or procedures;

b) Those that can be made at the departmental level, but need capacity development support (e.g., land use inventories, preparing tender packages, communications); 
c) Those that need inter-agency cooperation in land use planning (e.g., cooperation between FD and the DALMS within the MoALI in landscape planning, or additional incentives needing approval from Myanmar Investment Commission; and

d) Those that need legislative change, for example through amendments to the Forest Law, the Forest Rules, or passage of the Land Law.

To achieve the Government's targets for plantations and to attract quality investment, a range of perceived risks and constraints need to be addressed. Possible actions include:

a) Addressing social risks, in particular potential conflicts related to land and consequent risks for plantation protection; this demands adequate surveys and consultations in land use allocation, and the adoption of partnership models;

b) Adoption and promotion of a wider range of plantation enterprise models, including management of existing government forests in combination with plantation establishment that allow larger management units to be made available, and links with CF;

c) More adequate lease tenure for multiple rotations (subject to meeting performance requirements);

d) Streamlined processes for lease acquisition and transparent and simplified licensing and decisionmaking processes;

e) Lighter regulatory requirements for timber harvest and transport;

f) Demonstration of government efforts to strengthen forest sector governance and tackle illegal logging; and

g) Better publicity to promote plantation investment, including identification of and information on available sites and investor incentives;

There is an expressed desire to create a formal multi-stakeholder body that includes representatives of the private sector. This indicates (e.g., associations), affected government agencies, CSOs representing community interests, and legislators. This would support policy reforms and guide implementation of the action plan.

Further technical, social and economic analyses; and data collection are needed to ensure that deliberations and decisions are properly informed. These should examine the potential impacts of suggested changes on, for example, investment feasibility, government revenues and local economies, social impacts and environments. The current lack of information on existing plantations - both government and private - indicates the need for development of a national plantation database to support rational development of trade and industry policies.

The medium to long-term impacts of the 2020 COVID-19 outbreak on plantation investments will most likely depend on investors' views of Myanmar's attractiveness compared to other countries and other investment options, rather than its immediate economic affects. Domestic and global demand for forest products is expected to return eventually and investors' decisions are likely to be based on factors such as their perceptions of political stability, governance quality, and ease of doing business. Given the employment needed for plantation establishment, the Government should consider prioritizing policy reforms to stimulate investment. 


\section{ANNEX 3: ASSESSMENT OF WOODFUEL}

\section{Methodology}

The Myanmar Woodfuels Sector Assessment was commissioned by the World Bank in collaboration with the FD and the NGO Geres to quantify woodfuel demand in Myanmar, characterize commercial value chains, identify hotspots of pressure on forests, and propose options for the development of a sustainable woodfuels sector. The assessment used data from studies and surveys carried out by ADB and Geres, as well as the Myanmar Population and Housing Census. Further, the findings are based on field and phone surveys carried out for the assessment, interviews with retailers, intermediaries and producers of woodfuels, hotspot modeling, and carbon footprint calculation using the approach developed by Bailis et al. ${ }^{36}$ The assessment provides an overview of the commercial woodfuels sector in Myanmar for policymakers and stakeholders to address current issues. It consists of an assessment of the woodfuel demand in Myanmar, an in-depth investigation of selected woodfuel value chains, and proposed intervention options.

\section{Woodfuel consumption}

60 percent of Myanmar's population rely on firewood as their primary cooking fuel. Total annual household demand for woodfuel is estimated at 23.8 million metric tons $(t)$ in wood-equivalent (34 million $\mathrm{m}^{3}$ ), comprising 10.8 million $\mathrm{t}$ of firewood collected for own use, 4.4 million $\mathrm{t}$ of purchased firewood, and 1.4 million t of charcoal ( 8.6 million t wood-equivalent). Electricity is the second most common cooking energy, used by 28 percent of households, with charcoal accounting for 9.4 percent and LPG for 1.4 percent. Despite a decline in woodfuels as primary cooking fuel in favor of electricity, firewood and charcoal continue to be used as supplementary fuels. Households using woodfuel in combination with electricity may reduce their woodfuel consumption by less than 50 percent compared with households using firewood or charcoal alone. These dynamics are important to understand the impacts of electricity and LPG adoption on woodfuel demand.

Household woodfuel consumption significantly outweighs the combined demands of commercial catering and industry. Total national woodfuel consumption is 25.4 million $t$ of wood-equivalent per year $\left(36.3\right.$ million $\left.\mathrm{m}^{3}\right)$. The estimated annual value of the charcoal market is around US\$300 million at retail, while firewood purchased and collected by households could be worth up to US\$1 billion. Commercial catering, on the other hand, consumes $460,000 \mathrm{t}$ of firewood and 105,000 t of charcoal per year, for a total of 1,090,000 $\mathrm{t}$ in firewood-equivalent, while the four main woodfuel-consuming industries (brickmaking, garment manufacture, fish paste and dry shrimp, and noodle production) consume an estimated 648,000 t/year of firewood.

Woodfuel value chains

Charcoal supply is well-structured. This can be seen in the transport from kiln sites to middlemen's depots, where quality grading may take place, and onwards to urban centers in covered trucks, where small-scale transporters distribute to wholesalers, retailers, and end-users. Charcoal for Yangon comes mainly from hardwood trees, potentially contributing to forest degradation, while charcoal in the Central Dry Zone comes mainly from village land and farmland. There is significant diversity in kiln design and producer skill, resulting in wide variation in efficiency. At least 108,000 t of unlicensed charcoal is exported each year to China (worth at least US\$21.4 million), and a further 77,000 t to Thailand (worth US\$8.72 million).

Price is more important than quality in firewood supply. For this reason, a higher percentage of lower grade species and residues are used as firewood. Rubberwood could supply $3.78 \mathrm{Mt}$ of firewood per year from residues and already supplies industrial consumers in the lower-central region, and has important potential.

${ }^{36}$ Bailis et al., "The Carbon Footprint of Traditional Woodfuels." 
Three areas are at risk due to charcoal production. A computer model was developed to project demand for commercial woodfuels to likely harvesting locations, and was overlaid with biomass stocks to identify potential hotspots of woodfuel-induced forest degradation. The model showed three areas at risk: Pathein and Bago (affected by the supply chain of Yangon); the Tanintharyi area (through exports to Thailand); and the intersection of Mandalay, Sagaing, Shan, and Kachin States.

\section{Proposed interventions}

Woodfuels meet the energy needs of a majority of households in Myanmar, as well as those of important commercial and industrial sectors. In a situation of diminishing forest resources, it is essential for both livelihood resilience and economic stability that forest resources are sustainably managed, that woodfuel processing and utilization becomes as clean and efficient as possible, and that fuel switching strategies are well-informed and approached strategically. The following interventions are proposed:

\section{a) Promote alternative fuels where appropriate}

LPG and electricity for household cooking. Subsidies, awareness and information campaigns, enforcement of safety standards and regulations and significant public investments would help to accelerate the uptake of LPG. The adoption of electricity for cooking is also likely to result in a switch in the main cooking fuel. However, despite the use of LPG and electricity for household cooking, woodfuel would still be used as supplementary fuel. Further research on the impact of electrification on woodfuel consumption is needed to inform policy.

Rice husk pellets and briquettes for industry. Pellets provide a low-carbon alternative to coal and oil for heat and steam production for industry. Myanmar has an annual output potential of more than 6 Mt of wood-equivalent in rice husks. Interventions should focus on offering financing products to cofund boiler modifications, and linking rice husk suppliers and industrial consumers. The adoption of rice husk pellets in the fisheries sector should also be investigated, together with the potential for high-efficiency pellet stoves. A subsidy or tax break for rice husk pellets should be considered.

Charcoal briquettes for commercial catering. Charcoal briquettes can partially substitute wood charcoal for commercial catering, and there is scope to grow this market. Technical assistance should be provided to briquetting firms to redesign production processes, raise quality and improve efficiency, drawing on expertise from the wider Mekong region. Co-financing should be offered for upgrades in capacity, drying facilities, and briquette quality. There is a need for minimum quality labeling for briquettes, and a communication campaign on such labeling.

\section{b) Support sustainable woodfuel production}

Large-scale plantations residues. Fuelwood plantations offer virtually no return on investment, so will remain driven by the public sector. Alternative plantation models focusing on higher value primary products (such as timber, veneer or rubber) are more likely to provide an economically viable supply of woodfuel from thinning, harvesting and processing residues. An assessment of the economics of woodfuel production from plantation residues, and the necessary regulatory environment to support such investment would be beneficial.

Tree plantations at village and household level. Decentralized, mixed-use tree growing for multiple purposes is a viable option for supplying woodfuels in areas of high deficit, in multi-strata home gardens and woodlots, and along field boundaries. Selected tree species should provide fruit, fodder, wood products, windbreak, shade, and nitrogen-fixing services, with woodfuels as a byproduct. This requires a shift away from current centralized and government-led interventions, to focus on mixedused forestry models that respond to farmers' needs and build on their existing practices.

Community forestry and forest restoration. The development of sustainably managed CFs could allow a consistent level of wood supply and for degraded areas to be restored to a level where they can contribute to energy supply. These activities should be directed to woodfuel deficit areas, though 
community-based resource management will not work in every situation. The development of CFEs has the potential to generate significant quantities of whole trees and residues for local charcoal producers. Such charcoal needs to be differentiated from illegally produced woodfuels with lightertouch regulation and tax incentives to ensure competitive market access.

\section{c) Reduce energy loss across the value-chain.}

Modernization of charcoal production. The enforcement of strict rules concerning charcoal is virtually impossible, as trucks carrying charcoal cannot be identified and there is no system for monitoring adherence to quotas. Most charcoal production is therefore illegal, providing no incentives for investing in greater sustainability. Easing regulatory conditions for sustainable charcoal would encourage compliance and bring the industry into the formal economy. Improved charcoal flow tracking with roadside checks and automatic number recognition could assist in reconciling output with licenses. With good law enforcement, fees and fines can be reinvested in sustainable forestry.

Charcoal production is relatively inefficient, with high variability in operator skill. Significant gains are best achieved by promoting incremental changes in charcoal-making operations. The organization of local and regional exchange visits could build a network of trainers. Technical materials and a training program for producers and FD staff should be introduced.

Cleaner and more efficient woodfuel use. Subsidies of up to $100 \%$ for improved household cookstoves are distorting the market and undermining in-country manufacture. These resources should rather be used for partial subsidy, to cover poor or remote locations, or to fund marketing and promotion. It is also recommended to develop a national cookstove strategy with harmonized guidelines on subsidies; marketing campaigns on improved cookstoves; support for local producers to boost quality and marketing capacities; and development of fiscal incentives for local firms to invest in the manufacture of high-grade stoves within Myanmar.

There is potential for improving the efficiency of steam production in industry using condensate recovery systems, pipe insulation, solar thermal pre-heating, fuel pre-drying and better in-house energy management. Additional efficiency gains can be achieved by switching to boilers optimized for rice husk pellets. Priority should be given to areas of woodfuel shortage in the Central Dry Zone. In the brickmaking industry, energy savings of 65 percent can be achieved by a switch to more efficient brick kilns, for which financial support will be needed.

\section{d) Build an enabling framework for sustainable woodfuels}

Given, the wide range of sectors with an interest in woodfuel, an inter-ministerial coordination mechanism is essential to answer to woodfuel challenges and opportunities. A Decision Support System is recommended, using geospatial modeling to calculate the fraction of non-renewable biomass at township level for different woodfuel value chains. Such a system would allow interventions to be prioritized based on their impact on forest resources and their $\mathrm{CO}_{2}$ emission reduction potential.

Carbon finance is widely applied to woodfuel projects, and there is growing interest from multinational companies in tree planting and other carbon offsets. This represents an opportunity to support tree planting and reforestation, integrated in a coherent strategy to contribute to long-term supply of woodfuels. By attributing a reduction in forest degradation to a woodfuel-related activity, this approach could also attract REDD+ financing. 
ANNEX 4: RECOMMENDATIONS FOR INTERVENTIONS IN THE FORESTRY SECTOR

\begin{tabular}{|c|c|c|c|c|}
\hline Challenge & Key message & Action & Timeframe & $\begin{array}{l}\text { Main } \\
\text { responsibility }\end{array}$ \\
\hline \multicolumn{5}{|c|}{ Planning, Management, and Monitoring of Production Forests } \\
\hline $\begin{array}{l}\text { Overharvesting } \\
\text { and weak controls } \\
\text { lead to } \\
\text { degradation of } \\
\text { forest reserves, } \\
\text { with loss of } \\
\text { commercial value, } \\
\text { livelihood benefits, } \\
\text { and ecosystem } \\
\text { services. }\end{array}$ & $\begin{array}{l}\text { Review of RF } \\
\text { and PPF (forest } \\
\text { stocks, } \\
\text { boundaries and } \\
\text { management } \\
\text { plans, where } \\
\text { necessary). } \\
\text { Based on site- } \\
\text { specific review, } \\
\text { define how } \\
\text { production } \\
\text { forests should } \\
\text { be managed; } \\
\text { and adapt } \\
\text { district forest } \\
\text { management } \\
\text { plans } \\
\text { (restoration, } \\
\text { conservation, } \\
\text { private } \\
\text { plantations, CF). }\end{array}$ & $\begin{array}{l}\text { Establish a National Forest } \\
\text { Inventory system; } \\
\text { - } \quad \text { Produce major forest type } \\
\text { maps; } \\
\text { - Validate reserve } \\
\text { boundaries and maps; } \\
\text { - Create a forest production } \\
\text { information system. } \\
\text { - Strengthen monitoring } \\
\text { and law enforcement } \\
\text { capacity for adherence to } \\
\text { forest management as per } \\
\text { forest management plans } \\
\text { and harvest allowances. }\end{array}$ & Short & FD \\
\hline $\begin{array}{l}\text { Weak } \\
\text { understanding of } \\
\text { regulated markets } \\
\text { and implications of } \\
\text { regulations from } \\
\text { consumer } \\
\text { countries limits } \\
\text { market-readiness. }\end{array}$ & $\begin{array}{l}\text { Improving } \\
\text { Timber Legality } \\
\text { Assurance } \\
\text { System is critical } \\
\text { for market } \\
\text { positioning and } \\
\text { creating } \\
\text { investment } \\
\text { climate for high- } \\
\text { value } \\
\text { production and } \\
\text { export. } \\
\text { Definition and } \\
\text { implementation } \\
\text { of national } \\
\text { certification } \\
\text { standards } \\
\text { should align } \\
\text { with regional } \\
\text { and } \\
\text { international } \\
\text { requirements. }\end{array}$ & $\begin{array}{l}\text { - } \text { Align MTLAS with } \\
\text { requirements of key } \\
\text { consumer countries; } \\
\text { - Implement national } \\
\text { certification standards; } \\
\text { - Consider third-party } \\
\text { verification; } \\
\text { - Implement good } \\
\text { governance } \\
\text { recommendations under } \\
\text { FLEGT; } \\
\text { - Improve law enforcement } \\
\text { across agencies. }\end{array}$ & Medium & $\begin{array}{l}\text { MoNREC, FD, } \\
\text { MTE, Myanmar } \\
\text { Timber } \\
\text { Merchant } \\
\text { Association, } \\
\text { Myanmar } \\
\text { Forest } \\
\text { Certification } \\
\text { Committee, } \\
\text { private sector }\end{array}$ \\
\hline \multicolumn{5}{|c|}{ Plantations (state-owned and private) } \\
\hline $\begin{array}{l}\text { State-owned } \\
\text { plantations have } \\
\text { high mortality due } \\
\text { to insufficient } \\
\text { maintenance and } \\
\end{array}$ & $\begin{array}{l}\text { Improve long- } \\
\text { term } \\
\text { management of } \\
\text { state-owned } \\
\text { plantations. } \\
\end{array}$ & 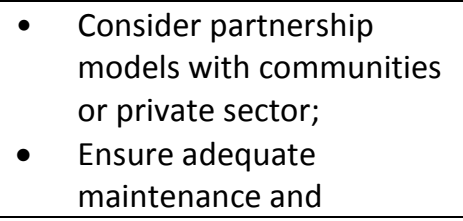 & $\begin{array}{l}\text { Short } \\
\text { Long }\end{array}$ & FD \\
\hline
\end{tabular}




\begin{tabular}{|c|c|c|c|c|}
\hline Challenge & Key message & Action & Timeframe & $\begin{array}{l}\text { Main } \\
\text { responsibility }\end{array}$ \\
\hline $\begin{array}{l}\text { inadequate } \\
\text { budgets. }\end{array}$ & & $\begin{array}{l}\text { supervision support for } \\
\text { public plantations. }\end{array}$ & & \\
\hline $\begin{array}{l}\text { Domestic } \\
\text { entrepreneurs } \\
\text { constrained by } \\
\text { unpredictable } \\
\text { timber supply from } \\
\text { MTE auctions and } \\
\text { a focus on } \\
\text { minimally } \\
\text { processed timber } \\
\text { exports. } \\
\text { As demand for } \\
\text { wood products } \\
\text { grows, planted } \\
\text { forests provide } \\
\text { attractive } \\
\text { investment } \\
\text { opportunities. But } \\
\text { Myanmar lacks an } \\
\text { integrated } \\
\text { plantation industry } \\
\text { to cope with } \\
\text { sophisticated } \\
\text { markets. } \\
\text { Foreign investors } \\
\text { perceive } \\
\text { investment } \\
\text { challenges in } \\
\text { Myanmar, } \\
\text { including complex } \\
\text { processes, weak } \\
\text { infrastructure, } \\
\text { political economy, } \\
\text { land conflicts, } \\
\text { tenure insecurity, } \\
\text { and lack of } \\
\text { incentives. }\end{array}$ & $\begin{array}{l}\text { Commercial } \\
\text { plantations have } \\
\text { significant } \\
\text { potential to } \\
\text { create rural } \\
\text { jobs, boost } \\
\text { exports, provide } \\
\text { secure timber to } \\
\text { build a thriving } \\
\text { internationally } \\
\text { competitive } \\
\text { wood industry. } \\
\text { Develop a } \\
\text { comprehensive } \\
\text { reform package } \\
\text { to improve } \\
\text { business climate } \\
\text { for high-end } \\
\text { investors to } \\
\text { stimulate } \\
\text { national forest } \\
\text { industry } \\
\text { development. }\end{array}$ & 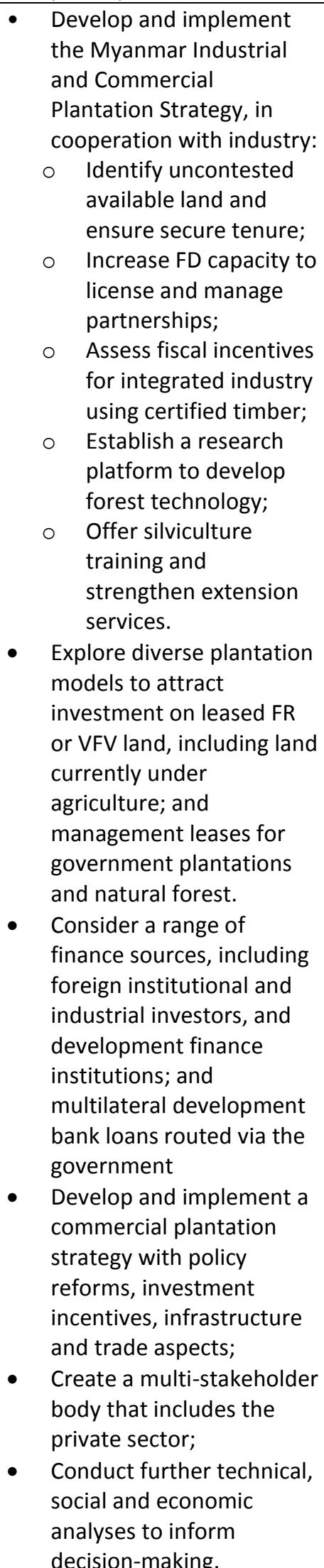 & Short/medium & $\begin{array}{l}\text { FD, Ministry of } \\
\text { Industry, } \\
\text { Myanmar } \\
\text { Investment } \\
\text { Commission, } \\
\text { Myanmar } \\
\text { Timber } \\
\text { Merchant } \\
\text { Association }\end{array}$ \\
\hline
\end{tabular}




\begin{tabular}{|c|c|c|c|c|}
\hline Challenge & Key message & Action & Timeframe & $\begin{array}{l}\text { Main } \\
\text { responsibility }\end{array}$ \\
\hline \multicolumn{5}{|l|}{ Processing } \\
\hline $\begin{array}{l}\text { Small and } \\
\text { medium-scale } \\
\text { timber processors } \\
\text { face challenges } \\
\text { with credit } \\
\text { financing, enabling } \\
\text { environment, } \\
\text { access to timber, } \\
\text { market } \\
\text { information, } \\
\text { productive } \\
\text { infrastructure, and } \\
\text { research and } \\
\text { technology } \\
\text { support. }\end{array}$ & $\begin{array}{l}\text { Improve } \\
\text { enabling } \\
\text { environment for } \\
\text { wood SMEs, } \\
\text { processing, and } \\
\text { handling. } \\
\text { Attract industry } \\
\text { that can } \\
\text { promote vertical } \\
\text { integration in } \\
\text { cooperation } \\
\text { with } \\
\text { smallholders. }\end{array}$ & $\begin{array}{l}\text { Create cross-ministerial } \\
\text { task team to assess and } \\
\text { improve enabling } \\
\text { environment for SMEs; } \\
\text { - Simplify procedures to } \\
\text { establish and run wood } \\
\text { processing enterprises; } \\
\text { - Promote technology and } \\
\text { skills training for national } \\
\text { labor force; } \\
\text { - Promote national and } \\
\text { foreign investment in } \\
\text { integrated industries' } \\
\text { Assess market } \\
\text { acceptability of lesser } \\
\text { utilized species; } \\
\text { Disseminate state-of-the- } \\
\text { art processing technology; } \\
\text { Collect and disseminate } \\
\text { market information. }\end{array}$ & $\begin{array}{l}\text { Short } \\
\text { Medium } \\
\text { Medium } \\
\text { Medium }\end{array}$ & $\begin{array}{l}\text { MoNREC, } \\
\text { Ministry of } \\
\text { Finance, } \\
\text { Ministry of } \\
\text { Industry, MTE, } \\
\text { Myanmar } \\
\text { Investment } \\
\text { Commission, } \\
\text { Myanmar } \\
\text { Timber } \\
\text { Merchant } \\
\text { Association, } \\
\text { Ministry of } \\
\text { Commerce }\end{array}$ \\
\hline \multicolumn{5}{|c|}{ Myanmar Timber Enterprise (MTE) } \\
\hline $\begin{array}{l}\text { High-value log } \\
\text { export by MTE } \\
\text { with little value } \\
\text { addition, high } \\
\text { wastage, and } \\
\text { limited } \\
\text { transparency. } \\
\text { Overharvesting } \\
\text { due to weak } \\
\text { control and } \\
\text { political influence. }\end{array}$ & $\begin{array}{l}\text { Reform MTE } \\
\text { with } \\
\text { consideration of } \\
\text { entire value } \\
\text { chain. All } \\
\text { reforms should } \\
\text { take into } \\
\text { account a strong } \\
\text { regulatory, } \\
\text { planning, and } \\
\text { control function } \\
\text { of the FD. }\end{array}$ & $\begin{array}{l}\text { - Carry out a functional } \\
\text { review and reform of } \\
\text { forest sector institutions, } \\
\text { including MTE; } \\
\text { - Undertake a capacity and } \\
\text { skills assessment, with } \\
\text { reorientation of staffing, } \\
\text { greater decentralization, } \\
\text { and more outsourcing. } \\
\text { Pass on pension } \\
\text { obligations, away from } \\
\text { the books of MTE, while } \\
\text { taking practical } \\
\text { considerations as well as } \\
\text { existing regulations into } \\
\text { account. }\end{array}$ & $\begin{array}{l}\text { Short } \\
\text { Medium }\end{array}$ & $\begin{array}{l}\text { MoNREC / FD, } \\
\text { MTE } \\
\text { FD, MTE }\end{array}$ \\
\hline \multicolumn{5}{|c|}{ Community-based forest management } \\
\hline $\begin{array}{l}\text { Limited handover } \\
\text { capacity and slow } \\
\text { approval of CF } \\
\text { applications. } \\
\text { High dormancy } \\
\text { rate of CF User } \\
\text { Groups (CFUGs). } \\
\text { Significant local } \\
\text { capacity gaps in CF } \\
\text { implementation. }\end{array}$ & $\begin{array}{l}\text { Improve and } \\
\text { simplify the } \\
\text { approval } \\
\text { process of CF } \\
\text { establishment } \\
\text { (to ensure } \\
\text { equity and } \\
\text { inclusiveness); } \\
\text { develop } \\
\text { efficient } \\
\text { delivery } \\
\text { mechanism for } \\
\text { scale-up of CF } \\
\text { establishment }\end{array}$ & $\begin{array}{l}\text { - Accelerate establishment } \\
\text { of CF; } \\
\text { Develop delivery } \\
\text { mechanism for CF } \\
\text { implementation, } \\
\text { including: } \\
\circ \quad \text { Clarify responsibilities } \\
\text { and strengthen } \\
\text { deliver functions of } \\
\text { local FD staff and } \\
\text { agricultural extension } \\
\text { services; } \\
\text { Develop cadre of } \\
\text { service providers and }\end{array}$ & Short & $\begin{array}{l}\text { FD (e.g., } \\
\text { Central } \\
\text { Forestry } \\
\text { Development } \\
\text { Training Cen- } \\
\text { ter, CF Unit, } \\
\text { Forest } \\
\text { Research } \\
\text { Institute, } \\
\text { Myanmar } \\
\text { Forest School) } \\
\text { MoALI, CF } \\
\text { National } \\
\text { Working } \\
\text { Group, CSOs }\end{array}$ \\
\hline
\end{tabular}




\begin{tabular}{|c|c|c|c|c|}
\hline Challenge & Key message & Action & Timeframe & $\begin{array}{l}\text { Main } \\
\text { responsibility }\end{array}$ \\
\hline & $\begin{array}{l}\text { and } \\
\text { implementation. }\end{array}$ & $\begin{array}{l}\text { community } \\
\text { facilitators; } \\
\text { Create open access CF } \\
\text { database and } \\
\text { information systems; } \\
\text { Strengthen CF } \\
\text { outreach program. }\end{array}$ & & \\
\hline $\begin{array}{l}\text { Ethnic areas with } \\
\text { customary tenure } \\
\text { and forest } \\
\text { management } \\
\text { systems need } \\
\text { practical solutions. }\end{array}$ & $\begin{array}{l}\text { Recognize } \\
\text { customary } \\
\text { tenure systems } \\
\text { and support } \\
\text { their effective } \\
\text { forest } \\
\text { management. }\end{array}$ & $\begin{array}{l}\text { Explore opportunities for } \\
\text { recognizing ethnic } \\
\text { initiatives for community- } \\
\text { governed forest } \\
\text { conservation and } \\
\text { management models (that } \\
\text { align with broader } \\
\text { national objectives). } \\
\text { Develop legal and } \\
\text { technical processes for } \\
\text { effective tenure for } \\
\text { customary groups. }\end{array}$ & $\begin{array}{l}\text { Short to } \\
\text { Medium }\end{array}$ & $\begin{array}{l}\text { Ministry of } \\
\text { Ethnic Affairs }\end{array}$ \\
\hline $\begin{array}{l}\text { Critical capacity } \\
\text { constraints to CF } \\
\text { among community } \\
\text { members. }\end{array}$ & $\begin{array}{l}\text { Support } \\
\text { systematic } \\
\text { capacity } \\
\text { building of } \\
\text { CFUGs, } \\
\text { including } \\
\text { through } \\
\text { associations/ } \\
\text { networks of } \\
\text { CFUGs at } \\
\text { district, } \\
\text { regional, and } \\
\text { national levels } \\
\end{array}$ & $\begin{array}{l}\text { Facilitate a national CF } \\
\text { network; } \\
\text { Identify best practice; } \\
\text { develop database and } \\
\text { practitioner handbook. }\end{array}$ & $\begin{array}{l}\text { Short to } \\
\text { Medium }\end{array}$ & $\begin{array}{l}\text { FD CF Unit, } \\
\text { Forest } \\
\text { Research } \\
\text { Institute, CF } \\
\text { National } \\
\text { Working } \\
\text { Group, CSOs } \\
\text { for technical } \\
\text { support }\end{array}$ \\
\hline $\begin{array}{l}\text { CFUGs and their } \\
\text { members have } \\
\text { limited access to } \\
\text { finance, especially } \\
\text { loans for value- } \\
\text { added processing. }\end{array}$ & $\begin{array}{l}\text { Support } \\
\text { business } \\
\text { development } \\
\text { for CFE (legal, } \\
\text { technical } \\
\text { incubator); } \\
\text { expand financial } \\
\text { services (credit, } \\
\text { finance, PES to } \\
\text { CFUGs). }\end{array}$ & $\begin{array}{l}\text { Develop financing options } \\
\text { for CFUGs, including from } \\
\text { MFIs; } \\
\text { Provide technical support } \\
\text { to non-parastatal } \\
\text { producer cooperatives; } \\
\text { Develop a CFE/SME } \\
\text { incubator and accelerator } \\
\text { support program; } \\
\text { Survey services provided } \\
\text { by cooperative-like } \\
\text { organizations to identify } \\
\text { gaps to be targeted by } \\
\text { incubator } \\
\end{array}$ & $\begin{array}{l}\text { Short to } \\
\text { Medium }\end{array}$ & $\begin{array}{l}\text { FD (e.g., CF } \\
\text { Unit) } \\
\text { CF National } \\
\text { Working } \\
\text { Group), MoPF, } \\
\text { Ministry of } \\
\text { Industry, SME } \\
\text { Dev't. Dept., } \\
\text { Dept. of } \\
\text { Cooperatives, } \\
\text { CSOs }\end{array}$ \\
\hline $\begin{array}{l}\text { CFUGs and the } \\
\text { private sector have } \\
\text { limited experience } \\
\text { of building } \\
\text { mutually beneficial } \\
\text { partnerships. }\end{array}$ & $\begin{array}{l}\text { Assess and } \\
\text { promote } \\
\text { expansion of } \\
\text { smallholder, } \\
\text { outgrower, and } \\
\text { other private } \\
\text { sector- } \\
\text { smallholder }\end{array}$ & $\begin{array}{l}\text { Implement capacity } \\
\text { development program for } \\
\text { small entrepreneurs; } \\
\text { Carry out market analysis } \\
\text { of NTFP and other wood } \\
\text { products; } \\
\text { - Create a CF platform that } \\
\text { promotes CF products and }\end{array}$ & Medium & $\begin{array}{l}\text { FD (CF Unit) } \\
\text { MoPF } \\
\text { SME Dev't. } \\
\text { Dep., Ministry } \\
\text { of Industry, } \\
\text { CSOs, relevant } \\
\text { cooperatives } \\
\text { and }\end{array}$ \\
\hline
\end{tabular}




\begin{tabular}{|c|c|c|c|c|}
\hline Challenge & Key message & Action & Timeframe & $\begin{array}{l}\text { Main } \\
\text { responsibility }\end{array}$ \\
\hline & $\begin{array}{l}\text { partnership } \\
\text { models to } \\
\text { encourage } \\
\text { mutually } \\
\text { beneficial } \\
\text { enterprise } \\
\text { partnerships } \\
\text { with private } \\
\text { sector. }\end{array}$ & $\begin{array}{l}\text { identifies potential } \\
\text { business opportunities } \\
\text { and partnerships; } \\
\text { Promote plantation } \\
\text { development in CF. }\end{array}$ & & $\begin{array}{l}\text { entrepreneur } \\
\text { associations } \\
\text { Relevant } \\
\text { private sector } \\
\text { actors }\end{array}$ \\
\hline $\begin{array}{l}\text { CF expansion has } \\
\text { often entailed } \\
\text { handing over } \\
\text { degraded } \\
\text { government } \\
\text { forests with } \\
\text { insufficient stock } \\
\text { for viable } \\
\text { enterprise, or } \\
\text { conservation } \\
\text { forests with } \\
\text { insufficient } \\
\text { tangible benefits. } \\
\text { There is potential } \\
\text { for using CF in } \\
\text { mangrove areas, } \\
\text { which have } \\
\text { experienced } \\
\text { significant decline. }\end{array}$ & $\begin{array}{l}\text { Mainstream CF } \\
\text { rollout across } \\
\text { different land } \\
\text { classifications, } \\
\text { including in } \\
\text { reserved } \\
\text { forests, in } \\
\text { mangrove } \\
\text { forests, on VFV } \\
\text { lands, and } \\
\text { explore ways to } \\
\text { promote CF } \\
\text { services to } \\
\text { ethnic } \\
\text { communities. }\end{array}$ & $\begin{array}{l}\text { Proactively expand CF in } \\
\text { reserved forests to } \\
\text { provide viable } \\
\text { opportunities for } \\
\text { sustainable, wood-based } \\
\text { CFE development; } \\
\text { Recognize existing } \\
\text { customary lands and, } \\
\text { elsewhere, explore } \\
\text { options for community } \\
\text { participation; } \\
\text { Accelerate CF } \\
\text { establishment in } \\
\text { mangrove areas; } \\
\text { Strengthen dialogue with } \\
\text { ethnic communities to } \\
\text { recognize customary } \\
\text { tenure and, where } \\
\text { appropriate, promote CF. }\end{array}$ & $\begin{array}{l}\text { Short to } \\
\text { Medium }\end{array}$ & $\begin{array}{l}\text { FD (CF Unit), } \\
\text { Dept. of } \\
\text { Agriculture, } \\
\text { Dept. of } \\
\text { Fisheries, local } \\
\text { communities, } \\
\text { NGOs }\end{array}$ \\
\hline \multicolumn{5}{|l|}{ Protection } \\
\hline $\begin{array}{l}\text { Myanmar's PAs } \\
\text { network area has } \\
\text { not reached the } \\
\text { NFMP target of } 10 \\
\text { percent of land. } \\
\text { Challenges for PAs } \\
\text { include incomplete } \\
\text { zoning, patchy } \\
\text { management } \\
\text { plans, inadequate } \\
\text { data management } \\
\text { systems, and weak } \\
\text { local capacity. }\end{array}$ & $\begin{array}{l}\text { Expand area } \\
\text { under } \\
\text { protection to } \\
\text { meet national } \\
\text { targets with } \\
\text { increased focus } \\
\text { on community- } \\
\text { based } \\
\text { conservation } \\
\text { models and } \\
\text { improved } \\
\text { stakeholder } \\
\text { engagement. }\end{array}$ & $\begin{array}{l}\text { - Continue gazettement of } \\
\text { planned PAs; } \\
\text { Strengthen multi- } \\
\text { stakeholder engagement } \\
\text { and dialogue, including } \\
\text { promoting CF in buffer } \\
\text { zones; } \\
\text { - Promote community } \\
\text { conservation models to } \\
\text { designate Community } \\
\text { Protected Areas, and } \\
\text { Indigenous and } \\
\text { Community Conserved } \\
\text { Areas; } \\
\text { Review zoning as part of } \\
\text { PA (and CPA) } \\
\text { establishment to diversify } \\
\text { management approaches, } \\
\text { including collaborative } \\
\text { arrangements; } \\
\text { Develop PA management } \\
\text { plans and provide } \\
\text { adequate budget for } \\
\text { implementation; }\end{array}$ & Medium & $\begin{array}{l}\text { MoNREC, FD } \\
\text { (Nature \& } \\
\text { Wildlife } \\
\text { Conservation } \\
\text { Division), } \\
\text { MoHT, CSOs }\end{array}$ \\
\hline
\end{tabular}




\begin{tabular}{|c|c|c|c|c|}
\hline Challenge & Key message & Action & Timeframe & $\begin{array}{l}\text { Main } \\
\text { responsibility }\end{array}$ \\
\hline & & $\begin{array}{l}\text { Invest in ecotourism and } \\
\text { create effective } \\
\text { management. }\end{array}$ & & \\
\hline $\begin{array}{l}\text { The national PA } \\
\text { system is } \\
\text { insufficiently } \\
\text { funded. }\end{array}$ & $\begin{array}{l}\text { Put in place } \\
\text { multipronged } \\
\text { approach to } \\
\text { improve } \\
\text { financial } \\
\text { sustainability of } \\
\text { the PAs system. }\end{array}$ & 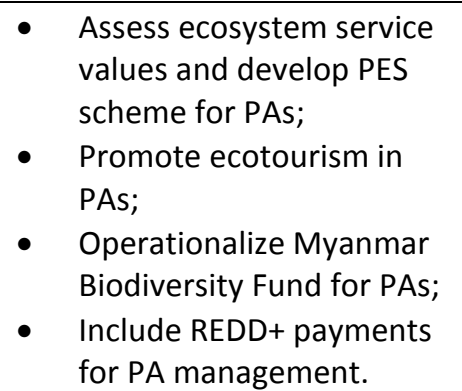 & Medium & $\begin{array}{l}\text { MoNREC, FD } \\
\text { (Nature \& } \\
\text { Wildlife } \\
\text { Conservation } \\
\text { Division), } \\
\text { MoPF, MoHT }\end{array}$ \\
\hline $\begin{array}{l}\text { More than half of } \\
\text { Myanmar's } \\
\text { mangroves have } \\
\text { been lost over the } \\
\text { past } 20 \text { years. }\end{array}$ & $\begin{array}{l}\text { Apply cross- } \\
\text { sectoral } \\
\text { spatially explicit } \\
\text { land use } \\
\text { planning for } \\
\text { sustainable } \\
\text { management of } \\
\text { coastal } \\
\text { resources }\end{array}$ & 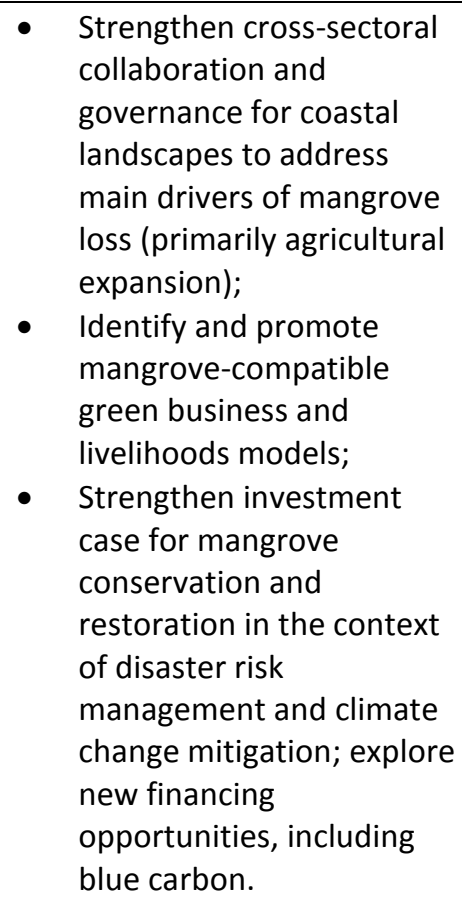 & Short & $\begin{array}{l}\text { MONREC (FD), } \\
\text { MOALI, } \\
\text { NCRMC }\end{array}$ \\
\hline \multicolumn{5}{|c|}{ Multi-stakeholder dialogue and citizen engagement } \\
\hline $\begin{array}{l}\text { Myanmar has been } \\
\text { deeply affected by } \\
\text { conflict. Social } \\
\text { risks, especially } \\
\text { those related to } \\
\text { land tenure and } \\
\text { the potential for } \\
\text { related conflict, } \\
\text { are a major issue } \\
\text { for all land-based } \\
\text { investment in } \\
\text { Myanmar. }\end{array}$ & $\begin{array}{l}\text { Multi- } \\
\text { stakeholder } \\
\text { processes that } \\
\text { are inclusive, } \\
\text { participatory, } \\
\text { and cognizant of } \\
\text { local conflict } \\
\text { dynamics are } \\
\text { needed to } \\
\text { prevent } \\
\text { tensions arising } \\
\text { from forest } \\
\text { conservation } \\
\text { and restoration } \\
\text { initiatives. }\end{array}$ & 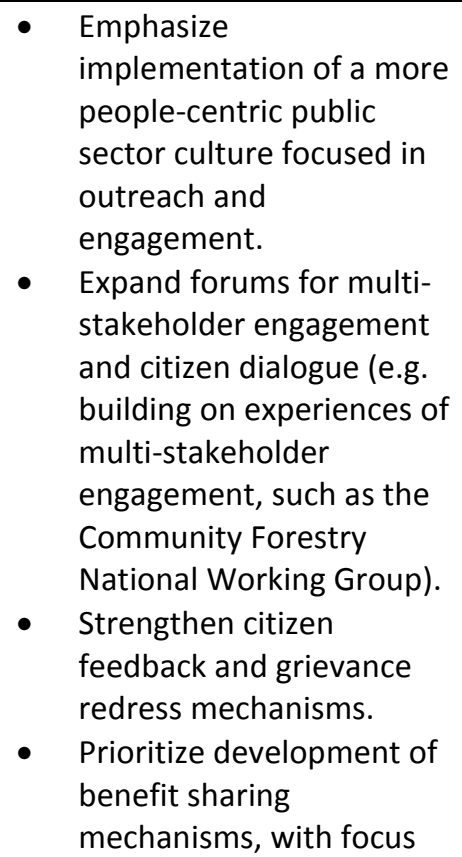 & Short & MONREC \\
\hline
\end{tabular}




\begin{tabular}{|c|c|c|c|c|}
\hline Challenge & Key message & Action & Timeframe & $\begin{array}{l}\text { Main } \\
\text { responsibility }\end{array}$ \\
\hline & & $\begin{array}{l}\text { on women, vulnerable } \\
\text { and marginalized groups. } \\
\text { Enhance FD capacity for } \\
\text { citizen dialogue, social } \\
\text { inclusion, and stakeholder } \\
\text { engagement and } \\
\text { consultations. }\end{array}$ & & \\
\hline $\begin{array}{l}\text { With a target of } \\
\text { almost } 40 \text { percent } \\
\text { of electricity } \\
\text { production from } \\
\text { hydropower, } \\
\text { watershed forests } \\
\text { are vital. }\end{array}$ & $\begin{array}{l}\text { Develop } \\
\text { financing } \\
\text { mechanisms for } \\
\text { rehabilitation of } \\
\text { critical } \\
\text { watershed } \\
\text { forests and for } \\
\text { establishment } \\
\text { of watershed } \\
\text { plantations. }\end{array}$ & $\begin{array}{l}\text { - Analyze potential for PES } \\
\text { and other schemes to } \\
\text { finance rehabilitation of } \\
\text { critical watershed forests; } \\
\text { and } \\
\text { - Expand watershed } \\
\text { plantations. }\end{array}$ & Medium & FD \\
\hline \multicolumn{5}{|c|}{ FD skill development } \\
\hline $\begin{array}{l}\text { In contrast with a } \\
\text { centralized FD } \\
\text { governance } \\
\text { system, emerging } \\
\text { modalities rely on } \\
\text { decentralized } \\
\text { partnerships, } \\
\text { requiring new skills } \\
\text { and capacities, } \\
\text { especially at } \\
\text { state/region and } \\
\text { local levels. }\end{array}$ & $\begin{array}{l}\text { Invest in } \\
\text { technology and } \\
\text { new skill } \\
\text { development } \\
\text { for FD with } \\
\text { emphasis on } \\
\text { state/region and } \\
\text { local levels. } \\
\text { Strengthen } \\
\text { citizen } \\
\text { engagement. }\end{array}$ & $\begin{array}{l}\text { - } \\
\text { caphance FD technical } \\
\text { and township level, } \\
\text { including monitoring (e.g., } \\
\text { remote sensing); } \\
\text { sustainable forest } \\
\text { management; value } \\
\text { addition and enterprise } \\
\text { development; and citizen } \\
\text { dialogue, social inclusion, } \\
\text { and trust building. } \\
\text { Engage, communicate, } \\
\text { and consult private sector } \\
\text { and civil society; } \\
\text { Establish mechanism for } \\
\text { citizen feedback. }\end{array}$ & $\begin{array}{l}\text { Short to } \\
\text { Medium }\end{array}$ & $\begin{array}{l}\text { MoNREC, FD, } \\
\text { state/region } \\
\text { Government, } \\
\text { Ministry of } \\
\text { Ethnic Affairs, } \\
\text { departments at } \\
\text { state levels }\end{array}$ \\
\hline $\begin{array}{l}\text { Weak governance } \\
\text { and transparency } \\
\text { lead to leakage of } \\
\text { forest resources } \\
\text { and benefits to } \\
\text { organized crime } \\
\text { and shadow } \\
\text { markets. }\end{array}$ & $\begin{array}{l}\text { Introduce } \\
\text { transparency, } \\
\text { accountability, } \\
\text { and citizen } \\
\text { engagement } \\
\text { measures and } \\
\text { mechanisms to } \\
\text { increase } \\
\text { efficiency and } \\
\text { facilitate control } \\
\text { mechanism. }\end{array}$ & $\begin{array}{l}\text { - Support President's } \\
\text { anticorruption initiative } \\
\text { and offer channels for } \\
\text { collaboration between } \\
\text { NGOs and FD; } \\
\text { - Improve transparency and } \\
\text { accountability } \\
\text { mechanisms, including } \\
\text { open access satellite- } \\
\text { based monitoring, citizen } \\
\text { engagement tools, } \\
\text { financial surveillance, and } \\
\text { law enforcement capacity. }\end{array}$ & $\begin{array}{l}\text { Medium to } \\
\text { Long }\end{array}$ & $\begin{array}{l}\text { MoPF, } \\
\text { MoNREC }\end{array}$ \\
\hline \multicolumn{5}{|l|}{ Forest tenure } \\
\hline $\begin{array}{l}\text { Protection and } \\
\text { recognition of } \\
\text { forest tenure } \\
\text { rights is critical if } \\
\text { forest-dependent } \\
\text { communities are }\end{array}$ & & $\begin{array}{l}\text { - Adopt and enforce a } \\
\text { comprehensive policy and } \\
\text { legal framework to reform } \\
\text { forest tenure, including } \\
\text { for local and ethnic } \\
\text { communities; }\end{array}$ & & \\
\hline
\end{tabular}




\begin{tabular}{|c|c|c|c|c|}
\hline Challenge & Key message & Action & Timeframe & $\begin{array}{l}\text { Main } \\
\text { responsibility }\end{array}$ \\
\hline $\begin{array}{l}\text { to play a greater } \\
\text { role in forest and } \\
\text { biodiversity } \\
\text { preservation. }\end{array}$ & & $\begin{array}{l}\text { Engage all stakeholders } \\
\text { and political leadership in } \\
\text { the implementation of } \\
\text { forest tenure reforms; } \\
\text { - Improve local capacities to } \\
\text { gather information on } \\
\text { forest land holding } \\
\text { patterns and socio- } \\
\text { cultural factors affecting } \\
\text { them; } \\
\text { Urge development } \\
\text { partners to support } \\
\text { dialogue on forest land } \\
\text { and resource } \\
\text { management; and } \\
\text { strengthening of research } \\
\text { capacities. }\end{array}$ & & \\
\hline \multicolumn{5}{|l|}{ Woodfuels } \\
\hline $\begin{array}{l}\text { Woodfuels meet } \\
\text { the energy needs } \\
\text { of most } \\
\text { households as well } \\
\text { as those of } \\
\text { important } \\
\text { commercial and } \\
\text { industrial sectors. } \\
\text { With diminishing } \\
\text { forest resources, it } \\
\text { is essential that } \\
\text { forest resources } \\
\text { are sustainably } \\
\text { managed, that } \\
\text { woodfuel } \\
\text { processing and } \\
\text { utilization } \\
\text { becomes as clean } \\
\text { and efficient as } \\
\text { possible, and that } \\
\text { fuel switching } \\
\text { strategies are well- } \\
\text { informed and } \\
\text { strategic. }\end{array}$ & $\begin{array}{l}\text { Address wood } \\
\text { fuel as the } \\
\text { major rural } \\
\text { energy source } \\
\text { and driver of } \\
\text { forest } \\
\text { degradation. }\end{array}$ & $\begin{array}{l}\text { Promote appropriate } \\
\text { alternative fuels: } \\
\text { LPG for household } \\
\text { cooking, with } \\
\text { awareness campaigns } \\
\text { and potential } \\
\text { subsidies; } \\
\text { rice husk pellets and } \\
\text { briquettes for } \\
\text { industrial heat and } \\
\text { steam, including } \\
\text { financial incentives } \\
\text { for boiler } \\
\text { modifications; } \\
\text { charcoal briquettes } \\
\text { for commercial } \\
\text { catering, with } \\
\text { technical assistance } \\
\text { for improved } \\
\text { production } \\
\text { techniques and } \\
\text { marketing. } \\
\text { Promote sustainable } \\
\text { woodfuel production } \\
\text { through: } \\
\text { residues from } \\
\text { commercial } \\
\text { plantations; } \\
\text { mixed-purpose } \\
\text { household planting } \\
\text { (agroforestry) in } \\
\text { woodfuel deficit } \\
\text { areas; } \\
\text { sustainably managed } \\
\text { CF, with support for } \\
\text { market access to }\end{array}$ & Medium & $\begin{array}{l}\text { FD, DZGD, } \\
\text { Ministry of } \\
\text { Electricity \& } \\
\text { Energy, } \\
\text { Ministry of } \\
\text { Industry, } \\
\text { private sector, } \\
\text { (I)NGOs, } \\
\text { carbon finance } \\
\text { organizations }\end{array}$ \\
\hline
\end{tabular}




\begin{tabular}{|c|c|c|c|c|}
\hline Challenge & Key message & Action & Timeframe & $\begin{array}{l}\text { Main } \\
\text { responsibility }\end{array}$ \\
\hline & & $\begin{array}{l}\text { compete with non- } \\
\text { compliant fuels. } \\
\text { - Support sustainable } \\
\text { charcoal industry through: } \\
\text { o lighter touch } \\
\text { regulation for } \\
\text { compliant producers; } \\
\text { and } \\
\text { training and } \\
\text { exchanges on } \\
\text { improved charcoal } \\
\text { production. } \\
\text { On cookstoves: } \\
\text { Develop a national } \\
\text { cookstove strategy to } \\
\text { harmonize subsidies } \\
\text { and support local } \\
\text { manufacture. }\end{array}$ & & \\
\hline \multicolumn{5}{|c|}{ Nature-based solutions } \\
\hline $\begin{array}{l}\text { Ecosystem } \\
\text { restoration can } \\
\text { reduce } \\
\text { vulnerability to } \\
\text { disasters and } \\
\text { increase resilience } \\
\text { to climate change. }\end{array}$ & & $\begin{array}{l}\text { Scale-up nature-based } \\
\text { solutions for disaster } \\
\text { resilience, including } \\
\text { mangrove restoration, } \\
\text { productive agroforestry, } \\
\text { green infrastructure, } \\
\text { forest restoration on } \\
\text { slopes and watersheds. }\end{array}$ & & \\
\hline
\end{tabular}




\section{ANNEX 5: WORLD BANK GROUP ENGAGEMENT}

\section{World Bank Group Investments}

Ongoing World Bank Group investments relevant to the CFN are summarized in Table 8.

Table 8: WB investments in Myanmar related to the CFN

\begin{tabular}{|l|l|l|l|l|c|}
\hline $\begin{array}{l}\text { Project } \\
\text { ID }\end{array}$ & Project name & Lead GP/Global Themes & $\begin{array}{l}\text { Appr. } \\
\text { FY }\end{array}$ & Closing date & $\begin{array}{c}\text { Net Comm. } \\
\text { Amt. - IDA } \\
\text { (\$M) }\end{array}$ \\
\hline P132500 & $\begin{array}{l}\text { Myanmar National } \\
\text { Community Driven } \\
\text { Development Project }\end{array}$ & Social & 2013 & 30-Nov-2021 & 480.00 \\
\hline P146332 & $\begin{array}{l}\text { Ayeyarwady Integrated River } \\
\text { Basin Management Project }\end{array}$ & Education & 2014 & 20-Jul-2021 & 80.00 \\
\hline P146482 & $\begin{array}{l}\text { Agricultural Development } \\
\text { Support Project }\end{array}$ & Water & 2015 & 30-Sep-2020 & 100.00 \\
\hline P149960 & $\begin{array}{l}\text { National Electrification } \\
\text { Project }\end{array}$ & $\begin{array}{l}\text { Mealth, Nutrition \& } \\
\text { Population }\end{array}$ & 2015 & 31-Mar-2021 & 100.00 \\
\hline P154389 & $\begin{array}{l}\text { Landslide Emergency } \\
\text { Recovery Project }\end{array}$ & $\begin{array}{l}\text { Finance, } \\
\text { Competitiveness and } \\
\text { Innovation }\end{array}$ & 2017 & 30-Jun-2021 & 100.00 \\
\hline P158194 & $\begin{array}{l}\text { Myanmar SE Asia Disaster } \\
\text { Risk Management Project }\end{array}$ & $\begin{array}{l}\text { Urban, Resilience and } \\
\text { Land }\end{array}$ & 2017 & 31-Dec-2021 & 200.00 \\
\hline P160931 & $\begin{array}{l}\text { Myanmar SE Asia Disaster } \\
\text { Risk Management Project }\end{array}$ & $\begin{array}{l}\text { Urban, Resilience and } \\
\text { Land }\end{array}$ & 2017 & 31-Oct-2023 & 116.00 \\
\hline
\end{tabular}

Investments in the proposed IDA pipeline are shown in Table 9.

Table 9 Indicative IDA lending program

\begin{tabular}{|c|c|c|}
\hline \multirow{2}{*}{ Focus Area } & \multicolumn{2}{|c|}{ IDA Program } \\
\hline & FY20 & FY21 \\
\hline $\begin{array}{l}\text { Focus Area 1: Building human } \\
\text { capital and fostering peaceful } \\
\text { communities }\end{array}$ & $\begin{array}{l}\text { - IAQEP - US\$ } 100 \mathrm{M} \text { (with co- } \\
\text { financing from GPE US\$70 M } \\
\text { and EU SDTF US\$10 M) } \\
\text { - Maternal and Child Cash } \\
\text { Transfers for Improved } \\
\text { Nutrition Project (US\$100 } \\
\text { M) (Approved September } \\
\text { 26, 2019) } \\
\text { EHSAP Additional Financing } \\
\text { US\$100 M (US\$10 M co- } \\
\text { financing from GEF) }\end{array}$ & $\begin{array}{l}\text { - Enhancing Institutional } \\
\text { Capacity of State and Region } \\
\text { Governments in Myanmar } \\
\text { Project (US\$100 M) } \\
\text { - } \text { Myanmar Peaceful and } \\
\text { Prosperous Communities } \\
\text { Project (US\$200 M) }\end{array}$ \\
\hline $\begin{array}{l}\text { Focus Area 2: Fostering } \\
\text { responsible private sector-led } \\
\text { growth for inclusive economic } \\
\text { opportunities }\end{array}$ & $\begin{array}{l}\text { - Power System Efficiency and } \\
\text { Resilience Project (US\$350 } \\
\text { M) } \\
\text { - Myanmar National Food and } \\
\text { Agriculture Systems Project } \\
\text { (US\$85 M) }\end{array}$ & $\begin{array}{l}\text { - PFM Phase } 2 \text { Project (US\$50 } \\
\text { million) (Indicative) } \\
\text { - Myanmar Private Sector } \\
\text { Growth and Competitiveness } \\
\text { (US\$100 M) }\end{array}$ \\
\hline $\begin{array}{l}\text { Focus Area 3: Enhancing climate } \\
\text { and disaster resilience and } \\
\text { sustainable natural resource and } \\
\text { environmental management }\end{array}$ & & $\begin{array}{l}\text { - Myanmar Forest Restoration, } \\
\text { Development and Investment } \\
\text { Program (US\$100 M) }\end{array}$ \\
\hline
\end{tabular}

The Myanmar Forest Restoration, Development and Investment Program (FREDIP) (P168254) aims to improve collaborative forest management and increase benefits for forest dependent communities 
in targeted sites. The Forest Law (2018) and new CFI (2019) allows for the first time (non-state) tenure over teak, and commercial community forestry to scale up CF and CFE, including leveraging private investments (MFD); catalyzing SME development; and capturing the 'peace dividend' from inclusion and devolution of management control and commercial utilization of forests in border / conflict areas from State to ethnic communities. Major contribution to delivering on Myanmar NDC first pillar.

\section{World Bank Analytical and Knowledge Activities}

The following Analytical and Knowledge Activities are relevant to the CFN (Table 10).

Table 10: Analytical and knowledge activities related to the CFN

\begin{tabular}{|c|c|c|c|}
\hline Task ID & $\begin{array}{l}\text { Task Name } \\
\text { (Lead GP/Global Themes) }\end{array}$ & $\begin{array}{l}\text { Planned } \\
\text { Completion } \\
\text { FY }\end{array}$ & Description \\
\hline P171461 & $\begin{array}{l}\text { Myanmar Energy Policy Dialog } \\
\text { and Sector Development } \\
\text { (Energy \& Extractives) }\end{array}$ & 2022 & $\begin{array}{l}\text { ASA informs ongoing policy dialog with the } \\
\text { government of Myanmar to support the } \\
\text { sustainable energy sector development and } \\
\text { reform }\end{array}$ \\
\hline P164883 & $\begin{array}{l}\text { Supervision Support to Italian } \\
\text { Financing for Myanmar Off- } \\
\text { Grid Electrification (Energy \& } \\
\text { Extractives) }\end{array}$ & & $\begin{array}{l}\text { ASA advises the client on off-grid solutions } \\
\text { that rely on renewable energy technologies } \\
\text { such as solar and mini-hydro. }\end{array}$ \\
\hline P168826 & $\begin{array}{l}\text { Sustainable Solid Waste and } \\
\text { Pollution Management in } \\
\text { Myanmar (Environment, } \\
\text { Natural Resources \& the Blue } \\
\text { Economy) }\end{array}$ & 2020 & $\begin{array}{l}\text { ASA provides planning and capacity building } \\
\text { support to achieve environmentally and } \\
\text { financially sustainable solid waste } \\
\text { management services in selected cities; } \\
\text { prepares a plastic (waste) action plan; and } \\
\text { maps and analyzes key priority sources of air } \\
\text { and water pollution. }\end{array}$ \\
\hline P172379 & $\begin{array}{l}\text { Myanmar: Supporting Policies } \\
\text { and Strengthening Capacities } \\
\text { for Blue Economy } \\
\text { Development, Plastics } \\
\text { Reduction \& Climate } \\
\text { Mainstreaming Programmatic } \\
\text { ASA (Environment, Natural } \\
\text { Resources \& the Blue } \\
\text { Economy) }\end{array}$ & 2022 & $\begin{array}{l}\text { ASA strengthens policies and capacity for } \\
\text { fisheries management, sustainable } \\
\text { aquaculture development, coastal zone } \\
\text { spatial planning, including management and } \\
\text { sustainable use of mangrove forests, and } \\
\text { compatible value chains, policy development } \\
\text { for plastics reduction, and capacity building } \\
\text { for climate mainstreaming. }\end{array}$ \\
\hline P167157 & $\begin{array}{l}\text { Myanmar Coastal and Delta } \\
\text { Resilience Program (Urban, } \\
\text { Resilience and Land) }\end{array}$ & 2021 & $\begin{array}{l}\text { ASA strengthens the capacity of the GoM to } \\
\text { improve disaster and climate resilience of } \\
\text { coastal and delta communities in the } \\
\text { country. }\end{array}$ \\
\hline P169593 & $\begin{array}{l}\text { Myanmar Water Platform and } \\
\text { Strategy Development } \\
\text { (Water) }\end{array}$ & 2020 & $\begin{array}{l}\text { ASA develops the WBG's strategy for water } \\
\text { sector transformation, focusing on water } \\
\text { resources management and service delivery } \\
\text { issues. }\end{array}$ \\
\hline P173239 & Myanmar Poverty Assessment & & $\begin{array}{l}\text { ASA will explore the drivers of poverty and } \\
\text { inequality reduction in Myanmar and } \\
\text { identify the barriers to improving welfare of } \\
\text { the poor and disadvantaged going forward. }\end{array}$ \\
\hline P169426 & $\begin{array}{l}\text { Myanmar Mining Sector } \\
\text { Diagnostic (Energy \& } \\
\text { Extractives) }\end{array}$ & 2020 & \\
\hline P171495 & $\begin{array}{l}\text { Myanmar Urban Land Sector } \\
\text { Assessment (Urban, Resilience } \\
\text { and Land) }\end{array}$ & 2020 & \\
\hline
\end{tabular}




\begin{tabular}{|l|l|c|c|}
\hline Task ID & $\begin{array}{l}\text { Task Name } \\
\text { (Lead GP/Global Themes) }\end{array}$ & $\begin{array}{c}\text { Planned } \\
\text { Completion } \\
\text { FY }\end{array}$ & Description \\
\hline P172168 & $\begin{array}{l}\text { Supporting Myanmar recovery } \\
\text { planning after 2019 floods } \\
\text { (Urban, Resilience and Land) }\end{array}$ & 2020 & \\
\hline P170295 & $\begin{array}{l}\text { Supporting Peaceful } \\
\text { Transitions in Myanmar } \\
\text { (Social) }\end{array}$ & 2021 & \\
\hline
\end{tabular}

\section{Myanmar Strategic Country Diagnostic (SCD)}

This SCD provides timely diagnostic of development constraints and opportunities, as the country prioritizes implementation of its Myanmar Sustainable Development Plan (MSDP) - the Government's ambitious vision for creating a Peaceful, Prosperous and Democratic Myanmar. Though an independent and candid diagnostic, the SCD provides analysis directly relevant to the policy discussions prominent today.

In alignment with the government's MSDP, the SCD identified three interrelated pathways to advance Myanmar's triple transition, emphasizing the need to invigorate momentum for inclusive growth, share the benefits of growth more widely, and ensure sustainability for future generations. These pathways are reflected in the Government's own identified strategic priorities under the MSDP.

Figure 19: MSDP Pillars and Goals, highlighted in color of corresponding SCD analytical areas.

\begin{tabular}{|c|c|}
\hline Pathway & Policy Area for Progress \\
\hline \multirow{5}{*}{$\begin{array}{l}\text { 1. Strengthen economic and } \\
\text { financial sector management } \\
\text { to sustain growth and job } \\
\text { creation }\end{array}$} & 1.1 Maintain fiscal balance and macroeconomic stability \\
\hline & 1.2 Develop a sound, efficient, and inclusive financial system \\
\hline & 1.3 Improve the business environment and facilitate international integration \\
\hline & 1.4 Close the infrastructure and technology gap \\
\hline & 1.5 Improve income generation opportunities and accessibility in rural areas \\
\hline \multirow{4}{*}{$\begin{array}{l}\text { 2. Building inclusive } \\
\text { institutions and human } \\
\text { capital for all to foster peace } \\
\text { and shared prosperity } \\
\text { 3. Managing natural } \\
\text { endowments sustainably and } \\
\text { building resilience for long- } \\
\text { term prosperity }\end{array}$} & 2.1 Foster peace, social cohesion, and more inclusive institutions \\
\hline & $\begin{array}{l}2.2 \text { Strengthen systems for equitable access to and the delivery of quality services } \\
\text { and risk protection that allow people to lead healthy lives }\end{array}$ \\
\hline & 2.3 Ensure education for all and skills for productive employment \\
\hline & $\begin{array}{l}\text { 3.1 Manage land and natural resources transparently, equitably, and sustainably } \\
\text { 3.2 Build resilience to disasters and mitigate impact of environmental degradation }\end{array}$ \\
\hline $\begin{array}{l}\text { Cross-cutting: Reform public } \\
\text { institutions for effective and } \\
\text { equitable policy } \\
\text { implementation }\end{array}$ & $\begin{array}{l}\text { 4.1 Improve effectiveness, transparency and accountability of public sector } \\
\text { institutions } \\
4.2 \text { Generate demand for good governance and improved service delivery }\end{array}$ \\
\hline
\end{tabular}

The five Goals of the MSDP are regrouped and embedded within the three pillars of the SCD diagnostic: growth, inclusion and environmental sustainability. MSDP's Goal 2, Economic Stability and Macroeconomic Management, and Goal 3, Job Creation and Private-Sector-Led Growth, are included in the growth pillar of the SCD. MSDP's Goal 1, Peace and Governance, and Goal 4, Human Resources and Social Development, are covered in the inclusion pillar. MSDP's Goal 5, Natural Resources and the Environment, matches the environmental sustainability pillar of the SCD. A visual representation of how the SCD analytical framework reflects the goals of the MSDP is provided in figure 18-1 and figure 18-2, by highlighting corresponding themes in the same color. 

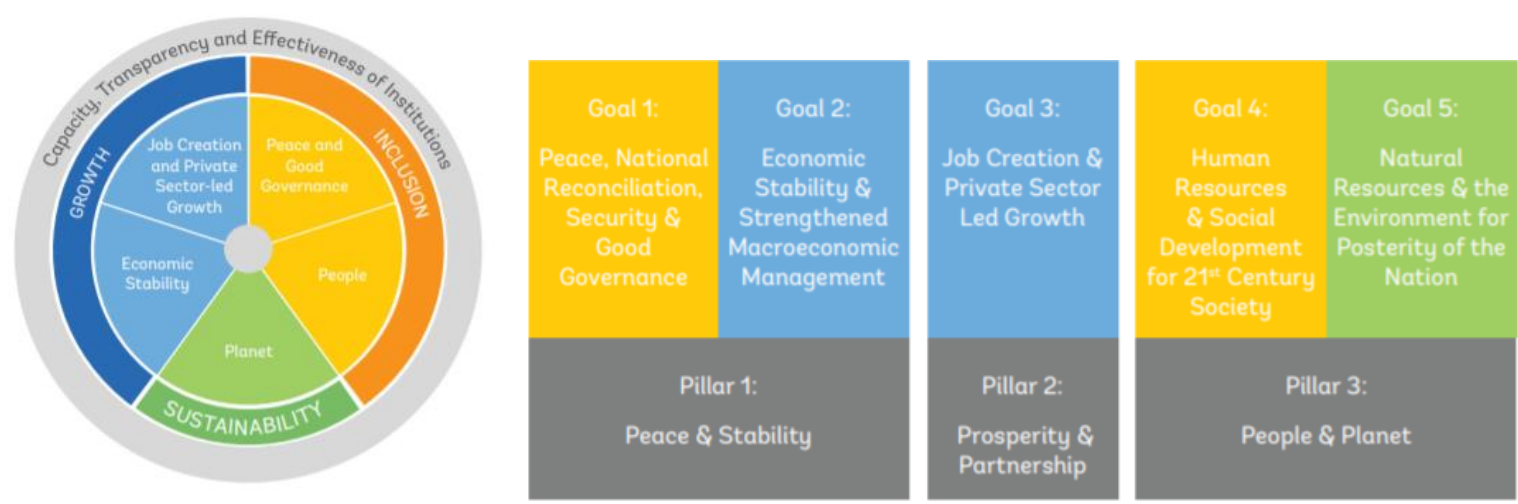

\section{Myanmar Country Partnership Framework}

The Myanmar Country Partnership Framework (CPF) for FY2020-FY2023 focuses on advancing progress towards the twin goals of reducing poverty and increasing shared prosperity and supporting the country through a challenging transition. It represents the second CPF since the World Bank's reengagement in Myanmar and is built upon a second-generation, comprehensive SCD and intended to support implementation of the country's national strategic development goals, as outlined in the MSDP.

The CPF is built around three focus areas that aim to advance Myanmar's economic transition sustainably, while ensuring that the benefits of the transition are shared more widely (see Table 11 below). Focus Area 1 (building human capital and fostering peaceful communities) places an immediate emphasis on inclusively investing in the people of Myanmar for long-term generational change and the generation of peace dividends. The objectives seek to expand equitable access to quality basic services and community-level infrastructure in the most underserved communities, while progressively empowering local public institutions to responsively cater to the needs of local populations. Focus Area 2 (fostering responsible private-sector-led growth) aims to reinvigorate the economic transition by building government capacity to manage the economy for stability and growth, while establishing a competitive, connected and attractive environment for responsible businesses to generate jobs and inclusive economic opportunities for the people of Myanmar. Focus Area 3 is anchored in Myanmar's abundantly rich natural environment, which not only constitutes an essential lifeline but is also the source of growing vulnerability. It takes a forward-looking perspective and focuses on building the resilience of the country to cope with natural disasters while ensuring that natural resources and the environment are managed sustainably for the benefit of existing and future generations. Institution building features as a primary objective within each of the focus areas. 


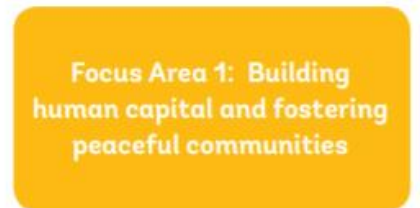

Improve inclusive access to community-level services and infrastructure

Improve inclusive access to, and quiality of, basic social services

Strengthen the capacity of public institutions to make policies, plan and deliver services more effectively, transparently and equitably
Focus Area 2: Fostering responsible private sectorled growth and inclusive economic opportunities

\section{Strengthen institutional} capabilities for

macroeconomic, public and financial sector management

Improve the environment for responsible business and facilitate trade

Narrow the infrastructure and technology gap

Enhance income-generation and productivity in selected sectors and zones
Focus Area 3: Enhancing

climate and disaster resilience

and sustainable natural

resource and environmental management

Strengthen the resilence of vulnerable communities against climate and natural disaster risks

Improve the sustainable management of the green, blue and brown environment

The WBG has been an important partner for Myanmar's first-generation economic reforms under the FY15-FY19 CPF. Following the hiatus in new IDA lending since 2017, the CPF establishes a phased program of engagement and largely coincides with the IDA19 cycle. In the initial years of CPF implementation, the IDA lending pipeline is confined to priority areas where the World Bank has already invested or is engaged in policy dialogue and where engagement complements the support of other development partners. On the basis of a mid-term evaluation of the country context and program performance (including on social inclusion), the CPF creates room for expanding the scope of WBG engagement in the latter years of CPF implementation. The program is also filtered to place an emphasis on promoting inclusion. 